\title{
Self-Assembled Proteins and Peptides as Scaffolds for Tissue Regeneration
}

\author{
Yihua Loo, Melis Goktas, Ayse B. Tekinay, Mustafa O. Guler,* Charlotte A. E. Hauser,* \\ and Anna Mitraki*
}

Self-assembling proteins and peptides are increasingly gaining interest for potential use as scaffolds in tissue engineering applications. They selforganize from basic building blocks under mild conditions into supramolecular structures, mimicking the native extracellular matrix. Their properties can be easily tuned through changes at the sequence level. Moreover, they can be produced in sufficient quantities with chemical synthesis or recombinant technologies to allow them to address homogeneity and standardization issues required for applications. Here. recent advances in self-assembling proteins, peptides, and peptide amphiphiles that form scaffolds suitable for tissue engineering are reviewed. The focus is on a variety of motifs, ranging from minimalistic dipeptides, simplistic ultrashort aliphatic peptides, and peptide amphiphiles to large "recombinamer" proteins. Special emphasis is placed on the rational design of self-assembling motifs and biofunctionalization strategies to influence cell behavior and modulate scaffold stability. Perspectives for combination of these "bottom-up" designer strategies with traditional "top-down" biofabrication techniques for new generations of tissue engineering scaffolds are highlighted.

\section{Introduction}

Commonly used tissue engineering scaffolds such as collagen, gelatin, hyaluronic acid, chitosan, alginate, and decellularized extracellular matrix (ECM) are typically derived from animal or plant sources. As such, their poorly defined chemical composition impedes regulatory approval due to potential immunogenicity and batch-to-batch variations. There is thus a niche for synthetic 3D biomimetic scaffolds that are amenable to incorporation of biologically active ligands for controlling cell behavior. Native tissues are composed of hierarchical organization of biological structures from the nanometer to the centimeter scale and their complex biological functions closely link to their high order organization; therefore such scaffolds need to mimic the hierarchical structure of natural tissues in order to provide the necessary structural and biomechanical framework. Furthermore, biomimetic scaffolds need to display the necessary biochemical and signaling cues for cellular function. The native ECM provides structural support and instructive cues to cells through the macromolecules found in its structure such as proteins, glycosaminoglycans and polysaccharides. ECM macromolecules contain bioactive signal sequences that are recognized by cells via cell transmembrane receptors called integrins. Interaction between integrins and bioactive epitopes of ECM activates signal transduction mechanisms, which can induce specific cellular functions including adhesion, migration, proliferation and differentiation. Such bioactive epitopes include: the RGD adhesive sequence found in the structure of ECM proteins such as fibronectin and vitronectin, ${ }^{[1]}$ the IKVAV peptide sequence from laminin known to induce neural attachment, migration and neurite outgrowth; ${ }^{[2]}$ and the YIGSR peptide sequence derived from the laminin $\beta$-chain..$^{[3]}$ Moreover, the native ECM provides to cells a highly dynamic complex microenvironment that enables cell motility and time-varying display of bioactive cues via continuous matrix remodeling. In natural cellular microenvironment, ECM is constantly degraded by proteases and remodeled by proteins secreted from cells. Mimicking the ECM can therefore be the best strategy to develop advanced functional materials to control cellular behavior and
Dr. Y. Loo, Prof. C. A. E. Hauser ${ }^{[+}$

Institute for Bioengineering and Nanotechnology

A* STAR

31 Biopolis Way, The Nanos 138669, Singapore

E-mail: charlotte.hauser@kaust.edu.sa

M. Goktas, Prof. A. B. Tekinay, Prof. M. O. Guler

Institute of Materials Science and Nanotechnology

National Nanotechnology Research Center (UNAM)

Bilkent University

Ankara, Turkey 06800

E-mail: moguler@unam.bilkent.edu.tr
Prof. A. Mitraki

Department of Materials Science and Technology

University of Crete

Greece 70013

E-mail:mitraki@materials.uoc.gr

Prof. A. Mitraki

Institute for Electronic Structure and Lasers (IESL)

Foundation for Research and Technology Hellas (FORTH)

Vassilika Vouton

Heraklion, Crete, Greece 70013

${ }^{[+]}$Present address: Division of Biological and Environmental Science and Engineering, King Abdullah University of Science and TechnologyThuwal 23955-6900, Kingdom of Saudi Arabia

DOI: $10.1002 /$ adhm.201500402 
to determine cell fate. Biological self-assembly offers a versatile bottom-up fabrication technology to construct such nanoscale materials imitating the complex hierarchical order of natural tissues. In particular, protein and peptide self-assembling scaffolds are gaining increasing interest compared to synthetic biodegradable polymers. ${ }^{[4,5]}$ Fibrous proteins such as silks and elastin dominate the area of protein scaffold design. Here we review recent advances on genetically engineered protein assemblies targeted for tissue engineering applications. The development of advanced molecular biology strategies allows the recombinant production of self-assembling protein scaffolds in sufficient quantities and addresses homogeneity and standardization issues required for applications. Furthermore, signaling and bioactive motifs such as cell-attachment motifs can be readily combined with structural framework motifs through genetic engineering at the sequence level. We also review de novo designer short peptides and peptide amphiphiles as scaffolds for tissue engineering. Short self-assembling peptides are mainly inspired from natural protein sequences but non-coded amino acids can also be incorporated through solid-state synthesis. Peptide amphiphiles are hybrid materials that comprise an alkyl tail and a peptidic, usually hydrophilic, tail. Short peptides and peptide amphiphiles that self-assemble into fibrillar hydrogel scaffolds are particularly interesting, in view of their topographical resemblance to the native extracellular matrix. Peptides with less than 12 amino acids and peptide amphiphiles can be easily synthesized on a commercial scale. During synthesis, functional motifs can be incorporated to modulate scaffold stability and influence cell fate and cell behavior. Such motifs can also be introduced through postassembly via covalent attachment to appending reactive groups on the peptides. Because these peptidic building blocks are chemically well-defined, regulatory approval may be expedited by the ability to well-characterize each batch of product.

\section{Genetically Engineered Protein Assemblies}

An increasing number of genetically engineered proteins are based on repetitive sequences found mainly in natural fibrous proteins such as collagen, elastin, silkworm and spider silks. However, the recombinant production of sufficient amounts of native, full-length proteins is challenging. As the desired products are typically high molecular mass proteins with repetitive sequences, heterologous hosts do not express these proteins very well and post-translational modifications, such as hydroxylation of prolines in collagens, also need to be resolved. In the last 20 years, considerable progress has been made to optimize protein expression in hosts such as bacteria, yeast, plants, or even in transgenic goats and silkworms. As this field has been excellently reviewed elsewhere ${ }^{[6]}$ our review will focus on designer proteins and peptides inspired by natural fibrous motifs. Indeed, the repetitive sequences are used as building blocks for the design and expression of "recombinamer" proteins, i.e., modular proteins consisting of a certain number of building blocks. ${ }^{[7]}$ These proteins self-assemble into macromolecular structures such as fibers, films, and spheres, and have been used in a variety of applications. We will further elaborate on examples of tailor - made proteins based on natural

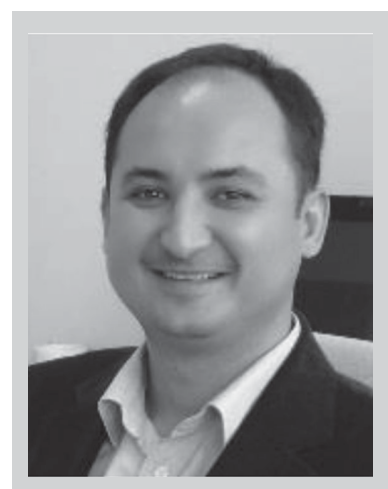

Mustafa O. Guler is an associate professor at the Institute of Materials Science and Nanotechnology, Bilkent University, Turkey. He received his B.S. degree in chemistry from Bogazici University, M.S. degree in chemistry and biochemistry from Worcester Polytechnic Institute, and Ph.D. degree in chemistry from Northwestern University. He carried out postdoctoral

work at the School of Medicine at Northwestern University. $\mathrm{He}$ is experienced in materials chemistry, biomaterials and applications of nanotechnology in medicine, and functional materials.

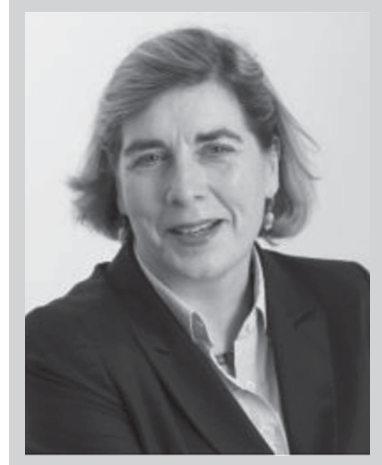

Charlotte A. E. Hauser is currently Professor of Bioscience at King Abdullah University of Science and Technology (KAUST), Thuwal, Saudi Arabia. She was until recently Principal Investigator at the Institute of Bioengineering and Nanotechnology, Singapore. She is an Adjunct Professor at Nanyang Technological University, Singapore. After her PhD (Univ. of Cologne/MIT), she worked as a postdoctoral fellow at MIT and INSERM, Paris. After working at the Max-Planck-Institute of Psychiatry, Munich, Germany, she was founder and CEO of Octagene in Munich/Martinsried. Her research includes molecular self-assembly, peptide biomaterials, amyloidogenesis, and regenerative therapies.

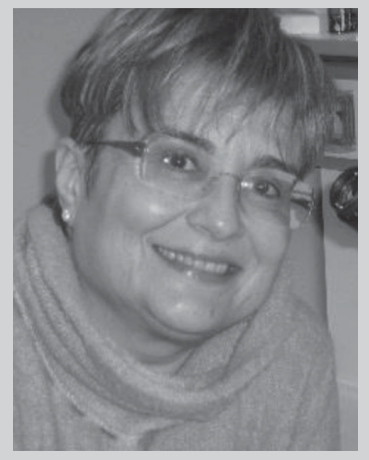

Anna Mitraki is a Professor in the Department of Materials Science and Technology, University of Crete, Greece and an affiliated scientist at the Institute of Electronic Structure and Laser, FORTH, Crete, Greece. She received her PhD in Biochemistry from the University Paris-XI, France and did postdoctoral work in the Department of Biology at the Massachusetts Institute of Technology (MIT), USA. She worked at the Institut de Biologie Structurale, Grenoble, France, before joining the University of Crete. Her research interests include protein folding and assembly, protein engineering and production, and design of protein and peptide biomaterials. 
building blocks. The strategy involves the design of the desired building block, chemical synthesis of the corresponding DNA sequence, and construction of multimeric sequences through concatenation or recursive directional ligation. Expression and purification of the designer constructs is then carried out at different scales ranging from simple laboratory setups to fermentation facilities. This approach enables the designer proteins to maintain their self-assembling propensity in order to replicate the biological performance of their natural counterparts. Two well-studied systems are designer silk-like proteins and elastinlike polypeptides (ELPs). More recently, inclusion bodies have received interest as "unconventional" protein scaffolds, though their applications in the field of tissue engineering is less explored.

\subsection{Designer Silk Proteins}

The term "silk" encompasses a range of fibrous materials produced by different insects for various physiological functions, including cocoon formation, web construction, and prey catching. ${ }^{[8]}$ Despite the diversity of functions, silk proteins have similar amino acid compositions, being rich in alanine, glycine and serine. ${ }^{[9]}$ They are high molecular mass proteins, organized in repetitive sequences, as exemplified by the GAGAGS motif in silkworm silk (Bombyx Mori). ${ }^{[10]}$ In spiders, as many as seven kinds of silks are produced, each fulfilling a different function. ${ }^{111]}$ The dragline silk is used for the framework construction of the web and as a lifeline for the spider. ${ }^{[12,13]}$ Dragline silks are composed of two main proteins, called MaSp1 and MaSp2 standing for major ampulate spindroins 1 and 2. ${ }^{[14]}$ MaSp1 spindroins are composed of numerous sequence repeats of poly (Ala) or Gly-Ala repeats and GGX, X being most frequently Ala, Tyr, Leu and Gln. MaSp2 contains poly (Ala) sequence repeats as well as GPGXX repeats, $X$ being mainly Gly, Tyr and Gln. ${ }^{[15]}$ The GPGXX motif is also the dominant sequence repeat of the flagelliform silk that spirally fills the webframe and is used for capturing the insect prey. ${ }^{[16]}$ Polar sequences that are thought to play a "spacer" role are also found. Poly (Ala) or poly (Gly-Ala) repeat motifs fold into tightly packed antiparallel beta-sheet within the assembled fiber, as probed by structural methods such as Fourier transform infrared (FTIR), X-ray diffraction or NMR. ${ }^{[17-20]}$ The GGX repeats are thought to adopt either $3_{10}$ helical, or random conformation. ${ }^{[19,21]}$ The GPGXX motif likely adopts an elastin-like, beta-spiral conformation similar to the elastin structural motif. ${ }^{[22]}$ The tightly packed antiparallel beta-sheet crystallites confer high tensile strength, while the glycine rich motifs confer elasticity, ${ }^{[23,24]}$ As a result, the combination of these structural motifs gives rise to a material that is both strong and elastic at the macroscopic level, ${ }^{[25]}$ leading to superior material properties compared to synthetic, manmade fibers. ${ }^{[26,27]}$ The repetitive sequence motifs are flanked by non-repetitive $\mathrm{N}$ - and C-terminal domains that are highly conserved among species $^{[28-31]}$ and adopt alpha-helical secondary structure arranged in bundles. ${ }^{[2,33]}$ These flanking domains play an important role in self-assembly, as demonstrated by recent studies. ${ }^{[34-38]}$ The biocompatibility of both silkworm silk and spider silks have been known since antiquity, as proven by their empirical use for wound healing. ${ }^{[39]}$ Their importance for contemporary tissue engineering was heralded in a pioneering 1914 publication, where Ross Granville Harrison reported that spider web mesh filaments could guide the growth of embryonic frog spinal neurons. ${ }^{[40]}$ Over the last 30 years the majority of efforts for recombinant silk-like material production focused mainly on spider silks, in view of the availability of silkworm silk since silkworms are entirely domesticated. In contrast, due to the cannibalistic nature of spiders, they cannot be farmed. Efforts for expression of recombinant proteins from spider silk cDNA have been focused in bacteria (E.coli), yeast (Pichia Pastoris), mammalian cells, transgenic tobacco plants, and transgenic animals (for recent reviews, see ref. [6b,c]. Production in high yields suitable for applications is a considerable challenge for native-sized, high molecular mass constructs. One strategy which has produced encouraging results is the use of metabolically engineered E. coli strains with elevated Glycyl-tRNA pool, which was used to produce modular proteins comprising 32-96 repeats of the module [SGRGGLGGQGAGMAAAAAMGGAGQGGYGGLGSQGT]n. ${ }^{[41]}$ Another strategy to achieve efficient recombinant production was to design shorter spider silk proteins. For example, repetitive silk sequences were reversibly transcribed to DNA sequences compatible with E.coli codon usage and the DNA cassettes of a single repeating motif were subsequently ligated using a seamless cloning technique to produce modular proteins. ${ }^{[42]}$ A number of motifs can be subsequently combined to give an "ensemble repeat" motif, for example the 35 aa motif GSSAAAAAAAAASGPGGYGPENQGPSGPGGYGPGGP that comprises GPGXY repeats and one octaalanine (A)8 stretch. This motif, named eADF4 as it is inspired from the dragline silk of the European garden spider Araneus diadematus, was the basis for the design of recombinant variants that comprise $n$ copies of it, $n$ varying from 1 to $16 .^{[33]}$ Variants that are composed of 2-16 repeats self-assemble into fibrils upon addition of cosmotropic phosphate ions, but not the variant with one repeat ${ }^{[43]}$ (Figure 1A). A detailed kinetic and structural characterization of the assembly process suggested that the proteins convert from initially soluble forms in random coil conformation to insoluble, antiparallel beta-sheet conformation. ${ }^{[43]}$ The assembly process presented a lag phase characteristic of nucleation and growth kinetics; the lag phase disappeared with the addition of seeding nuclei or already assembled (eADF4) C16 fibrils. The fibrils formed by this variant were previously shown to adopt a cross-beta conformation by X-ray fiber diffraction, Thioflavin $\mathrm{T}$ and Congo Red binding. ${ }^{[4]}$ In the cross-beta conformation, the beta-strands are perpendicular to the long fibril axis and give a characteristic X-ray fiber diffraction pattern with a meridional reflection of 4.7 Å corresponding to inter-strand spacing and a more diffuse equatorial reflection around $10 \AA$ corresponding to beta-sheet spacing. ${ }^{[45]}$ Preformed (eADF4)C16 fibrils were also able to induce fibril formation by the otherwise soluble monomer variant (eADF4)C1. Overall, it was proposed that self-assembly is mediated by docking and hydrogen bonding formation of polyalanine stretches to form antiparallel cross-beta sheets. ${ }^{[43]}$ Once this nucleus with exposed hydrophobic side chains is formed, further recruitment and docking of soluble monomers to the exposed fibril ends is facilitated, leading to fibril elongation. Covalent interconnection of the repeating motif seems to be a 
A
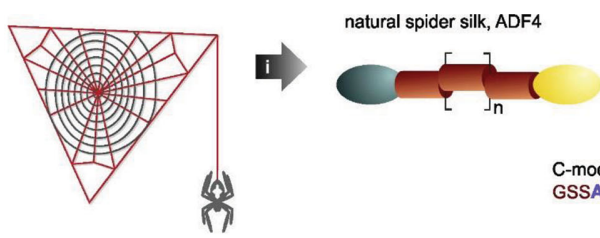

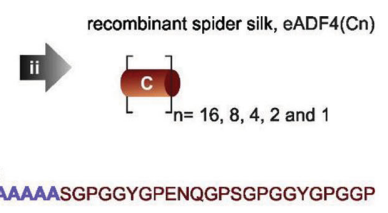

GSSAAAAAAAASGPGGYGPENQGPSGPGGYGPGGP
B

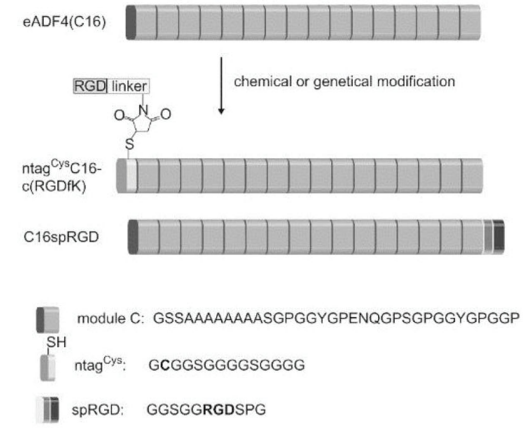

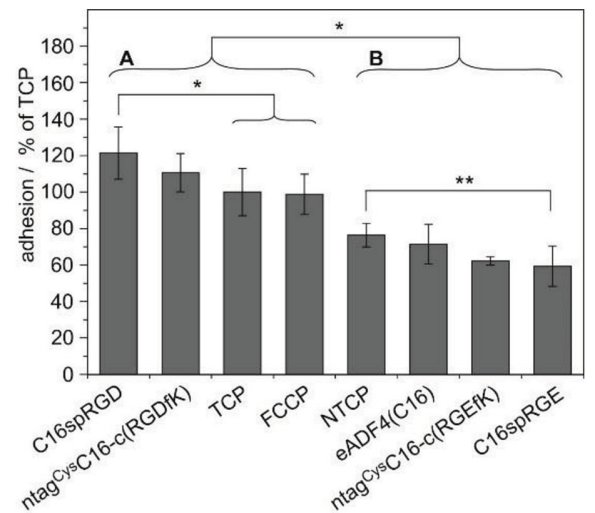

Figure 1. A) Modular structure of natural and recombinant spider proteins. The natural dragline silk of the European garden spider comprises at least two major proteins, ADF3 and ADF4, both consisting of a repetitive core (red) and $\mathrm{N}$-and $\mathrm{C}$-terminal nonrepetitive domains (green and yellow). The repetitive consensus motif of the core (C-module) was the basis for the design and optimized expression of variants with $n$ numbers of modules termed (eADF4) (Cn). Reproduced with permission. ${ }^{[43]}$ Copyright 2014, Elsevier. B) Functionalization strategies of the (eADF4)C16 variant with RGD motifs. For the chemical modification, the cyclic RGD motif (RGDFK), f standing for D-phenylalanine was chemically coupled to the cysteine-containing (eADF4)C16 (ntag ${ }^{\mathrm{Cys}}$ ) protein via maleimide chemistry. The genetically modified variant C16spRGD, was generated by hybridizing the RGD motif and a spacer sequence with (eADF4)C16. C) Adhesion of BALB/3T3 mouse fibroblasts to, C16spRGD (genetically engineered) variant films, and (ntag Cys) C16 c(RGDfK), (chemically modified) variant films, as compared to the corresponding RGE variant films and (eADF4)C16 films. Adhesion was also measured for non-treated (NTCP) and treated (TCP) cell culture plates and fibronectin-coated cell culture plates (FCCP). Adhesion was normalized to the value for treated (TCP) cell culture plates that was set as 100\%. A significantly higher cell adhesion was observed for the C16spRGD (genetically engineered) variant films. Panels $(B, C)$ reproduced with permission. ${ }^{[56]}$ Copyright 2012, Elsevier.

crucial parameter for the assembly process, since at least two repeats are required for fibril formation. ${ }^{[43]}$ The (eADF4)C16 is the most studied variant that was shown to self-assemble fibrils $^{[46]}$ and also non-natural forms such as capsules, ${ }^{[47]}$ spheres, ${ }^{[48]}$ films, ${ }^{[49,50]}$ hydrogels, ${ }^{[51]}$ and non-woven mats, ${ }^{[52]}$ leading to potential applications in biotechnology. ${ }^{[53,54]}$ The subsequent introduction of a cysteine residue through genetic engineering allowed functionalization with enzymes, peptides or inorganic nanoparticles, establishing the proof-of-principle for a variety of applications. ${ }^{[55]}$ To further enhance its function, specific cell attachment motifs were incorporated into in the eADF4C16 protein. The RGD motif was introduced to the eADF4 C16 sequence through genetic engineering, by appending the GRGDSPG sequence to the C-terminus ${ }^{[56]}$ (Figure 1B). The cyclic RGD motif c(RGDfK), f standing for D-phenylalanine was chemically coupled to the cysteine-containing (eADF4)C16 protein via maleimide chemistry ${ }^{[56]}$ (Figure 1B). Both proteins were processed into films that were found to support cell adhesion and proliferation of mouse fibroblast cell line BALB/3T3 compared to the non-RGD containing proteins, or compared to the negative control sequence $\mathrm{RGE}^{[56]}$ (Figure 1C). In terms of in vivo applications, films of the
(eADF4)C16 protein were tested as coatings of silicone breast implants. In the absence of a coating, the hydrophobic surface of these silicone implants favors nonspecific attachment of serum proteins, which causes inflammation and induces tissue formation, leading to periprosthetic capsular fibrosis. Silk protein film coatings present a more acceptable surface to the body and were found to significantly reduce capsule thickness and post-operative inflammation. ${ }^{[57]}$ Recently, the (eADF4) C16 protein passed a number of preclinical safety tests to evaluate toxicity and immune reactions, and is now commercially available from AM silk. Applications other than implant coatings (BioShield-S1), include wound care dressings (SanaSilk) and skin care products.

Miniature dragline spider silk proteins that carry four polyAlanine/Glycine- rich repeats and the non-repetitive C-terminal domain, called 4RepCT were also recombinantly produced (Figure 2A). The purified protein self-assembles into macroscopic fibers in physiological buffer ${ }^{[58]}$ (Figure 2B). The fibers can be processed into mesh, films and foams that support attachment, growth, and collagen type I secretion of fibroblasts. ${ }^{[59]}$ Moreover, cell attachment motifs can be genetically incorporated and do not affect the self-assembling propensity 
A

GSGNSGIQGQ GGYGGLGQGG YGQGAGSSAA AAAAAAAAA GGQGGQGQGG YGQGSGGSAA AAAAAAAAAA AAAGRGQGGY GQGSGGNAAA AAAAAAAAAA AAGQGGQGGY GRQSQGAGSA AAAAAAAAAA AAAGSGQGGY GGQGQGGYGO SSASASAAAS AASTVANSVS RLSSPSAVSR VSSAVSSLVS NGQVNMAALP NIISNISSSV SASAPGASGC EVIVQALLEV ITALVQIVSS SSVGYINPSA VNQITNVVAN AMAQVMG

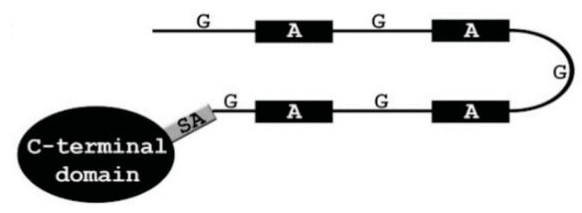

B
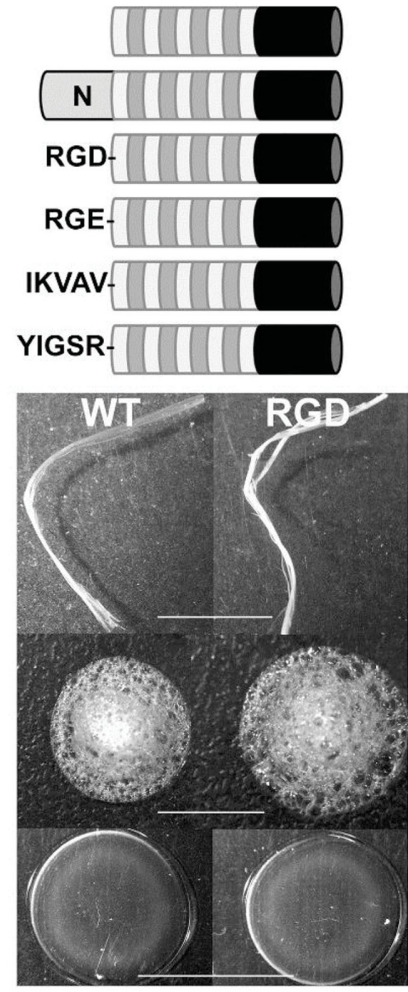

C
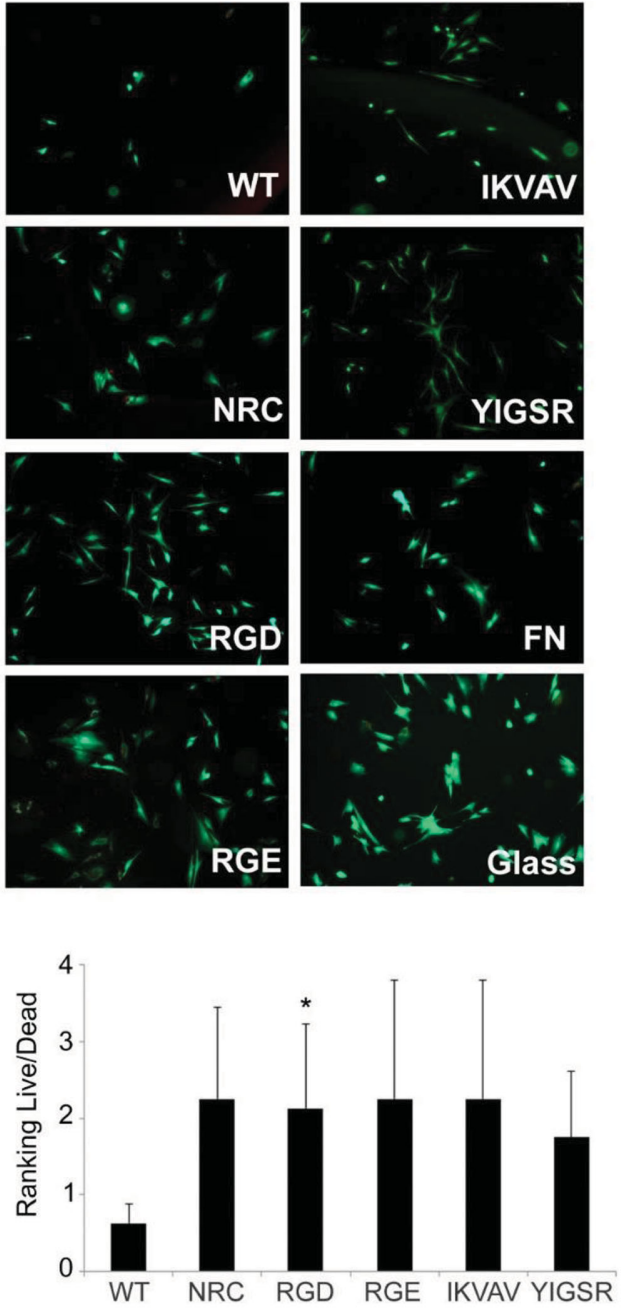

Figure 2. A) Sequence and schematic representation of the 4RepCT protein. Poly-alanine segments are shown in bold (symbolized with the black boxes marked with "A") and serine/glycine-rich segments in bold italics (symbolized with lines marked " $\mathrm{C}$ "). The non-repetitive C-terminal domain sequence is shown in italics and is symbolized with the back oval shape. The grey box marked with "SA" corresponds to a stretch that is rich in serines/alanines. Reproduced with permission. ${ }^{[59]}$ Copyright 2010, Elsevier. B) Schematic representation of functionalized 4RepCT proteins. WT stands for the 4RepCT protein, NRC for the 4RepCT protein with the N-terminal domain, and RGD, RGE, IKVAV, and YIGSR stand for the 4RepCT protein with the respective functional sequences. Photographs of different forms of matrices for WT (left) and the RGD variant (right) are as follows (from top to bottom): fibers, foams and films. The scale bar is $1 \mathrm{~cm}$. C) Live and dead stained fibroblasts cultured for $24 \mathrm{~h}$ on films of functionalized 4 RepCT proteins. FN stands for fibronectin films. Reproduced with permission. ${ }^{[60]}$ Copyright 2013, Elsevier.

of the 4RepCT protein, while remaining exposed following self-assembly. The RGD peptide from fibronectin and the nonfunctional control RGE were incorporated at the N-terminus of the protein. ${ }^{[60]}$ Other cell-binding motifs used were the peptide YIGSR and the IKVAV peptide from laminin (Figure 2B). Four different cell types (fibroblasts, keratinocytes, endothelial and Schwann cells) showed significantly improved adherence to the RGD-containing matrices ${ }^{[60]}$ (Figure 2C). The Schwann cells also adhered to the IKVAV-containing matrices, while no significant effect was detected in YIGSR-containing matrices. Materials based on the 4RepCT protein are commercialized as Spiber biomaterials. Apart from short peptide motifs, longer peptide sequences or entire biologically active domains can also be fused to genetically engineered proteins inspired from spider 
silks, generating multifunctional proteins. Block copolymers were designed comprising a basic building block, $\mathrm{AB}$, $\mathrm{A}$ being a hydrophobic alanine and glycine block GAGAAAAAGGAG and B being a hydrophilic block that contains four GGX repeats separated by the GSQGSR sequence. 6-15 mers of the AB basic building block were recombinantly expressed in bacteria and subsequently adopted various morphologies, ranging from fibrils to micelles in aqueous or alcohol solvents. ${ }^{[61]}$ Fusions of these protein blocks with silica-nucleating peptides such as the KSLSRHDHIHHH or with the R5 peptide from the silaffin protein from diatoms (SSKKSGSYSGSKGSKRRIL) were generated and found to act as scaffolds for silica templating. ${ }^{[62,63]}$ Fusion proteins of the hexamer with bone sialoprotein were found to conserve the self-assembling ability of the silk domain while incorporating the functionality of the bone sialoprotein. ${ }^{[64]}$ Films made from the fusion protein directed the proliferation and osteogenic differentiation of human mesenchymal stem cells in osteogenic medium. ${ }^{[64]}$ The functional domain can be replaced with antimicrobial peptides such as human defensins and hepcidin, giving rise to fusion proteins with microbicidal activity that concurrently supported the growth of mammalian cells. These new developments open new avenues in the design of anti-infection biomaterials. ${ }^{[65]}$

\subsection{Elastin-Like Polypeptides (ELPs)}

Elastin is a structural protein of the extracellular matrix that confers elasticity to tissues such as aorta, lungs and skin. Insoluble elastin fibers assemble following the proteolytic cleavage of its soluble precursor, tropoelastin. ${ }^{[66]}$ The primary sequence of elastin is characterized by the pentapeptide repeats VPGXG, $\mathrm{X}$ being any amino acid except proline. The proline and glycine residues are essential for the adoption of a flexible beta-turn structure as the main secondary structure of elastin. ${ }^{[67]}$ The molecules of elastin have high extensibility, and resume their original shape after stress release with low hysteresis, or high resilience. ${ }^{[68]}$ ELPs, for "elastin-like polypeptides" are macromolecules based on these repeating units that can be designed in a controlled number and recombinantly expressed..$^{[7]}$ The term "recombinamers" was coined to convey their dual nature, as recombinant proteins and poly-mers. ${ }^{[69]}$ Concatamers of the basic structural motif can be designed and expressed using a process of "recursive directional ligation" (RDL). RDL is based on the design of a DNA monomer with complementary sticky ends and the creation of concatamers through repeated cycles of digestion and ligation. ${ }^{[70]}$ These recombinant proteins mimic the structural properties of natural elastin, particularly the propensity for self-assembly. They are able to undergo reversible thermal transition above a certain critical temperature in a process called inverse temperature transition or coacervation. ${ }^{[7]}$ Below this transition temperature called (Tt), the elastin chains are thought to be essentially in random conformation and surrounded by water clathrates. Above this temperature, the chains fold into a "beta-spiral" conformation and assemble mainly through intrachain and interchain hydrophobic interactions, forming a separate phase. The transition temperature depends on conditions such as $\mathrm{pH}$, ionic strength, but also on amino acid composition. Thus, ELPs can be rationally designed to produce responsive materials with controlled properties. ${ }^{[1]} \mathrm{An}$ enormous amount of literature exists for the ELPs and their applications in tissue engineering that has been extensively reviewed previously. ${ }^{[4,72,73]}$ For the purposes of this article we focus on the increasing number of recent studies of designer ELPs targeted for tissue engineering. Charged amino acids can be introduced at the position $\mathrm{X}$, for example when a glutamate is introduced at this position at acid $\mathrm{pH}$ where its carboxyl side chains are protonated, the ELP [(VPGVG) 2 -(VPGEG)(VPGVG) $]_{15}$ forms flat polymer sheets on surfaces. ${ }^{[74]}$ At neutral $\mathrm{pH}$ where the carboxyl side chains are deprotonated, the negatively charged glutamates along with their hydrating water molecules get segregated from the rest of the hydrophobic polymer; as a result, nanopores form in the film. ${ }^{[74]}$ In solution, this $\mathrm{pH}$ dependence influences also the transition temperature. A number of $\left[(\mathrm{VPGVG})_{2}-(\mathrm{VPGEG})-(\mathrm{VPGVG})_{2}\right]_{\mathrm{n}}$ ELPs were designed, $\mathrm{n}$ being equal to $5,9,15,30$, and 45 in order to study the this $\mathrm{pH}$ dependence. For example, for the $\left[(\mathrm{VPGVG})_{2}\right.$ (VPGEG)-(VPGVG) $\left.{ }_{2}\right]_{45}$, at PH 2.5, the transition temperature is $28{ }^{\circ} \mathrm{C}$, while at $\mathrm{pH} 8$ shifts to $85^{\circ} \mathrm{C}$, an enormous shift given that the glutamates represent $4 \%$ of the recombinamer chain residues. ${ }^{[71]}$ Lysine can be introduced at position X, to enable crosslinking and conjugation chemistries. Moreover, multifunctional ELPs can be designed that comprise cell attachment motifs or protease digestion sites. Such an example is illustrated by the design of the recombinamer [(VPGIG) $)_{2}$-(VPGKG)(VPGIG) $2_{2}$ (EEIQIGHIPREDVDYHLPY)-(VPGIG) $)_{2}$ (VPGKG)$(\text { VPGIG) })_{2}$-(VGVAPG) $\left.]_{3}\right]_{n}$ where $n=10 .{ }^{[75]}$ The (VPGIG) module confers the material properties and stimuli-responsive nature, while the VPGKG module can be used for crosslinking chemistry. The EEIQIGHIPREDVDYHLPY sequence contains the REDV motif from the CS5 fibronectin domain which is specific for endothelial cell recognition. The VGVAPG sequence allows recognition by elastase in order to mimic the physiological pathways of elastin digestion during ECM remodeling. Subsequent designs incorporated the entire RGD-containing sequence from fibronectin, AVTGRGDSPASS, on (VPGIG) and (VPGKG)-based ELPs (Figure 3A). The RGD-containing ELP was used to coat polylactic acid (PLA) surfaces, via physisorption or chemical attachment. The functionalized surfaces with the RGD-containing ELP were found to enhance attachment and proliferation of rat mesenchymal stromal cells (rMSCs) compared to surfaces functionalized with the control ELP. ${ }^{[76]}$ This recombinamer was immobilized on titanium surfaces, again through physisorption or covalent attachment, leading to adhesion and proliferation of hMSCs. Of note, nonspecific protein attachment was significantly lower in the coated surfaces compared to the bare metal surface, and the surfaces with covalently attached ELPs showed higher stability than the ones with physisorbed ELPs, suggesting their suitability to improve implant biocompatibility. ${ }^{[77]}$ ELPs targeted for calcium deposition, were designed by incorporating the 15 aa sequence DDDEEKFLRRIGRFG from the human salivary peptide statherin (which has high affinity for hydroxyapatite) with the basic building blocks VPGIG and VPGKG ${ }^{[78]}$ (Figure 3A). These ELPs were covalently attached through the lysine residue to titanium surfaces that were previously etched with alkali and silanized. The functionalized surfaces were able to nucleate deposition of amorphous calcium phosphates and these 
A ELP
Material

ELP sequence (bioactive sequence)

Bioactivity

IK

(VPGIG VPGIG VPGKG VPGIG VPGIG) 24

Control

RGDS

[I(VPGIG) $\left.)_{2}(\mathrm{VPGKG})(\mathrm{VPG} \mid G)_{2}\right]_{2}$ AVTGRGDSASS[(VPGIG) $\left.\left.)_{2}(\mathrm{VPGKG})(\mathrm{VPG} \mid G)_{2}\right]_{2}\right]_{6}$

Cell Adhesion

HAP

[[(VPGIG) $\left.)_{2}(\mathrm{VPGKG})(\mathrm{VPG} \mid G)_{2}\right]_{2}$ DDDEEKFLRRIGRFG [(VPGIG) $\left.\left.)_{2}(\mathrm{VPGKG})(\mathrm{VPGIG})_{2}\right]_{2}\right]_{3}$

Mineralization

HAP-RGDS

II(VPGIG) $)_{2}(V P G K G)(V P G I G)_{2} l_{2}$ DDDEEKFLRRIGRFG[(VPGIG) $)_{2}(V P G K G)(V P G I G)_{2} l_{2} l_{4}[(\mathrm{C}$

Mineralization

and PGIG) $\left.)_{2}(\text { VPGKG)(VPGIG) }]_{2}\right]_{2}$ AVTGRGDSPASS [(VPGIG) $)_{2}$ (VPGKG) (VPGIG) $2_{2} l_{4}$

Cell Adhesion

REDV

((VPGIG) $)_{2}$ (VPGKG) (VPGIG) EEIQIGHIPREDVDYHLYP (VPGIG) $)_{2}$ (VPGKG) (VPGIG)

Cell Adhesion

B
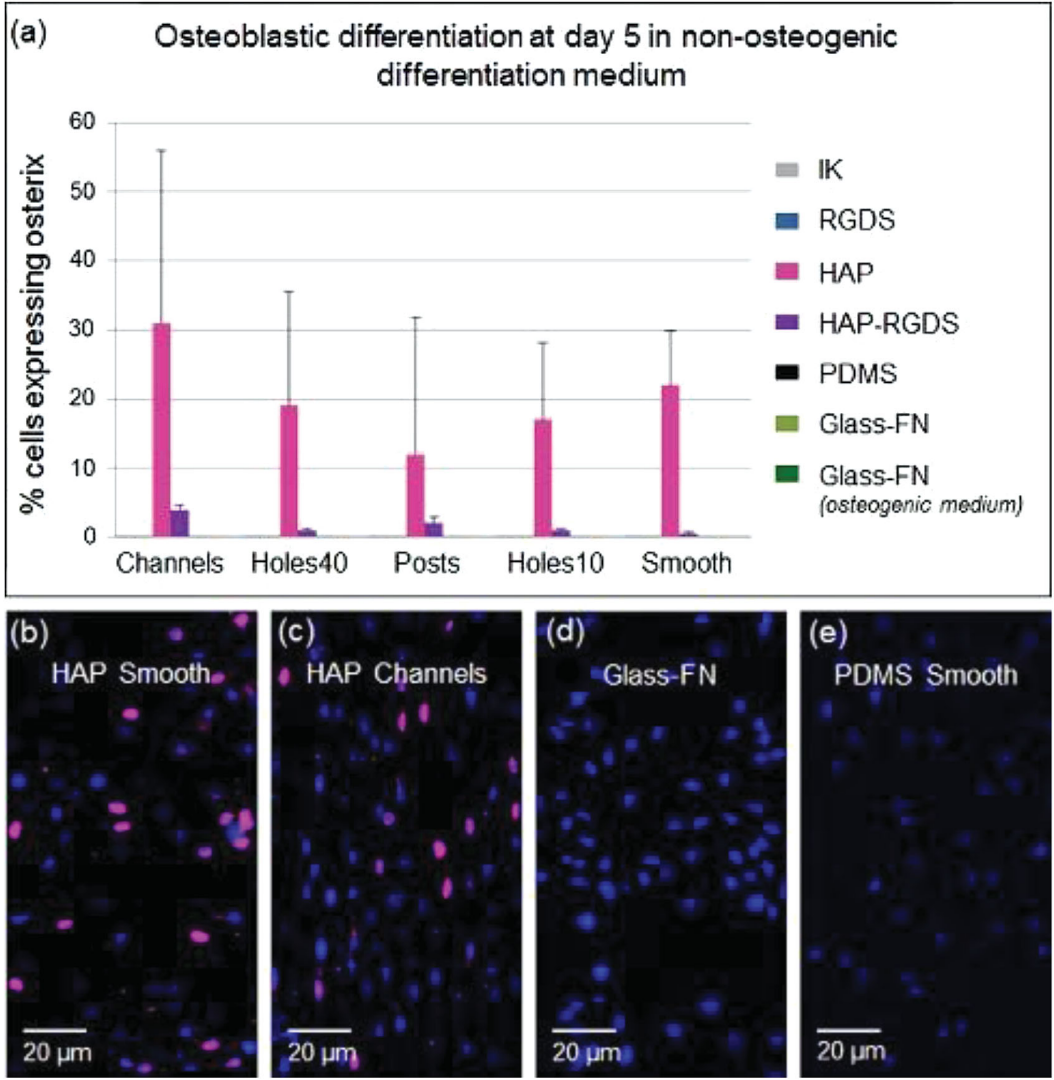

Figure 3. A) Sequence of designer elastin-like recombinamers with incorporated bioactive motifs. The basic elastin-like building blocks VPGIC and VPGKG are represented in yellow and blue letters, respectively. The bioactive sequences are represented in red letters. The 15 aa sequence DDDEEKFLRRIGRFG from the human salivary peptide statherin confers high affinity for hydroxyapatite and the RGDS and REDV motifs target cell attachment. B) Osteoblastic differentiation measured by the expression of transcription factor osterix in the nuclei of rat mesenchymal stem cells. a) Percentage of cells expressing osterix. FN stands for fibronectin (FN in osteogenic media is the positive control). In (b-e) confocal images of nuclei expressing osterix (pink) and non-expressing (blue) are shown for smooth membranes fabricated by the HAP recombinamer (b), HAP membrane patterned with channels (c), fibronectin-coated glass (d), and smooth PDMS surface (e). Reproduced with permission. ${ }^{[79]}$ Copyright 2014, Elsevier. 


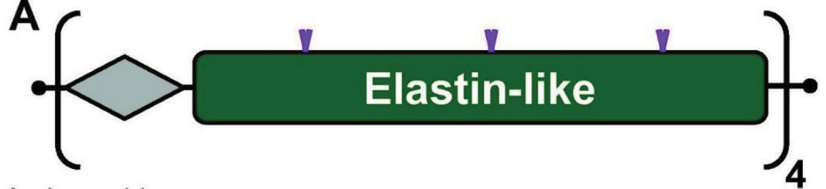

Amino acid sequence:

LQ[LDAS-Bioactive-SA((VPGIG) ${ }_{2}$ VPGKG(VPGIG $\left.)_{2}\right)_{3}$ VP $]_{4} \mathrm{LE}$

Bioactive sequence:

Cell-adhesive:

TVYAVTGRGDSPASSAA

Non-adhesive scramble: TVYAVTGRDGSPASSAA

\section{B}

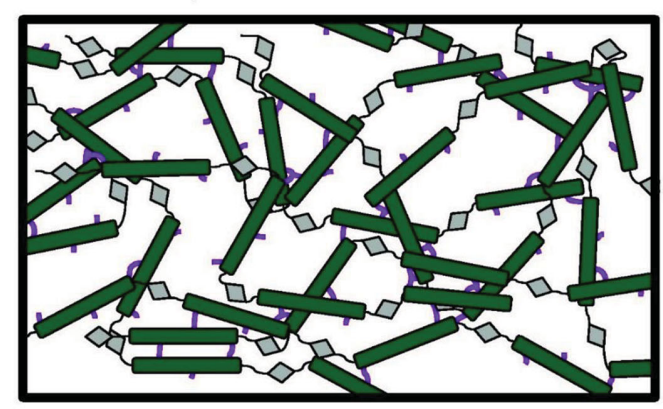

c

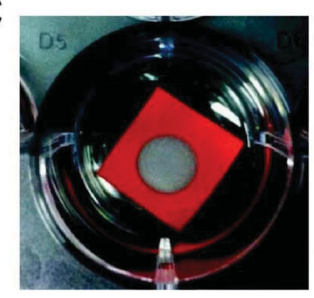

Cross-sectional view of DRG culture system

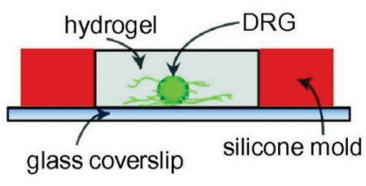

Figure 4. A) Schematic representation of modular elastin-like polypeptides with bioactive motifs. The basic elastin-like motifs are represented with a green box and the bioactive motif sequences as a grey diamond. B) The elastin-like domains contain lysines (purple) that can be crosslinked with amine crosslinking reagents to form a 3D network. C) Photograph (left) and schematic representation (right) of a semitransparent ELP hydrogel casted in a silicone mold (red) within a 24-well plate, designed to encapsulate DRG cells. Reproduced with permission.

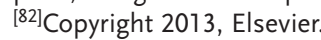

mineralized surfaces further supported and enhanced attachment and differentiation of a preosteoblast cell line. ${ }^{[78]}$ Cell attachment motifs such as RGDS or REDV were combined with the aforementioned calcium mineralizing sequences within the same ELR in order to test any synergistic effects towards bone regeneration applications. Membranes formed from such ELRs were recently tested, in combination with different topographies (smooth, channels, holes and posts), for their effect on rat mesenchymal stem cell fates ${ }^{[79]}$ (Figure 3C). ELR membranes containing only statherin sequences significantly enhanced osteogenic differentiation in non-osteogenic media on all topographies. Enhancement, although to a lesser extent was observed for the bifunctional statherin - RGDS membranes compared to fibronectin-coated controls in osteogenic media. ${ }^{[79]}$ These membranes were recently tested in a rodent bone defect model and encouraging bone formation was observed following implantation. ${ }^{[0]}$ The modular design of elastin - mimetic ELPs offers the possibility of tuning independently the display of bioactive motifs, the mechanical properties (by varying the density of crosslinking), and the degradation and remodeling rates of the designer scaffolds (by introducing protease cleavage motifs). Such designs are exemplified in the work of Heilshorn at al. where basic elastin motifs containing lysine residues were interspersed either with sequences containing the RGD motif or sequences sensitive to cleavage by urokinase plasminogen activator (uPA). ${ }^{[81]}$ The urokinase plasminogen activator is locally secreted by tips of growing neurons and was introduced to enable remodeling of the scaffold in post-implantation conditions. Hydrogels formed from constructs with RGD motifs were studied in vitro as scaffolds for the model PC12 neuronal-like cell line and were shown to support adhesion and neurite outgrowth. When constructs comprising RGD motifs were mixed in 1:1 ratio with three different constructs comprising uPA sites, or with the construct comprising the scrambled RDG motif, similar adhesivity was observed, indicating that degradation sites did not interfere with cell adhesion. ${ }^{[81]}$ Hydrogels with tunable mechanical properties and display of RGD sites could also be molded and studied in a three-dimensional context using silicone molds inserted in cell culture plates ${ }^{[82]}$ (Figure 4). The mechanical properties of the hydrogels could be tuned by varying the ratio of crosslinking reagent to the primary amine content, without affecting the display of available RGD sites (Figure 5A). Alternatively, the density of available RGD sites per volume unit could be tuned without affecting the mechanical properties of the hydrogel by homogenously mixing ELPs with and without the RGD motif (Figure 5B). The hydrogels could support the attachment of DRG neurons, and viability after 1 day was not affected by the variations in RGD density or crosslinking density (Figure 5 C,D). The sole presence of RGD ligands resulted in clear increase in length and number of extending neurites by day 3 of culture. In the range of 0.5 to $2 \mathrm{kPa}$ moduli, the most compliant hydrogels supported statistically better neurite outgrowth, with neurites extending by day 1 in $0.5 \mathrm{kPa}$ hydrogels, by day 3 in $1.5 \mathrm{kPa}$ hydrogels, and only by day 7 in $2.1 \mathrm{kPa}$ hydrogels. Moreover, these materials could be molded into hollow tubes, pointing to their eventual applicability as nerve guiding materials for in vivo applications. ${ }^{[82]}$

One of the big advantages of ELPs that carry bioactive motifs such as RGD is their amenability to thin film fabrication, or even multilayer film fabrication by LBL (layer-by-layer) procedures. The first thin films of and ELP containing the RGD motif were fabricated using as a substrate chitosan, a biocompatible and bacteriostatic anionic polysaccharide of marine origin. The chitosan-ELP interaction is presumably driven by electrostatic interactions between negatively charged aspartates above their pKa and the anionic groups of chitosan. The temperature responsiveness of ELP deposited on chitosan confer "smart" behavior to the chitosan substrate. Contact angle measurements showed that the ELP coated-surfaces turn more hydrophilic from $25{ }^{\circ} \mathrm{C}$ to $50{ }^{\circ} \mathrm{C}$. This was presumably due to the segregation of the hydrophobic parts of the polymer (confirmed by the appearance of nanometer-sized spherical structures, as can be seen using atomic force microscopy (AFM)) with concomitant exposure of the hydrophilic RGD moieties. At $37^{\circ} \mathrm{C}$, where the surface of these films is moderately hydrophobic, the films could support improved adhesion and proliferation of the osteoblast-like osteosarcoma cell-line SaOs-2 

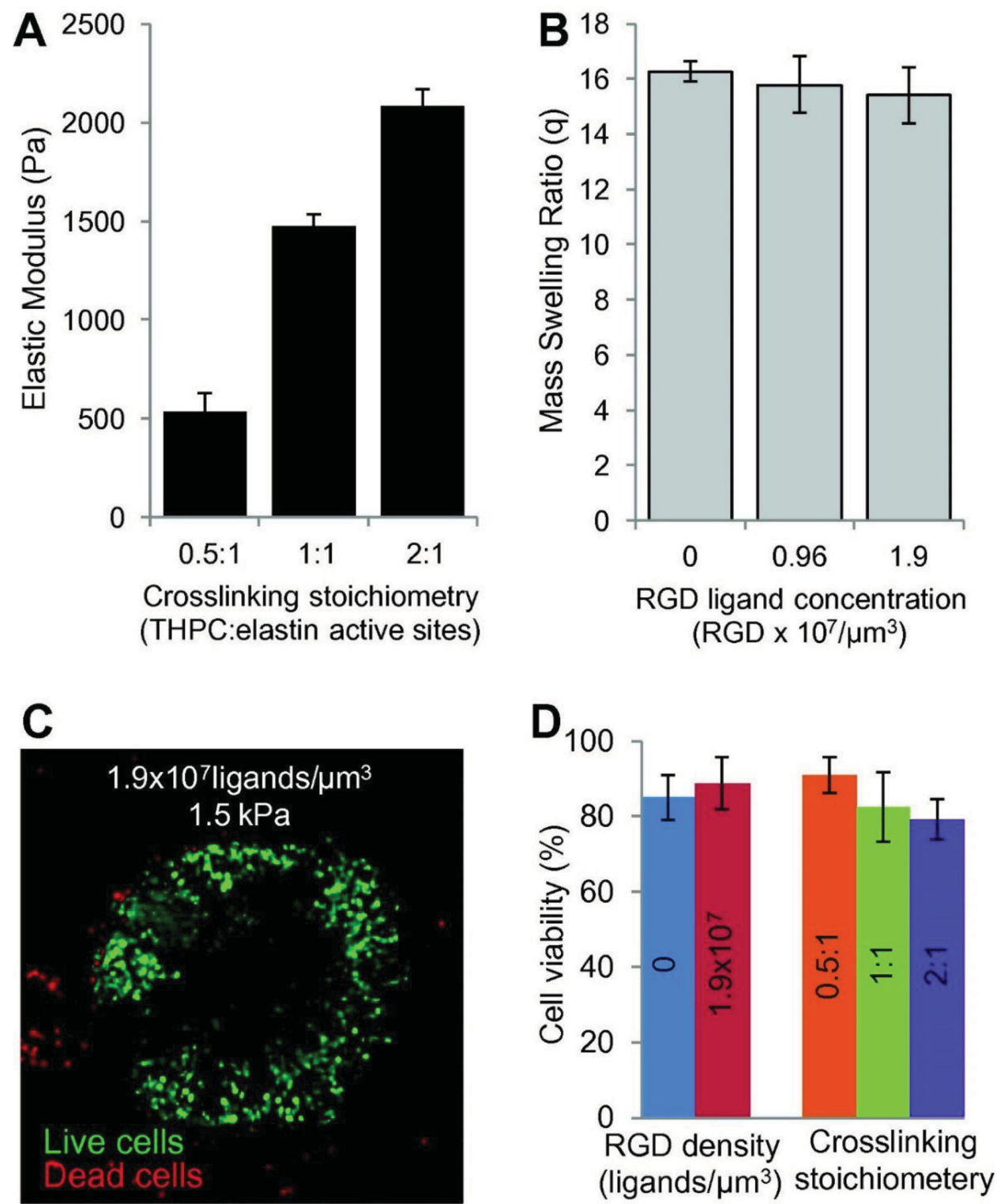

Figure 5. A) Elastic moduli of crosslinked hydrogels can increase with increasing the ratio of crosslinking reagent (THCP) to lysines contained in the ELP without affecting the display of RGD ligands. B) Alternatively, the density of RGD ligands can be tuned without altering the gel mechanical properties, as reflected by the mass swelling ratio. C) Live/ dead essay in DRG cell culture explants after one day of culture. D) Cell viability after 1 day

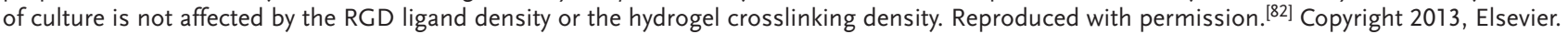

compared to bare chitosan films. ${ }^{[83]}$ This has provided the possibility for multilayer alternating films of ELPs and chitosan, that display sharp and reversible response not only to temperature, but also to $\mathrm{pH}$ and ionic strength; the same hydrophilic transition that was observed at $50{ }^{\circ} \mathrm{C}$ was also observed for $\mathrm{pH} 11$ and $1.25 \mathrm{~m}$ ionic strength. Again, improved adhesion and proliferation of the SaOs-2 cell line was observed when the last layer was an ELP-RGD layer compared to a chitosan layer, or to an ELP layer with a scrambled RDG sequence. ${ }^{[84]}$ The LBL strategy can elegantly be transferred from two to three dimensions; microcapsules of alternating ELP and chitosan layers can be fabricated by sequential adsorption using calcium carbonate spheres as sacrificial templates. These thermoresponsive microcapsules are non-cytotoxic and could be used as biocompatible vehicles for local injection at tissues combined with delivery of small molecule therapeutics, or even bigger molecules such as growth factors. ${ }^{[85]}$ Moreover, they can be internalized by hMSCs and progressively degraded inside the cells, further suggesting their eventual use in intracellular drug delivery applications. ${ }^{[86]}$

ELPs that combine elastin building blocks with silk building blocks are also the subject of intense investigation, since they combine the elasticity and resilience of elastin with the tensile strength of silk sequences. Depending of the relative ratio of the two building blocks, they either form gels in physiological temperatures, ${ }^{[87]}$ or solutions that can be electrospun into fibrous mats that support cell attachment and proliferation. ${ }^{[88]}$ 

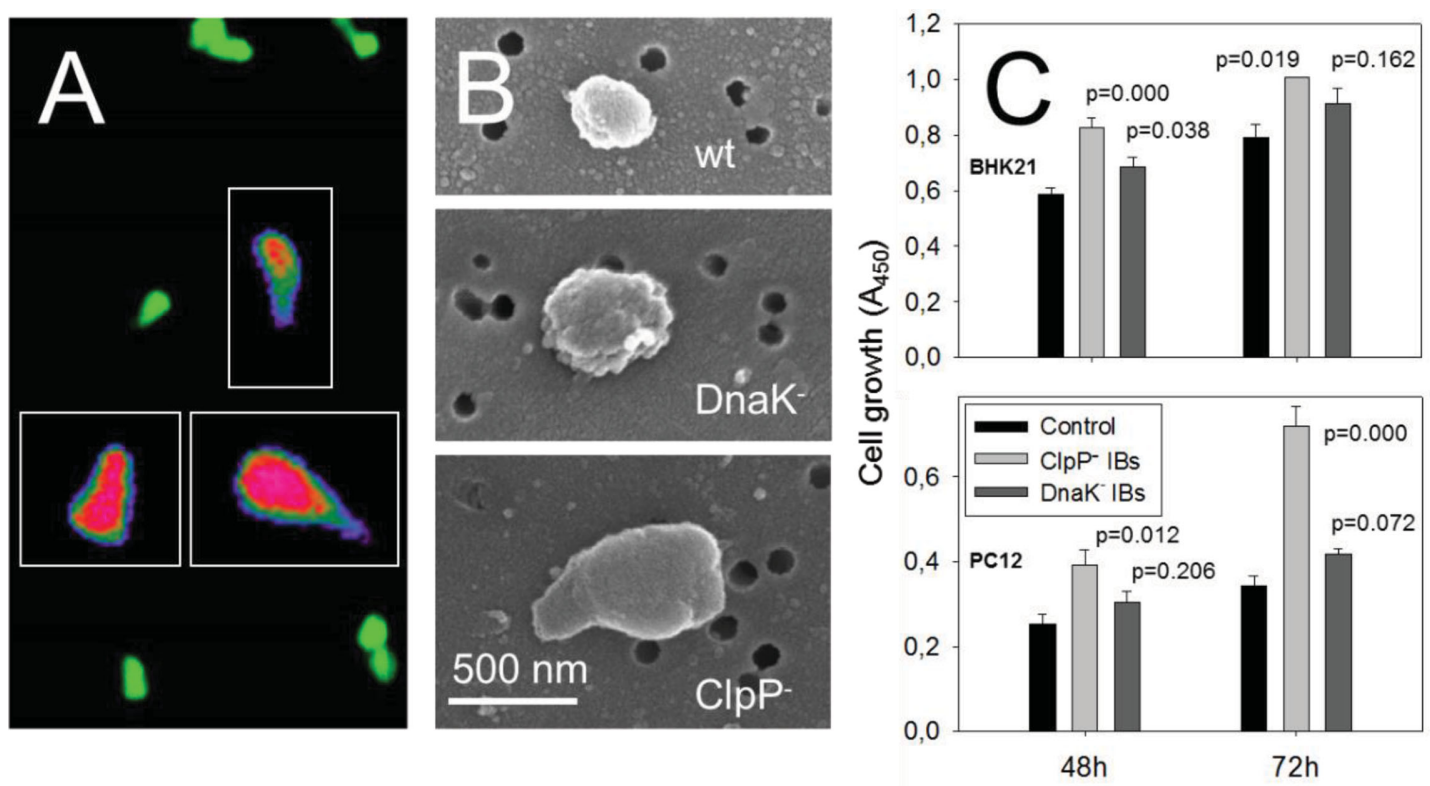

Figure 6. Geometries of inclusion bodies produced in various genetic backgrounds and their influence on cell growth. A) Confocal images of tearshaped inclusion bodies formed by a fluorescent protein (mGFP) produced in an E. coli strain deficient in the ClpP protease. B) Scanning electron microscope (SEM) images of inclusion bodies produced in the WT background, a strain deficient in the DnaK chaperone, and the strain deficient in the ClpP protease. C) Growth of two different mammalian cell lines, as measured by the MTT assay, on DnaK deficient and ClpP strains, compared to polystyrene surfaces without IBs. Reproduced with permission. ${ }^{[94]}$ Copyright 2010, IOP Publishing.

\subsection{Inclusion Bodies (IBs) Formed from Recombinant Proteins}

Another class of self-assembling protein materials that are recently emerging as promising biocompatible materials are inclusion bodies (IBs). Inclusion bodies are pseudospherical particles of aggregated polypeptide chains and are frequently formed during overexpression of heterologous proteins in E. coli. They are refractile with dimensions ranging from 50 to $500 \mathrm{~nm}$ and can be distinguished under phase contrast microscopy; in transmission electron microscopy, they appear as electron-dense deposits. ${ }^{[89]}$ They mainly contain the expressed protein and sediment at low centrifugation speeds following cell lysis, therefore can be non-chromatographically purified by repeated cycles of centrifugation. Recent structural studies with hydrogen/deuterium exchange coupled with NMR and solid-state NMR suggested that inclusion bodies contain segments of the polypeptide chain engaged in amyloid-like fibrils in cross-beta conformation. ${ }^{90]}$ A significant fraction of the chains seem to be properly folded, especially when enzymes or fluorescent proteins are expressed as fusion proteins with short aggregation-inducing peptide tags. ${ }^{[91]}$ Inclusion bodies behave as particulate, hydrated and porous nanomaterials that exhibit nanoscale topographical features similar to the ones presented by the natural ECM. ${ }^{[92]}$ When patterned on amino-terminated silicon surfaces, they support cell attachment and proliferation. ${ }^{[3]}$ Moreover, IBs patterned in different densities using microcontact printing promote preferential attachment and alignment of fibroblasts along the specific pattern. This paves the way for applications in 2D microscale surface engineering. The advantage of IBs is that their size, morphology, stiffness, and other physical properties can be tuned by careful selection of the bacterial production strains and culture conditions. ${ }^{[94]}$
For example, the usual shape of IBs is spherical or ovoid, presumably due to the balance of deposition and degradation processes of polypeptide chains at their surface. Different genetic backgrounds relevant to the protein quality control factors (such as chaperones and degrading proteases) could influence size, shape and topography of produced IBs, all of them being factors sensed by attaching cells. For example, strains deficient in the ClpP protease produce unusual tear-shaped IBS that slightly promote proliferation of new born hamster kidney (BHK21) cells compared to polystyrene control surfaces, while they promote proliferation of rat pheochromocytoma (PC12) cells much more efficiently (Figure 6).

Inclusion bodies are well-tolerated by mice after oral delivery in high doses, with the animals showing no weight loss, normal food intake and no signs of discomfort. No histological intestinal damage was also detected. ${ }^{[95]}$ This recent body of evidence suggest their potential use as biocompatible materials, ${ }^{[96]}$ although still their safety has to be fully assessed.

\section{Short Peptides that Self-Assemble Into Biomimetic Hydrogel Scaffolds}

Self-assembling peptide scaffolds have a long history of being applied as in vitro cell culture substrates, implantable scaffolds, regenerative therapies and matrices for the delivery of encapsulated or conjugated bioactive therapeutics. ${ }^{[97]}$ The biomimetic microarchitecture of short peptide hydrogel scaffolds promotes cell proliferation and migration even in the absence of bioactive motifs for cell signaling and attachment. Thus, the innate selfassembling property can be exploited to promote the delivery of cells and therapeutics, suggesting applications as minimally 
invasive injectable therapies. Considering that supramolecular self-assembly is reversible because it is predominantly held by weak non-covalent interactions, many short peptide hydrogels are capable of dynamic reassembly following mechanical perturbations and are thus self-healing. ${ }^{[98]}$

Another major advantage of using peptides is their inherent biocompatibility and biodegradability as many self-assembling peptides are inspired by motifs found in nature. Chemical synthesis also permits the inclusion of non-coded and synthetic amino acids, peptidomimetics and synthetic functional groups. This has significantly broadened the scope of peptidic building blocks, which has in turn led to greater understanding of the intrinsic nature of self-assembly and the extrinsic factors which modulate the physiochemical properties of the resulting scaffold. The combinatorial display of different bioactive motifs and enzymatic degradation sites, as well as incorporation of soluble factors, is integral to designing scaffolds that recapitulate the complex ECM microenvironment. The nanofibrillar topography and porous microarchitecture, combined with biomolecules encapsulated in the hydrogel environment provides a multitude of approaches for enhancing cell proliferation and differentiation in regenerative medicine.

There are several different classes of short peptides that form nanofibrous hydrogels, as defined by the secondary structure of the motif that drives self-assembly. Most notably, early work on self-assembling peptides was inspired by $\beta$-sheet and $\alpha$-helical sequences found in naturally occurring proteins. Since then, insights into peptide folding and the intermolecular interactions that drive self-assembly have led to the emergence of rationally designed de novo motifs. For a subset of these synthetic motifs, non-natural amino acids and functional groups have been incorporated to drive self-assembly via building blocks that cannot be replicated by nature.

\subsection{Short Peptides with $\beta$-Sheet Secondary Structure}

The $\beta$-sheet motif is characterized by periodic repeats of hydrophilic and hydrophobic amino acids, which subsequently stack via intermolecular hydrophobic interactions between the intermolecular hydrophobic interfaces and electrostatic interactions between the intermolecular hydrophilic interfaces to form nanofibers. Due to the strong intermolecular interactions that drive $\beta$-sheet self-assembly, the resulting hydrogels are very stable, which bodes well for long term in vitro cultures and in vivo implants for tissue regeneration. The stability of the $\beta$-sheet secondary structure also facilitates the incorporation of biochemical cues for modifying cell behavior; $\beta$-sheet peptide hydrogels are often modular scaffolds consisting of biofunctional motifs appended to the self-assembling domain.

The typical $\beta$-sheet motif is exemplified by the self-complementary RADA16 peptide. ${ }^{[99]}$ In an aqueous media, the hydrophobic alanines form overlapping hydrophobic interactions, while the positive arginine and negative aspartic acid residues of adjacent peptides pack together through intermolecular ionic interactions in a checkerboard-like manner. Consequently, the $\beta$-sheets stack to form $10 \mathrm{~nm}$ nanofibers, which in turn aggregate to form hydrogel scaffolds. These scaffolds are capable of self-healing: when sonication is repeatedly applied to disrupt the intermolecular interactions and force the collapse of the hydrogel into the liquid state, the peptide constituents gradually reassemble into nanofibers that were indistinguishable from those in the original hydrogel. The mechanical stiffness of the reassembled hydrogel is also uncompromised. ${ }^{[100]}$ The propensity for dynamic self-assembly into nanofibers is retained by D-chiral isoform peptides, which has the additional advantage of being resistant to enzymatic degradation. ${ }^{[101]}$ RADA16 hydrogel scaffolds promote cell growth, proliferation and migration ${ }^{[102]}$ and have been used in a wide range of biomaterial applications, including hemostasis, ${ }^{[101 a, 103]}$ cartilage $^{[104]}$ and bone ${ }^{[105]}$ repair, intervertebral disc therapy, ${ }^{[106]}$ hepatocyte differentiation, ${ }^{[107]}$ neuronal regeneration, ${ }^{[108]}$ cardiac tissue regeneration, ${ }^{[109]}$ and connective tissue repair. ${ }^{[110]}$ To promote specific cell-scaffold interactions, biologically active motifs for cell-adhesion and differentiation can be chemically conjugated prior to self-assembly (Figure 7). Such modifications do not compromise the mechanical integrity of the bulk structure and the appended motifs can be displayed in a specific manner so as to optimize their biological activity. ${ }^{[110,111]}$ For instance, osteogenic motifs ALKRQGRTLYGF (osteogenic growth) and DGRGDSVAYG (osteopontin cell adhesion) appended to the C-terminus of RADA16 promoted mouse pre-osteoblast MC3T3-E1 cell proliferation and osteogenic differentiation. ${ }^{[111 b]}$ These different functional motifs can be incorporated in the same scaffold by simply mixing them at various ratios. The resulting modified designer scaffolds can also be used to encapsulate soluble biomolecules. The facile encapsulation of drugs and growth factors enables the slow, controlled release of these biomolecules to adjacent cells. ${ }^{[112]}$ To date, RADA16 has been used to deliver epidermal growth factor to accelerate cutaneous wound healing, plateletderived growth factor, stromal cell-derived factor-1 and insulinlike growth factor to the post-infarction myocardium. ${ }^{109,113]}$ In view of its excellent biocompatibility, RADA16 has since been successfully licensed and is commercially available as PuraMatrix for laboratory and pre-clinical applications. Its clinical application as a surgical hemostatic agent has received the CE mark under the trade name PuraStat, for which it is currently undergoing post-market surveillance in the European Union and will be subject to investigational studies for US Food and Drug Administration (FDA) approval. PuraMatrix is also currently undergoing clinical trials as a dental bone regenerative therapy as a bone void filler to be inserted into bony voids to resorb and be replaced with bone for dental implants.

Using aromatic residues as the hydrophobic component of the $\beta$-sheet motif, a class of glutamate-rich peptides exemplified by Ac-QQKFQFQFEQQ- $\mathrm{NH}_{2}(\mathrm{Q} 11)$ self-assemble in an anti-parallel fashion to form nanofibrils. Modifying the peptides to incorporate a C-terminal thioester enables cross-linking via native chemical ligation with an $\mathrm{N}$-terminal cysteine. ${ }^{[114]}$ The cross-linked hydrogels are significantly stiffer while maintaining the nanofibrillar morphology of the parent hydrogels; resulting in enhanced endothelial cell proliferation. Similar to RADA16, functionalization with cell signaling motifs does not compromise Q11 self-assembly. Q11 bearing cell adhesion ligands RGDS, IKVAV, and YIGSR form multicomponent coassembling hydrogels that enhanced endothelial cell attachment, spreading and proliferation ${ }^{[115]}$ (Figure 8). $\beta$-sheet fibrillizing peptides are resistant to proteolysis, degradation, and turnover 
A

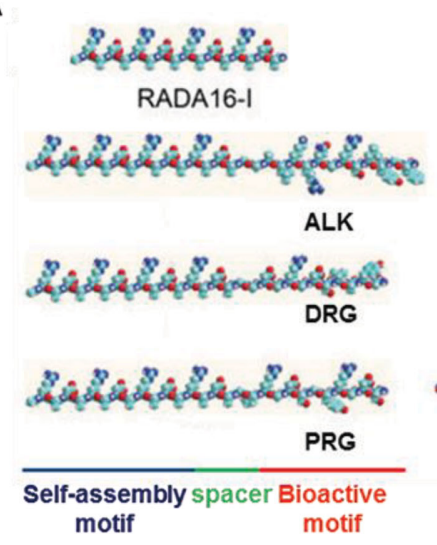

B

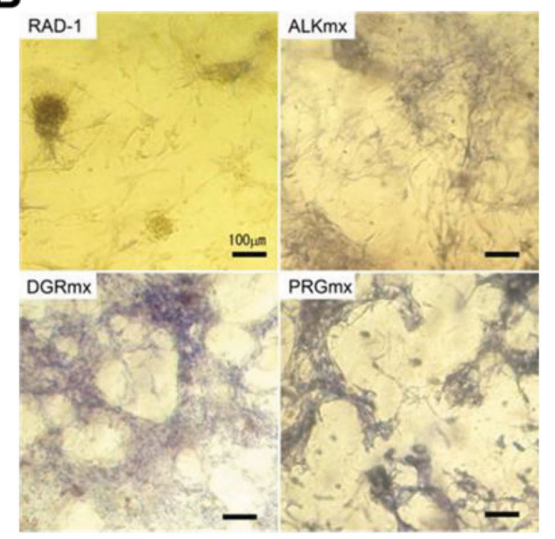

Figure 7. Functionalized peptides with short $\beta$-sheet motifs self-assemble into nanofibrous scaffolds that promote cell adhesion, proliferation and differentiation. A) RADA16 can be modified with bioactive motifs. As a proof-of concept, a motif from osteogenic growth peptide ALK (ALKRQGRTLYGFGG), a cell adhesion motif DGR from osteopontin (DGRGDSVAYG) and an integrin binding motif PRG with two RGD units (PRGDSGYRGDS) were appended onto the C-terminus of RADA16 during peptide synthesis. The modified peptides were then mixed with unmodified RADA16 to form composite functionalized ALKmx, DGRmx and PRGmx hydrogels. B) Pre-osteoblast MC3T3E1 cells cultured on the pure unmodified RADA16 hydrogels (RAD-1) demonstrate low alkaline phosphatase activity, as denoted by the weak bluish staining. Incorporating $1 \%$ (w/v) of the modified peptides significant increased cell attachment and alkaline phosphatase activity. Because alkaline phosphatase activity correlates with bone formation, the results suggest that the incorporation of ALK, DGR and PRG bioactive motifs promote the proliferation and differentiation of osteoblasts. Reproduced from ref. [111b].

in biological environments. As an alternative to the incorporation of enzyme cleavage sites to increase matrix biodegradability, Collier and co-workers have designed self-assembling depsipeptides by substituting amino acids in the Q11 peptide with their corresponding $\alpha$-hydroxy acid analogs. ${ }^{[116]}$ Replacing the amide bond with ester bonds in the peptide backbone facilitates biodegradation via hydrolysis, enabling the softening and eventual clearance of the $\beta$-sheet scaffold in vivo following tissue regeneration or drug delivery.

In addition to self-complementary $\beta$-sheet peptides, hydrogel scaffolds can be obtained by mixing oppositely charged $\beta$-sheet peptides. ${ }^{[117]}$ The electrostatic interactions between the comple-
A

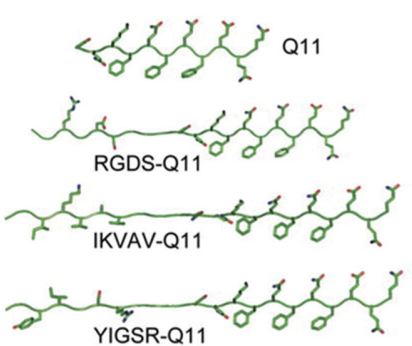

C

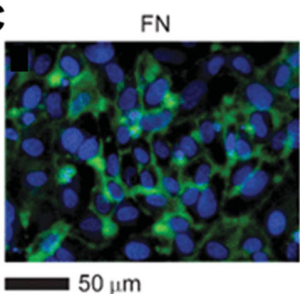

B

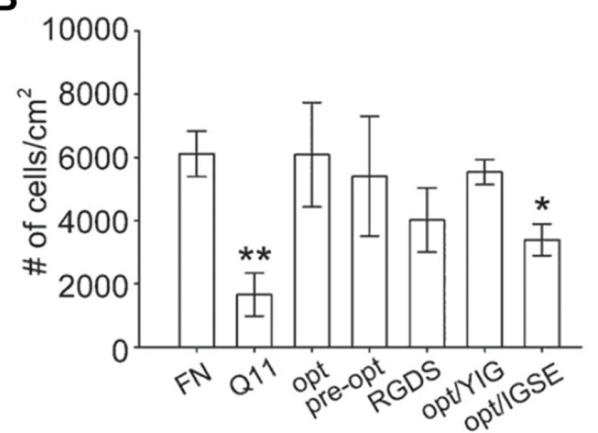

Q11
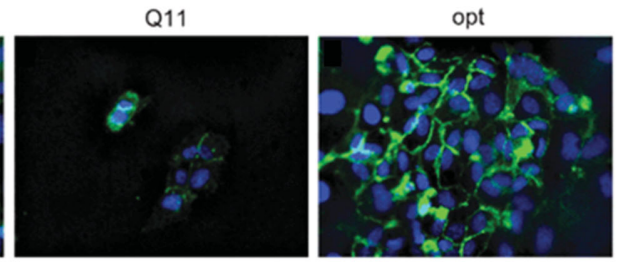

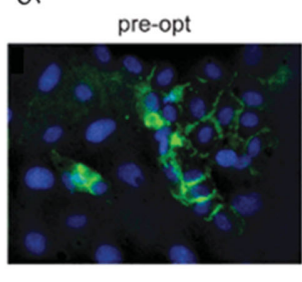

Figure 8. Q11 fibrillizing peptides bearing cell adhesion ligands form multicomponent co-assembling hydrogels that significantly enhanced endothelial cell attachment, spreading and proliferation. A) The modular nature of these peptides enabled multi-factorial experimental designs to evaluate interactions between different ligands and thus formulate a multi-ligand matrix which maximized endothelial cell growth. B) To verify the computational findings, human umbilical vein endothelial cells were cultured on the optimized matrix (opt), a "pre-optimized" formulation representing a combination of the best individual ligand concentrations (pre-opt), gels containing only the RGDS ligand (RGDS), optimized gels containing additional YIGSR-Q1 1 (opt/YIG), optimized gels containing additional IGSE-Q11 (opt/IGSE), and Q11 gels with adsorbed fibronectin (FN). Cell growth on the optimized matrix was comparable to that on fibronectin-coated gels, and greater than on the pre-optimized composite gel and gels with individual ligands. C) The improved growth rate on the optimized gels could be visualized using microscopy and corresponded to a qualitatively higher expression of endothelial marker PECAM-1/CD31 (stained green with DAPI nuclear counterstain). Reproduced with permission. ${ }^{[15]}$ Copyright 2011, Royal Society of Chemistry. 
mentary peptides stabilize the macromolecular structure, conferring stimuli-responsive properties. In other words, self-assembly, scaffold dissociation and dynamic reassembly (self-healing) are stimuli responsive and the mechanical properties of the hydrogel can be modulated by changes in $\mathrm{pH}$ and salt concentrations.

The self-assembly of charged $\beta$-sheet peptides can also be triggered by neutralization of the charged residues via judicious $\mathrm{pH}$ control. Taking advantage of this property, Hartgerink et al. designed a class of ABA multi-domain short peptides where in the B-domain is a neutral $\beta$-sheet motif (such as hexameric repeats of $\mathrm{QL}$, and $\mathrm{SL}$ ), flanked by identical A-domains containing charged residues, as exemplified by Ac$\mathrm{KK}(\mathrm{QL})_{6} \mathrm{KK}-\mathrm{NH}_{2}, \quad$ Ac-E $(\mathrm{QL})_{6} \mathrm{E}-\mathrm{NH}_{2}, \quad$ Ac-KK(SL) ${ }_{6} \mathrm{KK}^{-\mathrm{NH}_{2}}$, Ac$\mathrm{E}(\mathrm{SL})_{6} \mathrm{E}-\mathrm{NH}_{2} \cdot{ }^{[118]}$ The use of aliphatic versus aromatic residues in the B-domain alters the hydrogen bonding between adjacent $\beta$-sheets, resulting in changes in nanofiber morphology and the mechanical properties of the bulk hydrogel.[119] The incorporation of cysteine into the B-domain in Ac-E(CLSL) ${ }_{3} \mathrm{E}-\mathrm{NH}_{2}$ enabled intermolecular disulphide cross-linking, which enhanced the stability and mechanical strength of ABA hydrogels. Similarly, ABA peptides containing lysine can be enzymatically crosslinked using polyamine oxidase or lysyl oxidase. ${ }^{[120]}$ The modular nature of ABA $\beta$-sheet peptide hydrogels accommodates bioactive domains such as RGD cell adhesion motifs and matrix metalloprotease-2 cleavage sites. ${ }^{[121]}$ The resulting biofunctional scaffolds demonstrated increased cell viability, spreading and encouraged cell migration. These multidomain scaffolds can be concurrently loaded with growth factors via heparin binding, which promoted vascularization and connective tissue formation in vivo and can be applied towards regenerative endodontics. ${ }^{[122]}$ Hydrogels loaded with factors secreted by stem cells have also been successfully shown to revive glomerular epithelial cells following diabetes-induced kidney injury. ${ }^{[12 c]}$ The growth factor release can be further modulated by encapsulation into liposomes prior to loading into the peptide hydrogels. ${ }^{[123]}$ Such composite hydrogels can act as bimodal release systems-; therapeutics entrapped in the hydrogel are rapidly released while those loaded into liposomes are released after a delay, to deliver bioactive moieties at different rates to enhance tissue regeneration.

Some $\beta$-sheet peptides self-assemble into nanofibrous 3D scaffolds via intermediate macromolecular structures. A novel class of short (7 to 11 amino acids) $\beta$-sheet peptides developed by Aggeli and co-workers assemble in an anti-parallel fashion via hydrogen bonding to form nanotapes that are a singlemolecule thick. ${ }^{[124]}$ Pairs of nanotapes subsequently stack to form ribbons which are stabilized by $\pi-\pi$ interactions of the aromatic residues in the motif. Further aggregation of peptide ribbons into fibrils which in turn condense to form 3D fiber networks that entrap water. The physical properties, surface chemistry and stimuli responsiveness of the resulting peptide hydrogels can be modulated by subtle changes in amino acid sequence. ${ }^{[125]}$ Binary systems with oppositely charged complementary peptides have also been designed..126] The 11-mer peptide $\mathrm{P}_{11-4}$ (Ac-QQRFEWEFEQQ- $\mathrm{NH}_{2}$ ) has been applied as an injectable scaffold for treating bone defects, dental hypersensitivity and dental decay. ${ }^{[127]}$ The self-assembling peptide scaffold induces de novo nucleation of hydroxyapatite, increases enamel remineralization and retards demineralization. ${ }^{[128]}$ Recent clinical safety trials with a single application of $\mathrm{P}_{11-4}$ to dental lesions demonstrated safety in human patients and concomitant enamel regeneration within 30 days. ${ }^{[129]}$

Loop-and-strand sequences that occur in natural betastructured fibrous proteins can also be exploited towards the design of short, self-assembling peptides. Such an octapeptide, NSGAITIG from the fibrous shaft of the adenovirus fiber protein self-assembles into amyloid-type fibrils. ${ }^{[130]}$ The residues NSG belong to a loop and the rest of the sequence to a strand within the native protein structure. In the assembled fibril context, the residues $\mathrm{N}$ and $\mathrm{S}$ do not belong to the self-assembling core but remain accessible and prone to modification. ${ }^{[131]}$ Binding of inorganic materials such as metal nanoparticles ${ }^{[132]}$ and silica ${ }^{[133]}$ could be promoted through punctual amino acid changes at these positions without affecting assembly. When aspartates were introduced at these positions, the deposition of calcium phosphates was promoted on the fibrils. Furthermore, when immobilized on 3D laser-fabricated scaffolds, the mineralized fibrils strongly supported attachment and proliferation of a preosteoblastic cell line and exhibited a statistically significant increase of biomineralization. ${ }^{[134]}$

The introduction of an artificial tetrapeptide $\beta$-turn ( $\left.{ }^{\mathrm{D} V P P T}\right)$ containing of a single $\mathrm{D}$-amino acid, to join two $\beta$-sheets creates a $\beta$-hairpin conformation. Through rational design, Pochan, Schneider and colleagues developed a series of $\beta$-hairpin scaffolds. ${ }^{[135]}$ During self-assembly, these peptides fold into $\beta$-hairpins in response to changes in light, ${ }^{[136]} \mathrm{pH},{ }^{[137]}$ ion concentration, ${ }^{[138]}$ and temperature. ${ }^{[135 b]}$ The $\beta$-hairpins pack in an orderly fashion along their hydrophobic faces to form bilayers. The bilayers further aggregate to form crosslinked fibrils. The network branching and shear-thinning hydrogel properties can be further tuned by careful re-design of the flanking $\beta$-sheets to optimize the packing of adjacent $\beta$-hairpins. ${ }^{[139]}$ These peptides also exhibit tuneable, stimuliresponsive re-gelation kinetics following mechanical disruption. ${ }^{[140]}$ This property has been exploited to design injectable therapies for tissue regeneration where the shear-thinned hydrogel (containing stem cells) can be easily administered to the target site for rapid in situ gelation. The introduction of a second tetrapeptide $\beta$-turn produces a three-stranded $\beta$-sheet peptide which is also capable of self-assembly into nanofibrous hydrogels. ${ }^{[141]}$ Subsequent development of complementary peptide hydrogels was inspired by classical domain swapping mechanisms that trigger protein fibrillogenesis. ${ }^{[142]} \beta$-hairpin hydrogels have been used for sustained release of encapsulated proteins, wherein the release kinetics is influenced by the hydrophobicity, charge and molecular weight of the biomolecules. ${ }^{[143]}$ To enhance cell proliferation and influence cell behavior, cell signaling motifs such as MLPHHGA have be appended to direct hydroxyapatite mineralization for dental tissue regeneration ${ }^{[144]}$ (Figure 9). On a side note, several $\beta$-hairpin peptides demonstrated inherent antibacterial activity without causing concurrent hemolysis. ${ }^{[145]}$ Further optimization to incorporate more arginines into the flanking $\beta$-sheets increased their efficiency in killing gram-positive and gramnegative bacteria, including multi-drug resistant strains. ${ }^{[146]}$ Such peptides are of interest as injectable scaffolds for wound healing. 
A

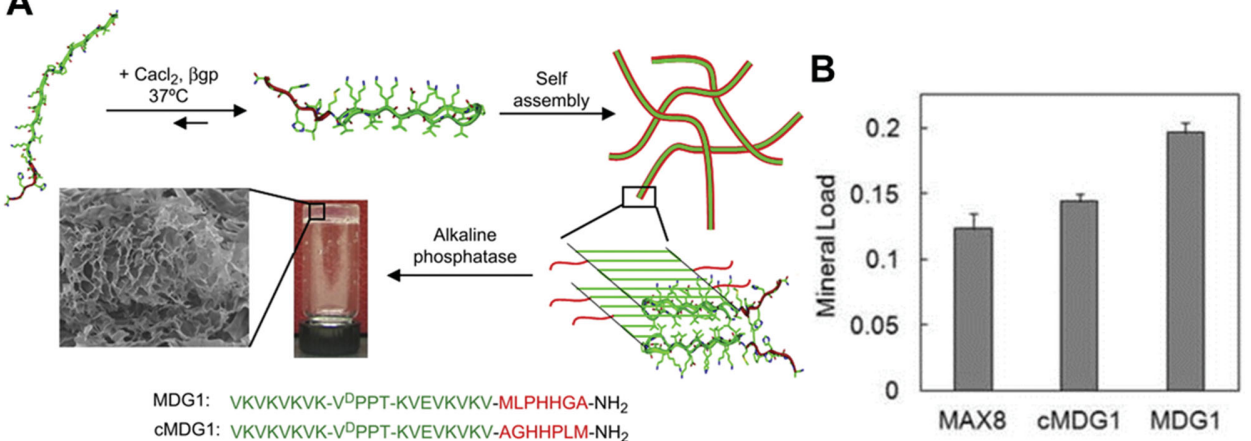

CMDG1: VKVKVKVK-VDPPT-KVEVKVKV-AGHHPLM-NH

MAX8 CMDG1 MDG1

C

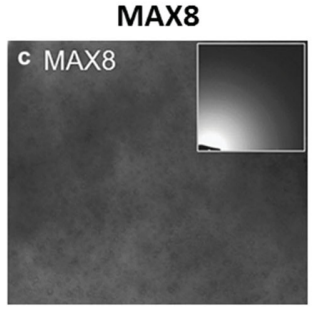

cMDG1

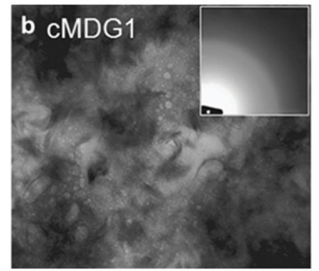

MDG1

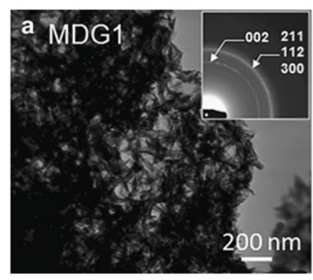

Figure 9. Cell signaling motifs, such as MLPHHGA (MDG), can be appended to MAX8 $\beta$-hairpin hydrogels to direct hydroxyapatite mineralization for dental tissue regeneration. A) The resulting peptide, MDG1 (mineral directing gelator), undergoes triggered folding to form an unsymmetrical $\beta$-hairpin that self-assembles in the presence of calcium chloride $\left(\mathrm{CaCl}_{2}\right)$ to yield a mechanically rigid hydrogel. $\beta$-glycerophosphate $(\beta$-GP) was also added to facilitate mineralization. In the presence of alkaline phosphatase (exogenous or secreted by cells), $\beta$-GP is hydrolysed and the free phosphate reacts with calcium ions to mineralize the matrix. B) Gels entrapping alkaline phosphatase and $\beta$-GP sequester calcium phosphate after $24 \mathrm{~h}$, with the MDG1 gel accommodating a slightly higher load than the control gels. This demonstrates that the appended C-terminal ligand does not affect gross mineralization. C) However, the ligand influences the crystal morphology. Transmission electron microscopy analysis further demonstrates distinct differences in the crystallinity of the deposited minerals within each of the peptide hydrogels. Mineral deposited within the MDG1 gel was highly crystalline and elongated, resembling biological apatite, while few and no particles were observed on the CMDG1 and MAX8 gels respectively. Reproduced with permission. ${ }^{[144]}$ Copyright 2010, Elsevier.

$\beta$-sheet self-assembling motifs gives rise to stable, biomimetic nanofibrous hydrogels. Exploiting the strong forces that govern $\beta$-sheet self-assembly, biofunctional domains can be conjugated to the self-assembling domain without affecting the bulk structural properties. This has enabled scientists to modulate the stability of the scaffold (through incorporation of enzymatic degradation sites), display bioactive epitopes (through the attachment of cell adhesion and cell signaling ligands) and release soluble biochemical cues to influence cell behaviour. The various molecular domains can be changed independently, further increasing the complexity of the resulting scaffold and enhancing their potential to mimic native ECM to optimize tissue regeneration.

\subsection{Short Peptides with $\alpha$-Helical Secondary Structure}

Self-assembling $\alpha$-helical motifs are typically based on heptad (7 residues) repeats which dictate the intra- and intermolecular peptidic interactions. During self-assembly, two or more $\alpha$-helical strands oligomerize to form coiled-coil structures that further elongate and aggregate into nanofibrous scaffolds.

Taking inspiration from leucine-zipper motifs, Woolfson and colleagues rationally designed a series of two-component $\alpha$-helical peptides that self-assemble into hydrogelating selfassembling fibers (hSAFs). ${ }^{[147]}$ Two peptides, each consisting of four heptad repeats, form heterodimer fibrils upon mixing at physiological conditions (Figure 10). The fibril is stabilized by an interhelical hydrophobic core of aliphatic residues at the first and fourth position of the heptad, and further stabilization is provided by asparagine pairing at specific locations. Charged residues at the fifth and seventh positions of the heptad enable electrostatic interactions which result in the staggered formation of "sticky ends" for facile lengthwise extension; while polar residues at the second, third and sixth position enable fibril aggregation into mature fibers and thus determine fiber thickness and flexibility. Branched fibrils can be obtained by introducing a third "blunt end" helical peptide. ${ }^{[148]}$ Biotin and short peptide "tags" can also be introduced as branches into linear hSAFs by appending to lysine residues within the heptad ${ }^{[149]}$ or the N-terminus during synthesis. ${ }^{[150]}$ This would allow for scaffold functionalization post-assembly to introduce bioactive motifs conjugated to streptavidin or antibodies. However, this approach is highly inefficient as the incorporation of tags often interferes with heterodimer formation, resulting in the fibril destabilization. To circumvent this, specific residues in the sixth position of the heptad can be substituted with synthetic amino acids bearing azido and allyl moieties, without compromising their propensity to self-assemble. ${ }^{[151]}$ Post-assembly, cell adhesion ligands such as RGDS can be appended by copper(I)catalyzed azide-alkyne and thiol-ene click reactions. ${ }^{[152]}$ Such bioorthogonal dual functionalization will enables the presentation of two different ligands independently to influence cell fate. While undecorated hSAF hydrogels support support 
SAF-p2a: KIRRLKQ KNARLKQ EIAALEY EIAALEQ

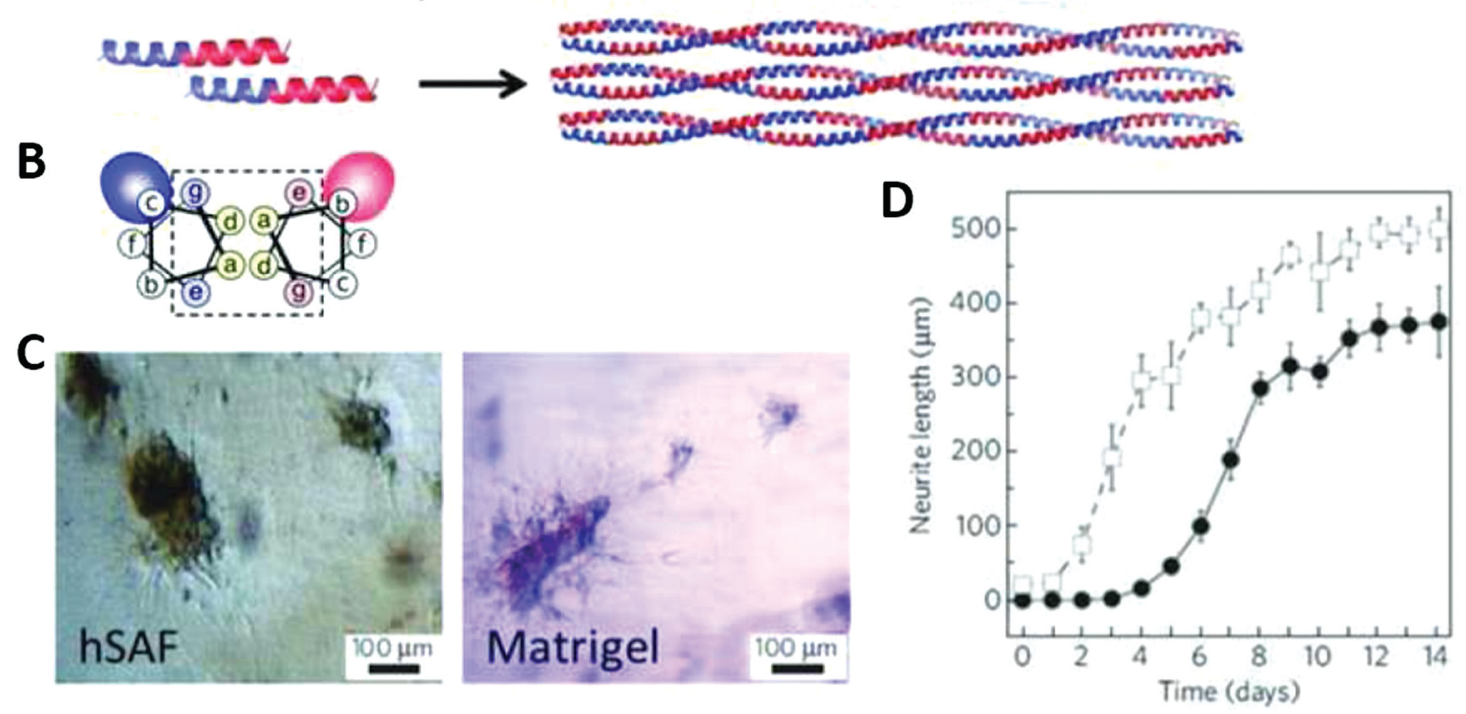

Figure 10. Functionalized short peptides with $\alpha$-helical motifs self-assemble into hydrogels which promote cell growth and tissue regeneration. A) Coiled-coil heptad $\alpha$-helical hSAF peptides form staggered parallel heterodimer fibrils which further aggregate into 3D nanofibrous hydrogels. Adapted with pemission from ${ }^{[152]}$. B) Helical wheel representation of the peptides. C) These hydrogels promote the growth and differentiation of rat adrenal pheochromocytoma ( $\mathrm{PC12}$ ) cells in vitro, as observed by neurite extension the presence of nerve growth factor. D) After a lag of 4 days, $\mathrm{PC} 12$ cells cultured on hSAF hydrogels (filled circles) developed neurites, which subsequently elongated over time. Cells cultured on Matrigel (open squares) were used as a positive control. Panels B, C, and D reproduced with permission. [147a] Copyright 2009, Nature Publishing Group.

neuronal cell growth and neurite extension, ${ }^{[147 a]}$ scaffolds functionalized with RGDS demonstrated greater cell adhesion, proliferation and differentiation of precursor cells. ${ }^{[152]}$

Trimeric $\alpha$-helical peptides that self-assemble into synthetic collagen scaffolds are of great interest as scaffolds for tissue engineering. Collagen is a major structural component of the ECM and is able to support cell attachment and proliferation which has led to its widespread utilization in cell and tissue scaffolds. However, as collagens are typically extracted from animal sources, concerns regarding contaminations by pathogens, batch-to-batch variability, and immunogenicity have largely curtailed their clinical applications. To circumvent these issues, scientists have synthesized collagen-mimetic peptides (CMP) based on X-Y-glycine motifs from natural collagen sequences. Stable triple helical structures have been obtained using homotrimeric ${ }^{[153]}$ and heterotrimeric ${ }^{[154]}$ motifs. However, these systems formed bulk amorphous aggregates rather than nanofibers. To facilitate fiber assembly, various strategies were evaluated, including the re-design of the $\alpha$-helical building blocks to generate sticky ends, ${ }^{[155]}$ the incorporation of hydrophobic residues at the periphery to facilitate aggregation, ${ }^{[156]}$ the inclusion of cysteine residues to form cysteine knots, ${ }^{[157]}$ and the conjugation of metal-binding ligands at the termini for metal-triggered fibril assembly. ${ }^{[158]}$ Chmielewski and colleagues successfully cultured human endothelial cells on nanofibrous hydrogels prepared from metal-triggered self-assembling CMPs. ${ }^{[158 b]}$ These scaffolds can also be functionalised with $\mathrm{N}$-terminal cell adhesion motifs and His-tagged growth factors to encourage cell proliferation. ${ }^{[159]}$ More recently, Kumar et al demonstrated that their sticky ended homotrimeric KOD CMPs formed hydrogels thatpromote hemostasis; platelets adhere to these hydrogels and become activated, resulting in the formation of blood clots. ${ }^{[160]}$ CMPs have also been exploited for functionalizing polymeric scaffolds. ${ }^{[161]}$ The innate ability of CMPs to associate with collagen fibers via strand invasion was exploited for immobilizing therapeutics to tissues to facilitate regeneration and for spatial photo-patterning of scaffolds to create complex tissue constructs. ${ }^{[162]}$

A unique class of ultrashort aliphatic peptides with sequences from 3-mers to 7-mers self-assemble into nanofibrous hydrogels via $\alpha$-helical intermediates. ${ }^{[163]}$ The uniqueness of this peptide class is based on their unusual behavior to go through structural transitions from random coil to helical intermediates before they reach their final $\beta$-turn structure. Therefore, the peptides are able to adopt various secondary structures, depending on their respective stage in the assembly process. The 3-mer peptides are the shortest aliphatic peptides reported to self-assemble into fibrous hydrogel scaffolds. In marked contrast to the $\alpha$-helical peptides previously described, these peptides do not conform to the heptad structure, and in fact belie the general view that $\alpha$-helical structures can only be observed in peptide sequences with at least 7 amino acids (corresponding to one complete turn of the helix). Consisting of three to seven aliphatic amino acids, the characteristic sequence motif consists of an acetylated N-terminus aliphatic tail of hydrophobic amino acids capped by a polar C-terminal residue (Figure 11). During self-assembly in aqueous conditions, the amphiphilic peptides form parallel-antiparallel $\alpha$-helical pairs 


\section{A}

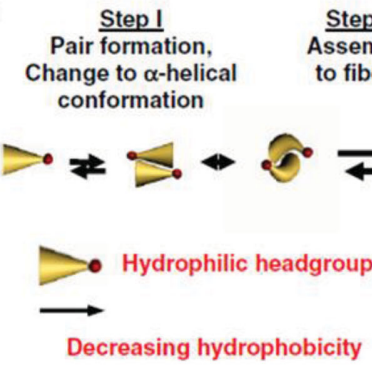

B

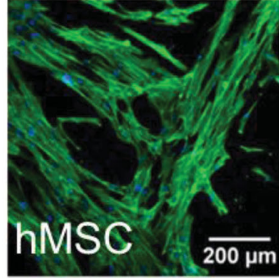

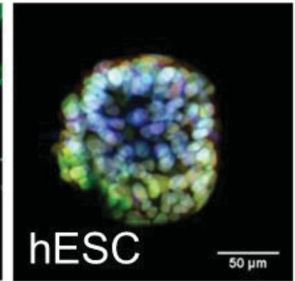

Step III

densation

of fibers

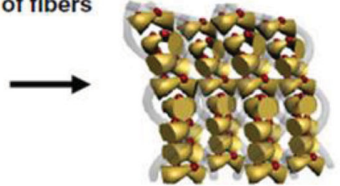

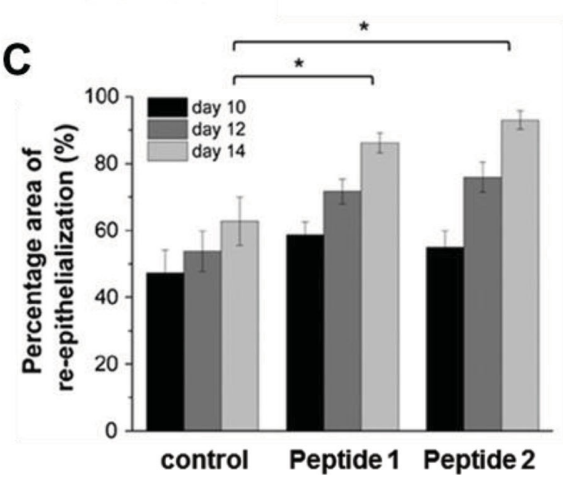

Figure 11. A class of ultrashort amphiphilic peptides are unique in that they $\alpha$-helical intermediates despite having less than 7 amino acids. A) This secondary structure is attributed to antiparallel pairing of peptide monomers. Subsequent stacking and aggregation gives rise to fibrils which in turn condense to form nanofibers which entrap water to form hydrogels. Reproduced with permission. ${ }^{[163]}$ B) These hydrogels support the 3D culture of encapsulated human adult mesenchymal and embryonic stem cells. Human mesenchymal stem cells (hMSC) elongated when cultured on the nanofibrous scaffolds, as reflected by cytoskeletal actin staining (in green, with blue DAPI nuclear counterstain). Reproduced with permission ${ }^{[233]}$ copyright 2015, American Chemical Society. Human embryonic stem cells (hESC) grow as colonies which maintain their pluripotency, as shown by immunohistochemical staining for Oct4 (green) and Nanog (red) transcription factors. C) The hydrogels can also be applied as wound dressings for partial thickness burns, wherein they accelerate skin regeneration. Reproduced with permission. ${ }^{[165]}$ Copyright 2014, Elsevier.

which subsequently stack into $\beta$-turn fibrils. Aggregation of fibrils gives rise to nanofibrous $3 \mathrm{D}$ networks that support cell growth for in vitro and in vivo biomedical applications. ${ }^{[164]}$ Most notably, the hydrogels enhanced epithelial regeneration and wound closure when applied as burn wound dressings. ${ }^{[165]}$ Monodispersed silver nanoparticles that were released from ultrashort peptide hydrogels effectively killed gram-positive and gram-negative bacteria. This offers additional possibilities for the wound care, when using peptide hydrogels. Their physical properties, particularly their high and tunable mechanical stiffness, also make them attractive candidates for orthopedic applications. ${ }^{[164]}$ The rigidity and stability can be further increased by crosslinking. Peptide candidates with $\mathrm{C}$-terminal cysteines are amenable towards oxidative crosslinking via the formation of intermolecular disulphide bonds. ${ }^{[166]}$ Biofunctional motifs can be similarly appended to enhance cell adhesion and influence cell behavior. Biofunctionalization can also be achieved by incorporating alkyne groups (to the peptide $\mathrm{N}$-terminus) for click chemistry. ${ }^{[167]}$

In view of the ordered pattern of molecular interactions in $\alpha$-helical self-assembling systems, changes to the peptide sequence modulates the macromolecular architecture and physiochemical properties of the resulting hydrogel scaffolds. However, significant care must be taken during bio-functionalization as large motifs conjugated to the peptidic building blocks can potentially de-stabilize the bulk hydrogel structure. Post-assembly modifications are thus favored, wherein bioactive moieties are attached to the assembled scaffold via click chemistry or strand invasion. These recent advances in functionalization have led to the development of better synthetic cell culture substrates, as well as bioactive scaffolds that promote cell proliferation, migration and differentiation for regenerative medicine.

\subsection{Short Peptides with Aromatic Residues and Chemical Functional Groups}

The shortest known aromatic peptides which form fibrous hydrogels are dipeptides with aromatic residues. The aromatic side chains are assumed to participate in $\pi-\pi$ stacking and contribute to the overall hydrophobic interactions that drive assembly into fibrillar scaffolds. The dipeptide IF is the shortest natural sequence known to form fibrillar networks, ${ }^{[168]}$ though very high concentrations (exceeding $150 \mathrm{mg} / \mathrm{mL}$ ) of peptide are needed for hydrogelation. The incorporation of additional aromatic residues facilitates selfassembly. Dipeptides of phenylalanyl-dehydrophenylalanine (F- $\Delta \mathrm{F}$ ) forms stimuli-responsive hydrogels which have been applied as tunable, self-regulated drug delivery platforms for the sustained release of vitamins, antibiotics and drugs. ${ }^{[169]}$ These hydrogels can be covalently functionalized with cell adhesion motifs (such as RGD) to support cell adhesion and proliferation $^{[170]}$ (Figure 12). The propensity for dipeptide self-assembly into nanofibrillar hydrogels can be enhanced by $\mathrm{N}$-terminus capping with aromatic functional groups, as exemplified by fluorenylmethoxycarbonyl-capped diphenylalanine (Fmoc-FF). ${ }^{[171]}$ Other N-terminal caps which also facilitate self-assembly include naphthalene and carboxybenzyl. ${ }^{[172]}$ These hydrogels can be functionalized by the 
A

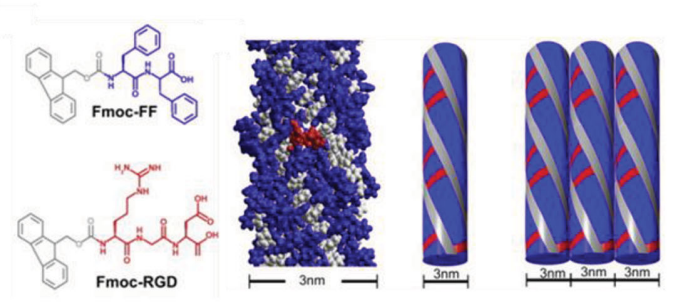

B

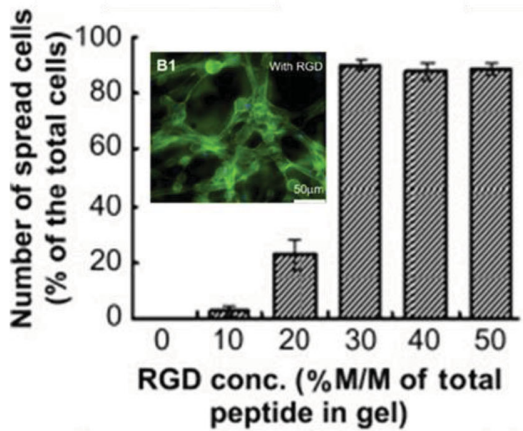

Figure 12. Short Fmoc-protected dipeptide scaffolds can be functionalized by mixing with Fmoc-protected ligands such as cell adhesion (RGD) motifs. A) The proposed supramolecular model suggests that the functionalized peptide self-assembles into $3 \mathrm{~nm}$ fibrils and further assembles laterally into larger ribbons with RGD sequences presented on the fiber surface. B) The functionalized peptides can be mixed with unmodified peptides to form functionalized hydrogels. The degree of functionalization can be controlled by varying the concentration of Fmoc-RGD peptides added. The functionalized Fmoc-FF/RGD hydrogels enabled fibroblast cell adhesion, with maximal cell spreading achieved when the composition of RGD-functionalized peptide exceeded $30 \%(\mathrm{M} / \mathrm{M})$. The insert reflects the attachment and spreading of the cultured fibroblasts after $48 \mathrm{~h}$ (stained with calcein in green). The cells also secrete extracellular matrix proteins to "remodel" the scaffold. Reproduced with permission. ${ }^{[177]}$ Copyright 2015, Elsevier.

conjugation of motifs (such as glycosylation ${ }^{[173]}$ and cell adhesion sequences ${ }^{[174]}$ ) pre-assembly. Functionalization can also be achieved by mixing Fmoc-protected peptide motifs (such as Fmoc-RGD) with Fmoc-FF. Such hydrogels support the growth of primary cells, notably chondrocytes ${ }^{[175]}$ and fibroblasts (which remodeled the matrix by secreting ECM) ${ }^{[176,177]}$ and are thus of interest as scaffolds for organotypic tissue culture (Figure 12).

Peptide self-assembly is an elegant and expedient bottom-up approach towards designing 3D biological scaffolds, in view of their nanofibrillar structure, biocompatibility, biodegradability, ease of synthesis and functionalization. In particular, advances in functionalization strategies have led to the development of better synthetic cell culture substrates, as well as bioactive scaffolds that promote cell proliferation, migration and differentiation for tissue engineering.

\section{Self-Assembled Peptide Amphiphiles to Mimic Native Extracellular Matrix}

Self-assembling peptide amphiphiles (PAs) nanofibers are a class of materials that can mimic the essential properties of native ECM including viscoelastic properties, nanofibrous topography and bioactive signaling. The $\beta$-sheet forming PA molecules can self-assemble into 1D nanostructures, predominantly nanofibers with a cylindrical geometry, through intermolecular hydrogen bonding. Under physiological conditions, these 1D nanofibers can form 3D hydrogel networks imitating the highly hydrated nanofibrous structure of native ECM. In addition, easy tunability of bioactivity by simply altering the amino acid sequences, allows construction of biomaterial platforms mimicking the specific functions of the ECM to direct desired cellular outcome for medical applications. Here, we highlight the molecular self-assembly mechanisms of PA molecules as well as the biophysical and biochemical cues at the interface of self-assembled peptide nanofibers with biological systems.

\subsection{Supramolecular Structure and Self-Assembly Mechanisms}

Nanofiber forming single tail peptide amphiphiles are a class of self-assembling building blocks to construct nanoscale engineered materials for biomedical applications with their inherent biocompatibility and biodegradability. ${ }^{[178]}$ A peptide amphiphile can be considered as a hybrid molecule containing a hydrophobic alkyl tail with a variable length and a relatively hydrophilic peptide sequence attached to this hydrophobic chain. ${ }^{[179]}$ The hydrophilic peptide sequence, which is adjacent to the hydrophobic alkyl group, can be composed of three key structural regions (Figure 13A). ${ }^{[180]}$ The first segment of the hydrophilic region that drives the nanofibrous assembly of PA molecules is the $\beta$-sheet forming peptide sequence, which consists of hydrophobic amino acids promoting the intermolecular hydrogen bonding. As a second segment, a charged peptide sequence containing acidic or basic amino acids can be attached to the $\beta$-sheet forming segment to enhance the solubility of PA molecules and to trigger self-assembly and gelation through $\mathrm{pH}$ changes or addition of counter ions. Finally, the N-terminus of the PA molecule and the third segment of the hydrophilic region can contain bioactive signaling epitopes with specific amino acid sequences that are derived from native ECM proteins to provide cell-material interactions. These specific bioactive epitopes can interact with cell surface receptors in a similar manner to native ECM proteins to mediate cellular responses by initiating specific signaling pathways within cells.

Self-assembly of PA molecules in aqueous environments depends on multiple driving forces. Three main energy contributions including hydrophobic collapse of the alkyl groups guided by entropic and enthalpic effects, hydrogen bonding and side chain interactions, and electrostatic interactions between the charged amino acids, determine the self-assembly into final nanostructures. Self-assembly occurs as a result of the driving force between alkyl chains to aggregate in aqueous environment which leads the formation of micellar nanostructures. ${ }^{[181]}$ Due to the hydrophobic packing, alkyl groups constitute 


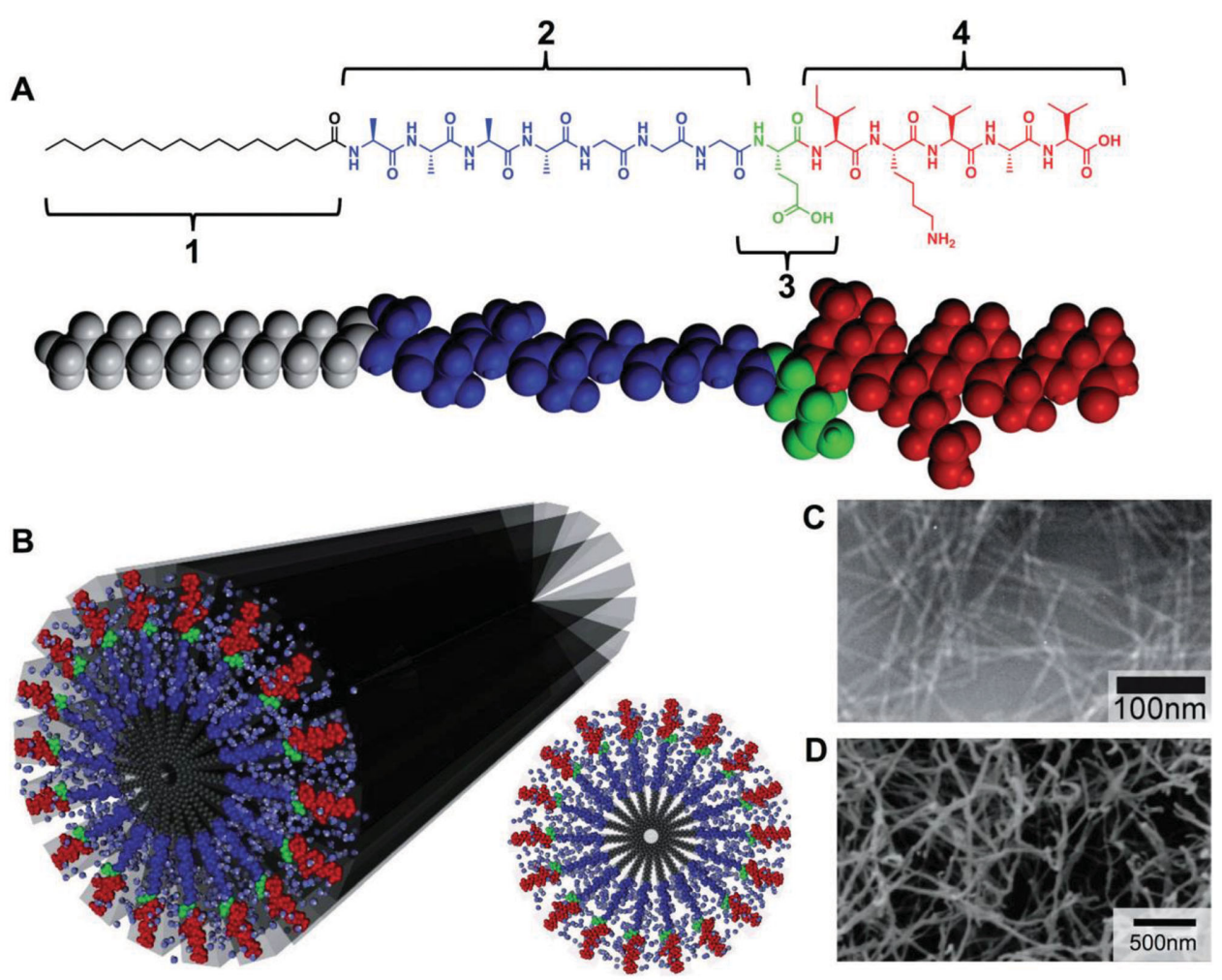

Figure 13. Molecular structure of a peptide amphiphile (IKVAV-PA) molecule. A-1) hydrophobic alkyl tail, A-2) $\beta$-sheet forming segment, A-3) charged amino acids providing solubility and further gelation, A-4) bioactive epitope. B) Self-assembly of PA molecules into nanofibers. C) Transmission electron microscope (TEM) image of PA nanofibers. D) SEM image of PA gel. Reproduced with permission. Copyright 2013, John Wiley and Sons. ${ }^{[184]}$

the inner core of the resulting nanofibers while the hydrophilic peptide segments are presented on the fibers' surfaces (Figure 13B). A crucial criteria for the self-assembly into nanofibers instead of spherical micelles is the $\beta$-sheet formation between the peptide segments. ${ }^{[182]}$ The $\beta$-sheet forming peptide region is composed of hydrophobic amino acids that are able to form intermolecular hydrogen bonding leading the formation of 1D cylindrical nanofibers. The strength of the intermolecular hydrogen bonding determines the self-assembly kinetics of the amphiphilic system. Spherical micelles with random $\beta$-sheets can form a weak hydrogen bonding system while the increased hydrogen bonding can break the spherical organization to form the cylindrical nanofibers with $\beta$-sheets coordinated along the long axis. ${ }^{[183]}$

Charged amino acids also assist the self-assembly since they are relatively weak acids or bases. A certain number of charged amino acids should be sufficient to provide solubility and to assist with purification. ${ }^{[184]}$ The presence of impurities and multivalent ions might change the range of electrostatic interactions in an aqueous environment, and as a result, self-assembly of the PA molecules can be affected from the environmental factors as well. Net electrostatic effect of a charge carrier in solutions is measured by Debye length. Low ionic strength and electrostatic repulsion between the charged residues result in long Debye length limiting the selfassembly into 1D nanofibers. ${ }^{[185]}$ Self-assembly can be triggered by adjusting the $\mathrm{pH}$ to acidic or basic values or by using screening electrolytes depending on the charge selection to shorten the Debye length. ${ }^{[179]}$ This $\mathrm{pH}$ or ion-responsive feature of PA molecules provides an injectable encapsulation platform which can be used for the delivery of bioactive molecules (i.e., proteins, growth factors, cells, etc.) with minimum invasion. ${ }^{[183]}$ Upon injection, self-assembly into nanofibers and gelation can be immediately triggered by the presence of electrolytes in the physiological environment. In addition, oppositely charged PA molecules can be mixed at certain volumetric ratios to induce self-assembly through charge neutralization. ${ }^{[186]}$ Under physiological conditions, oppositely charged PA molecules bearing various biological epitopes can selfassemble into nanofibers presenting multiplex bioactive signals in a high amount at their surfaces. By combining the coassembly strategy with the bioactive signaling epitopes, which constitute the last element of hydrophilic peptide segment, it can be possible to obtain functional hydrogels which present multiple bioactive signals in a synergistic way to regulate cellular functions.

\subsection{Presentation of Bioactive Signals}

To mimic the signaling role of the native ECM, many polymeric materials modified with well-known bioactive signal sequences have been introduced. However, beyond all of the available polymeric material platforms, PA molecules offer the most convenient building blocks through easy modification of their bioactivity by simply changing the amino acid sequences. 
The terminal domain of PA molecules has been successfully modified with bioactive RGD or RGDS sequence to provide enhanced cell attachment. ${ }^{[187,188]}$ Upon self-assembly, RGDS epitopes are presented at the surfaces of $1 \mathrm{D}$ cylindrical nanofibers similar to the fibrous nanoarchitecture of native ECM. It has been demonstrated that RGDS modified PA (RGDSPA) systems successfully facilitate adhesion, spreading and migration of different cell types including fibroblasts, ${ }^{[189]}$ bone marrow mononuclear cells $(\mathrm{BMNCs})^{[190]}$ and breast cancer cells. ${ }^{[191]}$ In addition to fibronectin, RGD motif is also found in the structure of other bone matrix proteins such as bone sialoprotein and osteopontin. ${ }^{[192]}$ Therefore, RGD bearing PAs not only provide the cellular adhesion but also serve as ideal scaffolds to induce bone tissue growth and biomineralization. ${ }^{[193]}$ It has been proposed that RGDS-PA can induce osteogenic differentiation of rat mesenchymal stem cells (rMSCs) ${ }^{[194]}$ RGDS-PA was also used for the functionalization of bone implants. NiTi implant surfaces supported enhanced adhesion and proliferation of pre-osteoblastic cells in vitro when they were functionalized with RGDS-PA. ${ }^{[195]}$ In addition, it has been demonstrated that RGDS-PA is also effective for enamel regeneration. ${ }^{[196]}$ When used as a scaffold for enamel organ epithelial (EOE) cells, RGDS presenting PA nanofibers induced enamel regeneration and expression of amelogenin and ameloblastin proteins which take part in natural enamel formation process.

Human corneal keratocytes (HTK) cultured on lamininmimetic PA nanofibers modified with YIGSR peptide sequence (YIGSR-PA) retained their characteristic morphology and showed enhanced proliferation when compared to fibronectinmimetic RGD-PA nanofibers. ${ }^{[197]}$ In addition, YIGSR-PA hydrogels increased keratocyte migration to the injured site and supported stroma regeneration when they were used in vivo for damaged rabbit corneas. ${ }^{[197]}$

There are also other short peptide sequences derived from native collagen, which is an important structural component of bone ECM, such as DGEA and GFOGER. Both DGEA and GFOGER peptide sequences are known to bind integrin $\alpha_{2} \beta_{1}$ which is a key transmembrane protein for cell adhesion and osteogenesis. ${ }^{[198,199]}$ However, the number of studies that used DGEA and GFOGER conjugated PA nanofibers remain limited. In one example, metal surfaces coated with DGEA-PA were found to induce initial adhesion, spreading and early osteogenic commitment of human mesenchymal stem cells (hMSCs) when compared to non-functionalized surfaces (Figure 14).[200] A similar result showing the osteoinductive effect of DGEA containing peptide amphiphiles was also obtained by Anderson and co-workers. ${ }^{[201]}$ DGEA functionalized PAs enhanced the alkaline phosphatase activity and osteogenic gene expressions of hMSCs. Luo et al. tested the adhesive effect of GFOGER functionalized collagen mimetic PAs on HepG2 cells and indicated that PA nanofibers functionalized with GFOGER sequence supported the enhanced cell adhesion as well as spreading when compared to non-functionalized PA nanofibers and non-amphiphilic GFOGER peptides. ${ }^{[199]}$

Another adhesive peptide sequence used in the functionalization of PA molecules is KRSR which is found in the structure of heparin-binding proteins of the native ECM. It has been demonstrated that KRSR peptide promotes specific adhesion of osteoblasts while attachment of endothelial cells (ECs) and fibroblasts is not affected. ${ }^{[202]}$ Additionally, enhanced osteogenic differentiation of osteoblast-like Saos-2 cells was previously shown on titanium alloy surfaces coated with the combination of KRSR functionalized PA nanofibers (KRSR-PA) and mussel adhesive protein, 3,4-dihydroxy-L-phenylalanine (Dopa), functionalized PA nanofibers (Dopa-PA). ${ }^{[203]}$ This hybrid application of mussel inspired Dopa-PA with other bioactive PA nanofibers also provides a great potential for efficient immobilization of bioactive molecules on metal implant surfaces. As a similar approach, PA molecules containing REDV peptide sequence (REDV-PA) derived from fibronectin were used together with Dopa-PA to functionalize stainless steel stent surfaces. ${ }^{[204]}$ Combinational approach of Dopa-PA and REDV-PA increased the stability of implant coating and selectively promoted endothelial cell adhesion, spreading and proliferation, while those characteristics of smooth muscle cells were inhibited (Figure 15).

Another bioactive peptide epitope that has been incorporated to PAs is laminin-derived IKVAV sequence. Previous studies have also supported that PA nanofibers and hydrogels functionalized with IKVAV bioactive epitope induce in vitro selective differentiation of neural progenitor cells (NPCs) into neurons and prevent formation of astrocytes. ${ }^{[180]}$ One important advantage of astrocyte inhibition is that astrocyte differentiation is a reason for scar formation after neural injury. ${ }^{[205]}$ Therefore, IKVAV functionalized PA hydrogels are considered as convenient materials for in vivo neural tissue regeneration. In one study using mouse spinal cord injury model, injection of IKVAV-PA hydrogel to the injury site reduced scar formation and cell death, induced oligodendroglia formation and also improved motor functions of the injured mice. ${ }^{[206]}$ As a cooperative approach, Mammadov et al. combined laminin-mimetic IKVAV-PA with a heparan sulfate-mimetic PA decorated with carboxylic acid, hydroxyl and sulfonate groups. ${ }^{[207]}$ Combination of these two bioactive components imitates the interaction of laminin with heparan sulfate proteoglycan (HSPG) similar to neural ECM. ${ }^{[208]}$ Hybrid PA system promoted the neurite outgrowth of PC-12 cells and prevented the inhibitory effect of chondroitin sulfate proteoglycans (CSPGs) on neurite outgrowth.

\subsection{Mechanical Control}

Cells can sense the mechanical properties of their surrounding microenvironment and as a response to mechanical stimuli, generated biochemical activity can result in changes in the regulation of cellular behavior. ${ }^{[209]}$ Along with the activation of signal transduction cascades, matrix stiffness can direct cellular functions such as migration, ${ }^{[210]}$ proliferation, ${ }^{[211]}$ and differentiation. ${ }^{[212]}$ Besides their ability to mimic cellular microenvironment with their highly hydrated and porous nature, PA hydrogels can serve as a modifiable platform to control the mechanical properties of the resulting hydrogel systems to orientate cell-material interactions and to direct cellular functions by altering the material stiffness. Various strategies, which include either non-covalent or covalent methods, have been implemented to modify the mechanical properties of PA hydrogels. 

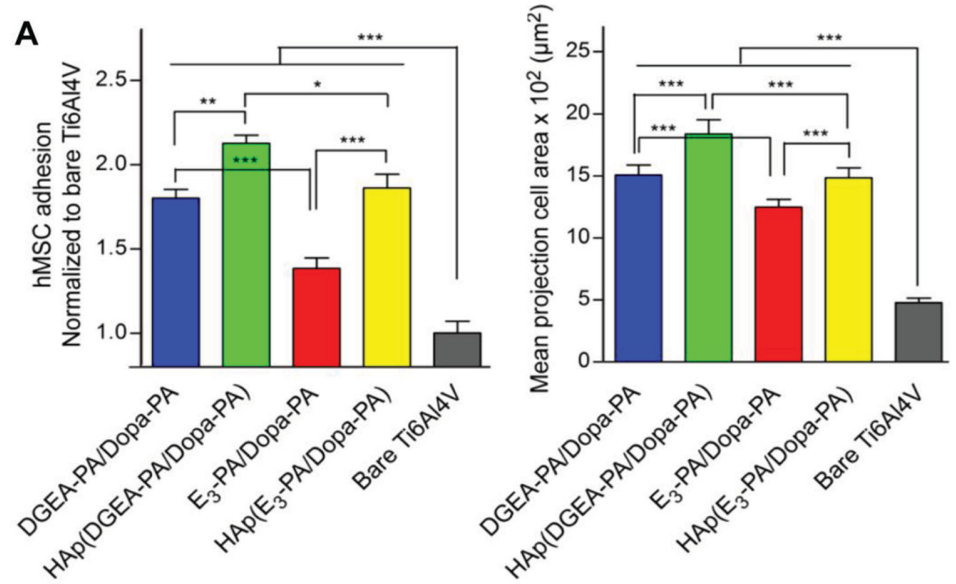

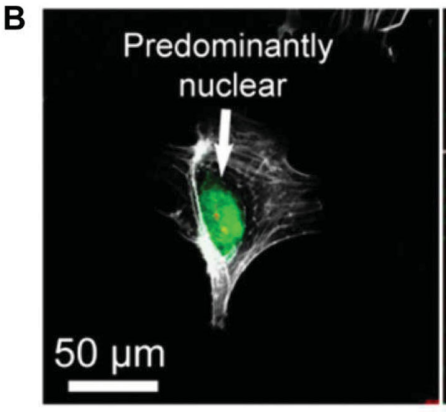

DGEA-PA/Dopa-PA

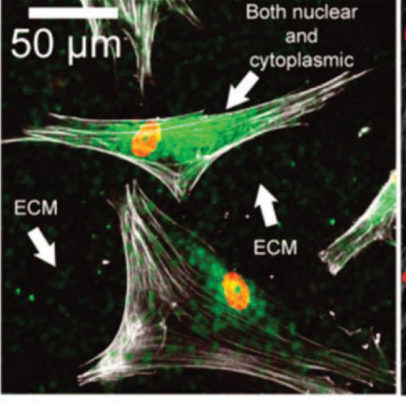

HAp(DGEA-PA/Dopa-PA)

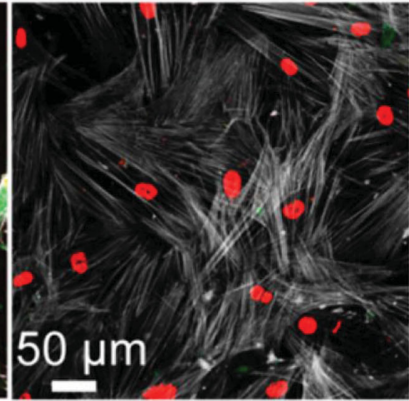

Bare Ti6Al4V

Figure 14. Early stage interactions of hMSCs with the osteoinductive nanofibers. A) Adhesion and spreading of hMSCs on the nanofiber coatings in serum-free medium at $2 \mathrm{~h} 15 \mathrm{~min}$. B) Confocal images of DMP-1 immunostaining. The arrows point the nuclear, cytoplasmic, or extracellular localization of DMP-1. Green shows DMP-1, gray shows filamentous actin, red shows the nucleus. Localization of DMP-1 protein inside the cell is informative about the differentiation stage of the cell within the osteoblast linage. On DGEA-PA containing PA combinations, more than $60 \%$ of the cells showed predominant nuclear localization, showing that more than half of the cells differentiated on these nanofibers were at the preosteoblast stage. Reproduced with permission. ${ }^{[200]}$ Copyright 2014, American Chemical Society.

One possible non-covalent method for controlling the viscoelastic properties of resulting gel systems is to direct selfassembly through altering the hydrogen bonding capacity of PA molecules by changing the internal peptide sequence. PA molecules were previously designed with different hydrogen bonding domains by changing the number and sequence of valine and alanine amino acids in the $\beta$-sheet segment. ${ }^{[213]}$ The ordering of the $\beta$-sheets had a pronounced effect on gel stiffness. Increased number of valine residues and decreased distance of the valine segment to the hydrophobic core resulted in formation of aligned hydrogen bonds along the fiber axis and enhanced mechanical stiffness of the resulting hydrogels. On the other hand, increased number of alanines and the presence of sequences promoting twisted $\beta$-sheets supported the formation of soft hydrogels by weakening the peripheral hydrogen bonds. Therefore, designing strategies based on the modification of molecular packing can provide control over the bulk mechanical properties of the PA hydrogels. Mechanical properties of PA hydrogels can also be altered by the presence of counter ions providing dynamic crosslinking through electrostatic screening of charged residues. The effect of multivalent ions were investigated on the bulk viscoelastic properties of PA hydrogels. ${ }^{[118]}$ When negatively charged PA molecules were self-assembled by addition of $\mathrm{Mg}^{+2}$, non-covalent crosslinking resulted in increased storage modulus of PA hydrogels by up to 10 fold. They also demonstrated a covalent crosslinking strategy via addition of cysteine residues to the peptide sequence. Under oxidizing conditions, formation of disulfide bonds between cysteine residues provided the covalent capture of nanofibers into a high molecular weight polymer network with 60 fold increased mechanical stiffness. As a similar approach, $\mathrm{Ca}^{2+}$ ions were used for gelation and controlled the bulk mechanical properties through inter-fiber crosslinking. ${ }^{[214]}$ The electrostatic screening through divalent or trivalent counterions resulted in mechanically more strong hydrogels by providing intermolecular and interfiber ionic crosslinking, while screening through monovalent ions does not. In addition, even the ions with same valence resulted in different mechanical stiffness; d-block divalent ions such as $\mathrm{Fe}^{2+}, \mathrm{Cu}^{2+}, \mathrm{Zn}^{2+}$ produced stronger hydrogels when compared to s-block divalent ions such as $\mathrm{Ca}^{2+}, \mathrm{Mg}^{2+}$, and $\mathrm{Ba}^{2+} \cdot[214,215]$ A reversible crosslinking method was developed with inspiration from mussel adhesive protein (Dopa) to improve the mechanical properties of self-assembled PA networks without damaging the intrinsic self-healing properties of the supramolecular system (Figure 16). ${ }^{[216]}$ Conjugation of Dopa residue to PA molecules provided $\mathrm{pH}$ dependent dynamic crosslinking of PA molecules to form tris $\mathrm{Fe}(\mathrm{Dopa})_{3}$ groups in the presence of 


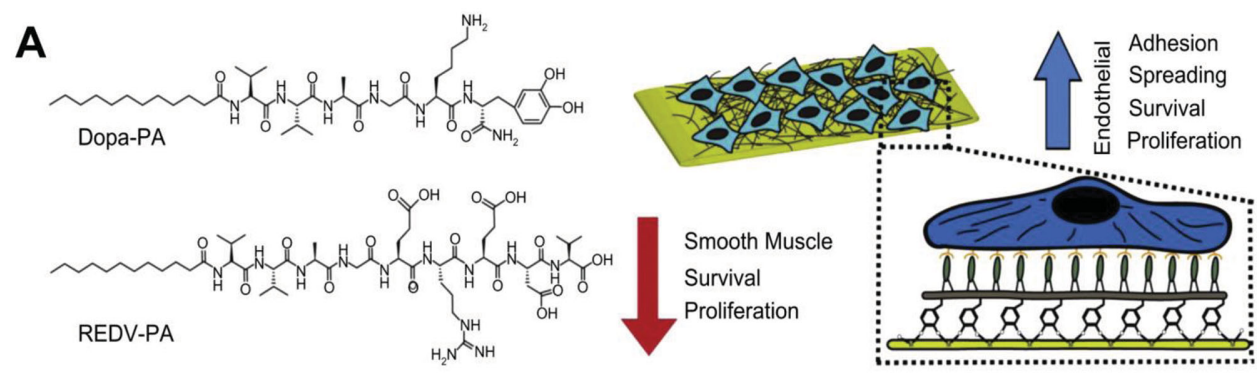

B

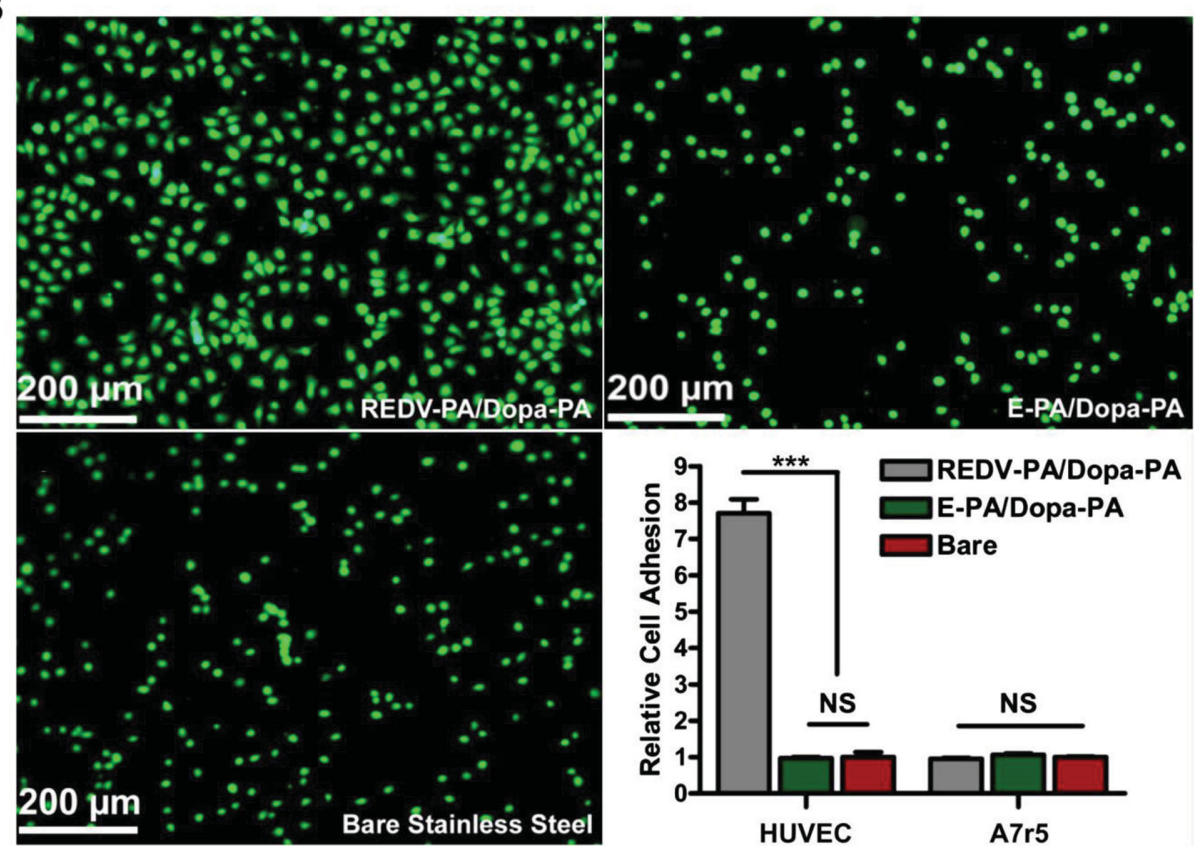

Figure 15. A) Design and chemical representation of Dopa-PA, REDV-PA molecules and schematic representation of REDV-PA/Dopa-PA network, which was designed to functionalize stainless steel surface to support endothelial cell adhesion, spreading, viability and proliferation. B) Representative Calcein AM stained fluorescent images of HUVECs adhered on the stainless steel surfaces coated with REDV-PA/Dopa-PA nanofibers, E-PA/Dopa-PA nanofibers and on the bare steel surface at $2 \mathrm{~h}$. Graph showing the relative adhesion of HUVECs and A7r5 smooth muscle cells on REDV-PA/DopaPA and E-PA/Dopa-PA coated surfaces with respect to the bare stainless steel surface at 2 h. $k^{2} * p<0.0001$, NS: No Significance. Reproduced with permission. ${ }^{[204]}$ Copyright 2011, Elsevier.

iron ions. Strikingly, the storage modulus of iron-crosslinked Dopa conjugated PAs (DopaK-Pa) was similar to the covalently crosslinked DopaK-PA and the system retained its $\mathrm{pH}$ dependent reversibility and self-healing properties as in the case of uncrosslinked supramolecular network.

\subsection{Hierarchical Assemblies of Peptide Amphiphiles}

As mentioned above, in order to induce the complex biological functions such as tissue regeneration, supramolecular systems should exhibit high order assemblies at the similar length scale. To mimic the high order organization of natural tissues, a limited number of hierarchical supramolecular PA assemblies have been introduced.

One of the most recent examples has been introduced by Capito and co-workers. ${ }^{[217]}$ By taking advantage of diffusion barrier at the liquid-liquid interface, hierarchically ordered membranes were developed upon dropping of negatively charged hyaluronic acid (HA) solution into positively charged PA solution (Figure 17). Following the contact of two solutions, PA molecules immediately assembled into aligned bundles perpendicular to the diffusion barrier at the interface and produced a closed microsac membrane. This hierarchical structure enabled permeability to growth factors and proteins, and supported the viability of encapsulated hMSCs up to 4 weeks. Additionally, upon induction with chondrogenic media, cells differentiated into chondrocytes.

One common example for the successfully accomplished hierarchical organization of PA assemblies is aligned monodomain gels bearing a resemblance to long range alignment of extracellular fibrils in the heart, brain and spinal cord (Figure 18). ${ }^{[18]} \mathrm{A}$ basic heat and cool methodology was used to induce the production of an aqueous liquid crystal solution. Dehydration of PA solution via heating followed by slow cooling transformed the bundled fibers into a liquid crystalline structure. When this liquid crystalline solution is pipetted into calcium chloride solution, the shear force 
A

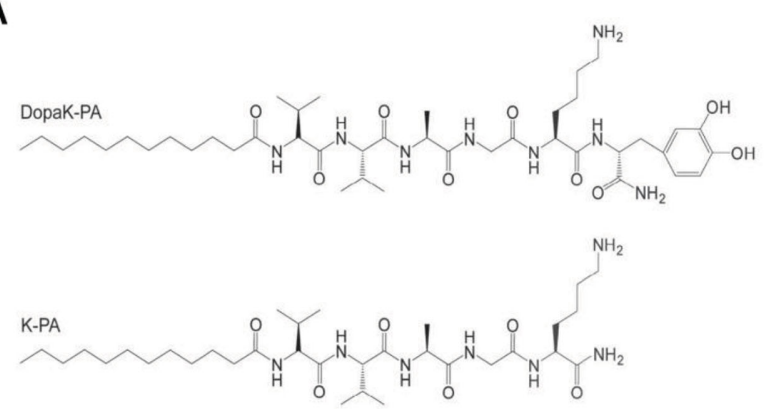

B

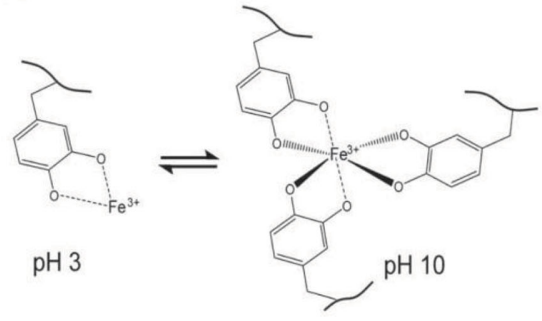

Iron-mediated reversible coordination
C

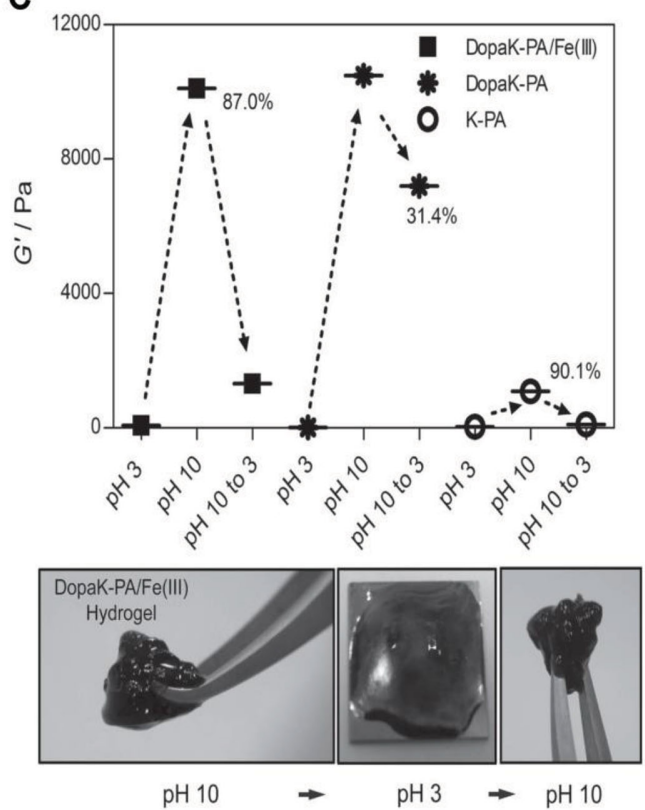

Figure 16. A) Chemical representation of DopaK-PA and K-PA. B) In the presence of iron, tris Fe(Dopa) ${ }_{3}$ complexes form dynamic cross-link points. C) $\mathrm{pH}$ dependent reversibility of the peptide networks. Reproduced with permission. Copyright 2012, John Wiley and Sons. ${ }^{[216]}$

through the pipette promoted hierarchical organization of gels into aligned fibers in macroscale. When cardiomyocytes were cultured on these aligned constructs, they proliferated, spread along the fiber axes and spontaneously generated electrical potential over the string-like gel structure. The same hierarchical organization has been shown to create

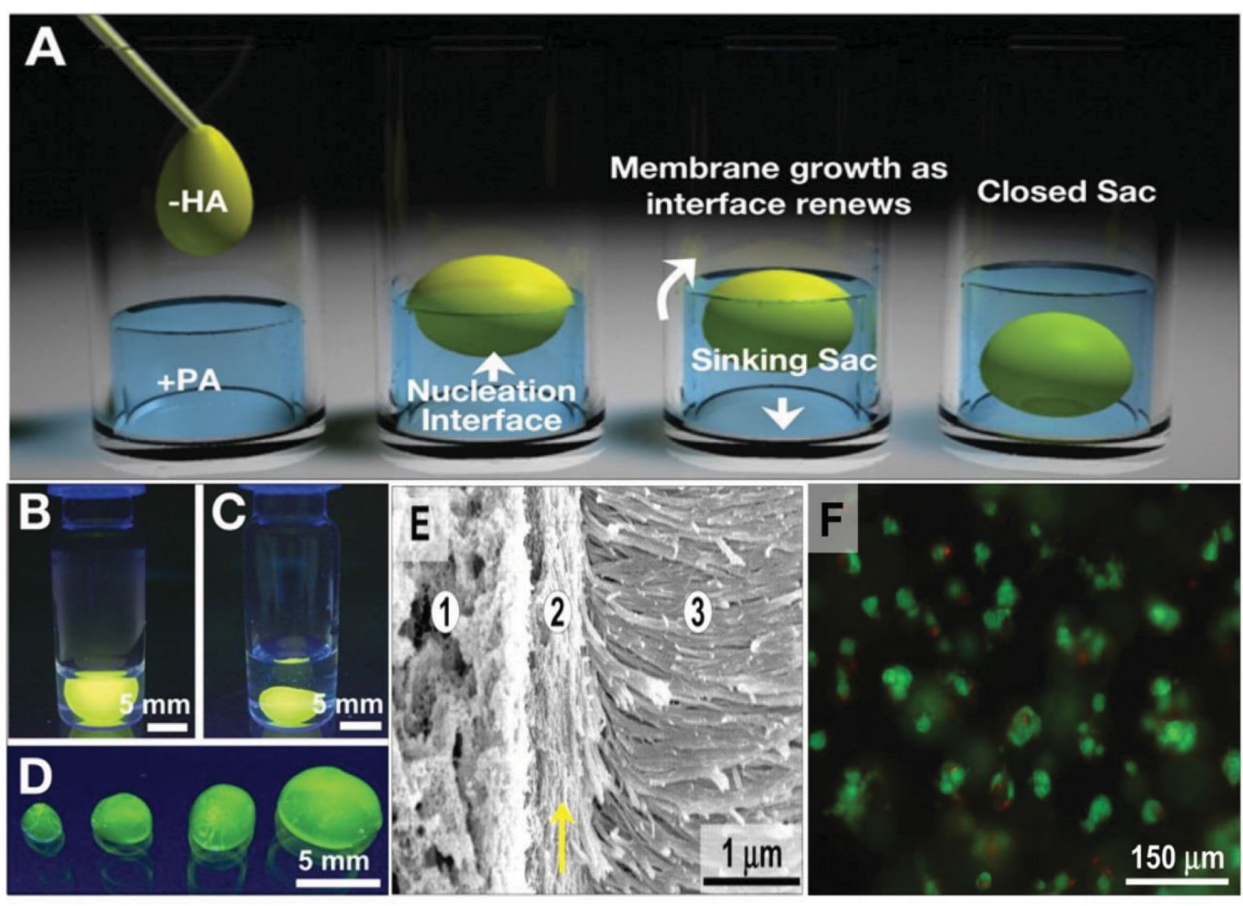

Figure 17. A) Schematic representation of the hierarchically ordered sac formation. B) Open and C) closed sac formed by injection of a fluorescently tagged hyaluronic acid (HA) solution into the PA solution. D) Self-assembled sacs with different sizes. E) Scanning electron microscopy image showing the organization of hierarchically ordered sac membrane: 1) a region with an approximately constant polymer density, 2) a region of parallel fibers where there is a maximum in polymer density, and 3) a region of perpendicular fibers where the polymer density decays with increasing distance from the amorphous region. F) Live/dead image of hMSCs cultured within the sacs showing that most of the cells are viable. Green: live cells, Red: dead cells. Reproduced with permission. Copyright 2008, American Association for the Advancement of Science. ${ }^{[217]}$ 

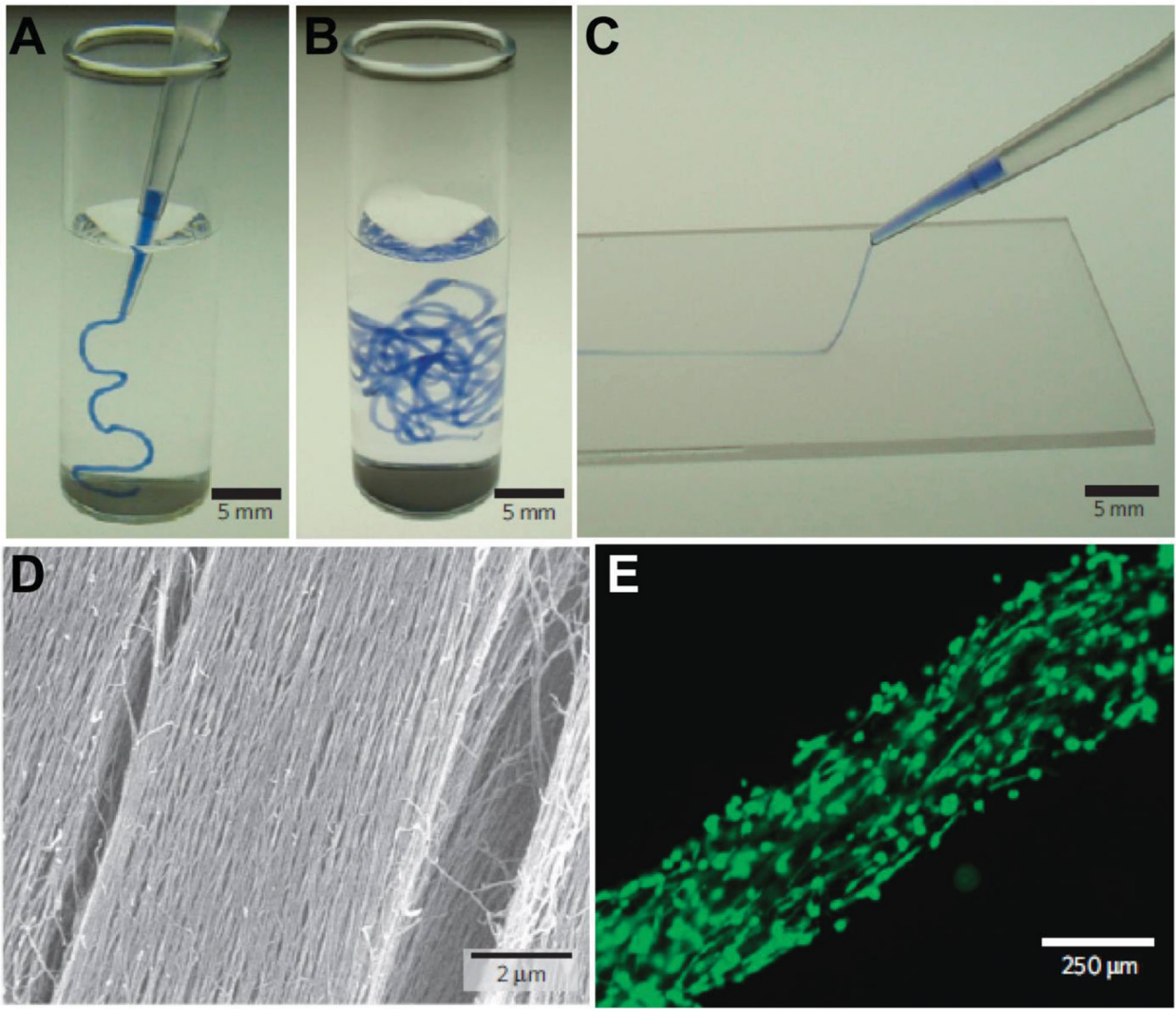

Figure 18. A,B) A peptide amphiphile solution stained with trypan blue injected into phosphate-buffered saline after heat treatment. C) The same solution dragged through a thin layer of aqueous $\mathrm{CaCl}_{2}$ to form a noodle-like string. D) of aligned nanofiber bundles in macroscopic strings formed by dragging thermally treated amphiphile solutions onto $\mathrm{a} \mathrm{CaCl}_{2}$ solution. E) Calcein-labeled image of cells cultured in string showing the cell alignment through the fiber axes. Reproduced with permission. ${ }^{[218]}$ Copyright 2010, Macmillan Publishers Ltd.

PA scaffolds mimicking the blood vessels. ${ }^{[219]}$ A rotating and retracting tube was used to align the PA fibers and calcium ions were applied to crosslink the PA fibers. Smooth muscle cells (SMCs) cultured on these artificial blood vessels showed aligned morphology along the tube axes confirming that the cell behavior can be instructed by hierarchically organized materials.

Artificial matrices of hierarchically assembled PAs can provide a convenient material platform imitating the complex structural organization of natural tissues to provide a proper physical environment to direct cell-cell and cell-material interactions.

\subsection{Dynamic Matrices}

To properly mimic the dynamic nature of native ECM, development of stimuli-responsive materials that are able to change their properties upon stimulation are desired. Although some dynamic self-assembled systems have been described, the number of stimuli responsive supramolecular PA hydrogels is still limited. A dynamic PA network was demonstrated with an enzyme sensitive peptide sequence, GTAGLIGQ, which has specific cleavage sites for matrix metalloproteinase-2 (MMP-2) (Figure 19).[220] Incorporation of MMP-2 specific peptide sequence resulted in cell-mediated proteolytic degradation of the network and enabled cell migration, spreading and proliferation as well as continuous remodeling of the matrix and further ECM production that can support the mechanical integrity of the matrix. In addition to promotion of cell motility and integration, matrix dynamicity is also important for dynamic presentation of bioactive epitopes through the remodeling to control cellular processes with time-dependence. In one approach, a PA molecule including a photocleavable nitrobenzyl group was used to display cell adhesive RGDS peptide in a triggered manner within the matrix. ${ }^{[189]}$ Fibroblasts attached and spread over the surface when RGDS was presented on PA nanofibers, while they showed limited spreading upon irradiation with UV light due to the cleavage of photo-reactive group releasing RGDS epitopes to the solution. As a similar photosensitive approach to control the self-assembly process of PAs in a dynamic manner, 2-nitrobenzyl group was conjugated to the $N$-terminal of the PA molecules. ${ }^{[221]}$ Due to the bulkiness of 2-nitrobenzyl group near the $\beta$-sheet forming segment, photosensitive PA molecules formed a quadruple helix. Upon exposure to UV light at $350 \mathrm{~nm}$, photosensitive bulky groups were released and helical structures were dissociated into cylindrical single fibrils.

Dynamic control of the self-assembly process can also be associated with multiple purposes. For example, PA molecule 

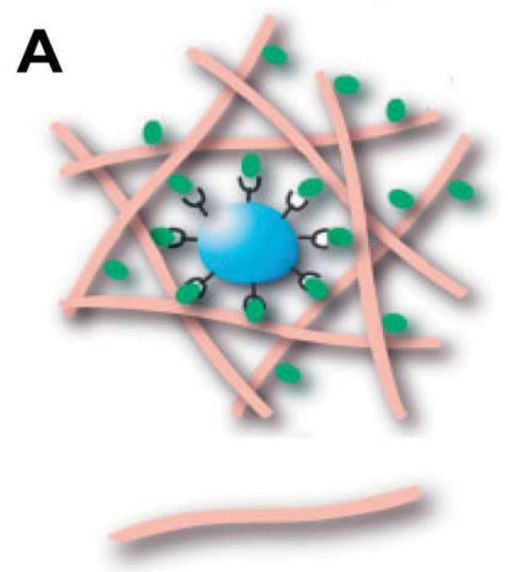

Nanofiber

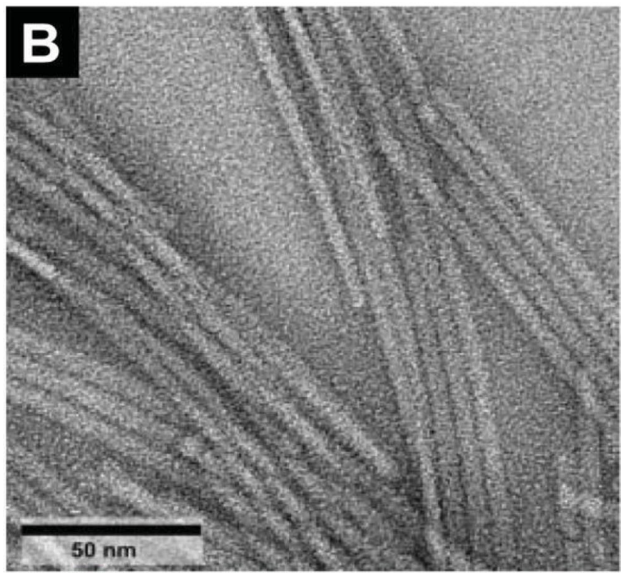

\section{D}

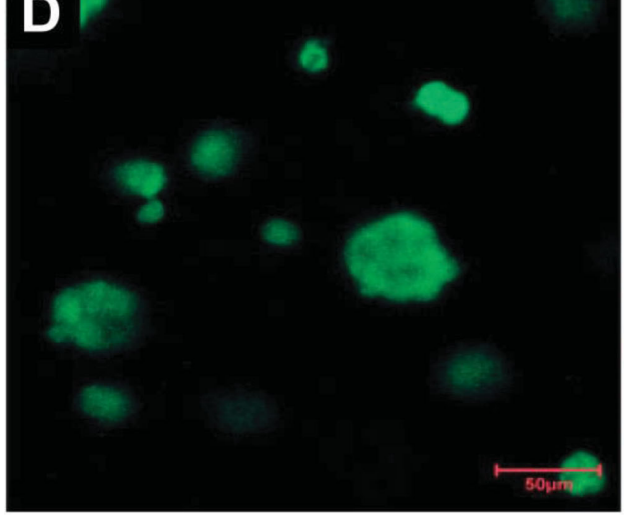

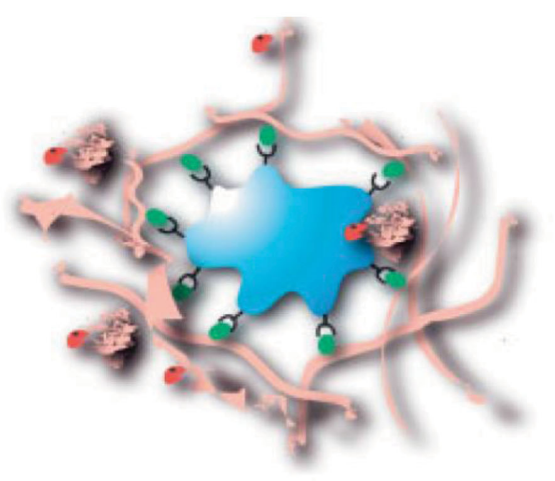

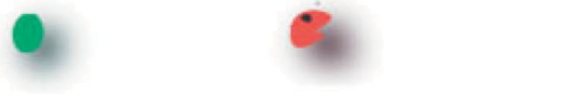

Enzyme
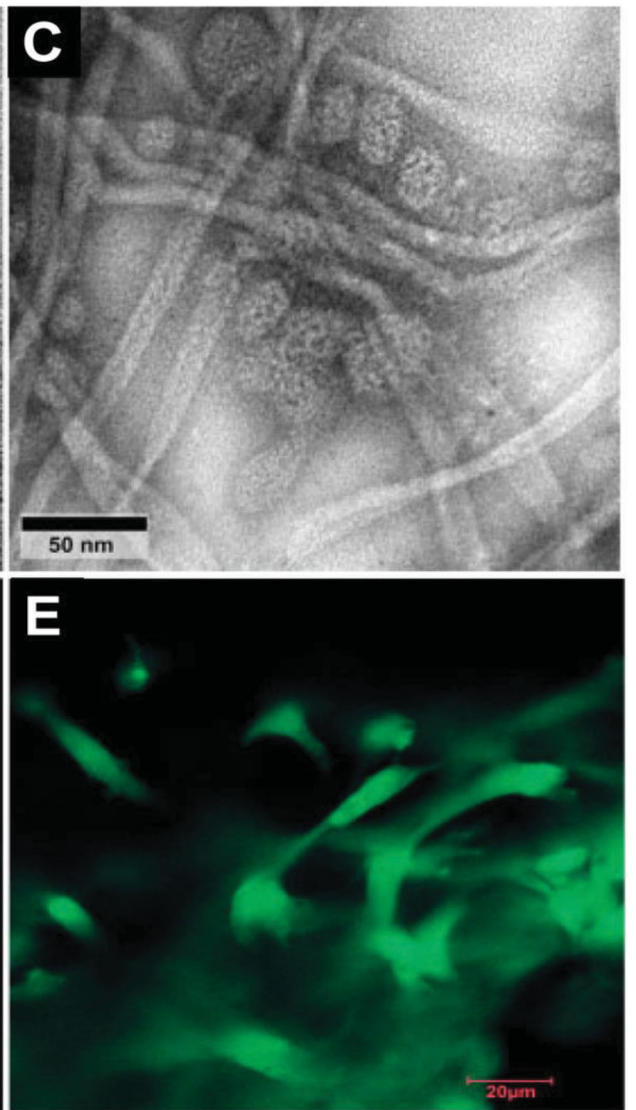

Figure 19. A) Schematic illustration of mechanism for cell-responsive nanofiber network. B) TEM image of nanofiber network before proteolytic degradation and C) after three weeks of incubation with type IV collagenase. D) No spreading was found in non-cell-adhesive network (RDCS) while E) elongation and spreading of cells through nanofiber networks was observed in cell-adhesive network (RGDS). This indicates that the cells produce enzymes to remodel the responsive network and track along the adhesive ligands through the network. Reproduced with permission. Copyright 2005, John Wiley and Sons. ${ }^{[220]}$

containing consensus substrate sequence (RRXSf, $\mathrm{X}=$ any residue, $\mathrm{f}=$ hydrophobic) specific to protein kinase A (PKA) was synthesized. ${ }^{[22]}$ Upon treatment with PKA, serine residues were phosphorylated and the nanofibrous structures were disassembled. They used this dynamic self-assembly strategy as a tool for targeted drug delivery and the drug loaded PA nanostructures were found to be cytotoxic against PKA secreting cancer cell lines.

These stimuli-responsive re-organizable materials can provide novel strategies to create multi-functional dynamic materials to study the effects of matrix modifications over time as a mimic of natural cell and tissue environment. 


\section{Summary and Future Outlook}

An overview of recent advances in self-assembling proteins, peptides, and peptide amphiphiles thatform scaffolds suitable for tissue engineering has been presented. In particular, special emphasis has been placed on the rational design of self-assembling motifs and biofunctionalization strategies to enhance cell survival and influence cell behavior.

The self-assembled scaffold motifs are diverse, ranging from minimalistic dipeptides and simplistic ultrashort aliphatic peptides to large "recombinamer" proteins. Alkyl tails or polymers can also be conjugated to facilitate self-assembly, forming peptide amphiphiles. The design of the building blocks are by-andlarge inspired by peptidic motifs in fibrous structural proteins such as collagen, silks and elastin. Interestingly, motifs derived from amyloid-forming proteins are also being explored, by virtue of the strong interactions that drive self-assembly and the structural rigidity of the resulting scaffolds. More recently, advances in chemistry to enable the synthesis and incorporation of modified amino acids and peptidomimetics have driven the concomitant emergence of de novo self-assembling motifs. These motifs are often composed of unique secondary structures that are not found in nature. Along with greater understanding of the intra- and intermolecular forces that drive selfassembly, computational tools are increasingly being used to optimize the rational design of self-assembling motifs, model their interactions and predict their bulk properties. This has significantly broadened the variety of self-assembling peptidic motifs.

The complexity of self-assembled scaffolds is further increased by the modular nature of many building blocks. The bulk properties of the scaffold can be tuned by combining blocks with different structural and mechanical properties. Cross-seeding between natural and designer building blocks is also possible, as exemplified by the recombinant protein $\left[(\mathrm{AEAEAKAK})_{2}-\mathrm{AG}(\mathrm{GPGQQ})_{6}-\mathrm{GS}\right]_{9}$-(AEAEAKAK)2AG(GPGQQ). ${ }^{[223]}$ By replacing the alanine stretches in spider silks with the amphiphilic $\beta$-sheet self-assembling motif $(\text { AEAEAKAK })_{2},{ }^{[224]}$ the resulting "recombinamer" self-assembled into a membrane consisting of beta-structured fibrils embedded in a less structured matrix which preserves the betaturn forming propensity of the GPGQQ domain for imparting elasticity. ${ }^{[223]}$ Given the myriad modular domains available, there are open-ended possibilities for the design of modular structural scaffolds.

Increasingly, non-structural modules are being appended to self-assembling scaffolds to confer biological functionality. Most notably, short cell-adhesion sequences of three to five residues are often conjugated to the self-assembling module as a proof-of-concept to demonstrate the ease of functionalization and to enhance biocompatibility. With the development of phage-display screening techniques, an increasing number of novel short biofunctional peptide candidates have been identified as promising ligands to fulfill specific applications in stem cell differentiation and immune modulation. Due to their length, short peptides do not typically hinder self-assembly, and can be easily added during peptide synthesis or post-assembly. Longer sequences such as the 19-mer silica-nucleating peptide R5 have also been successfully incorporated. Care has to be taken so that the appended sequences do not impede self-assembly, and remain accessible on the structural framework post-assembly. The latter is typically achieved via the insertion of flexible spacer sequences, especially in the recombinant protein context. Recombinant proteins offer the additional possibility of incorporating longer sequences, including entire protein domains. On the other hand, short self-assembling peptides are more amenable to computational approaches that can predict appropriate positions for incorporation of functional motifs. ${ }^{131,225-227]}$ The power of these approaches may be applicable to protein scaffolds in the near future, as computation design of self-assembling protein nanomaterials can recently be achieved with atomic level accuracy. ${ }^{[228]}$

To pave the way for widespread adoption, the commercial large-scale production of GMP-grade peptide and protein materials should be cost-effective. Most short peptides can be easily synthesized using automated solid-phase peptide synthesis at gram quantities. Larger "recombinamer" proteins are prepared using recombinant production approaches. Recent developments have also led to high production yields of short selfassembling peptides using recombinant production techniques. One such strategy involves fusion to SUMO (small ubiquitinrelated modifier) protein and subsequent cleavage of the peptide, which was successfully used to prepared variants of P11 peptides (such as P11-4, Ac-QQRFEWEFEQQ-NH ${ }_{2}$ ). ${ }^{[229]}$

Perhaps one of the bigger challenges that lie ahead is the combination of the "bottom-up" self-assembling peptides and proteins with the "top-down" processing strategies towards new generations of tissue engineering scaffolds. This combines the design flexibility and the control over purity and homogeneity that the self-assembling strategies offer with the advantages of top-down fabrication, i.e., the possibility to control the scaffold geometry and micro-/nano-topography. Examples include electrospinning, ${ }^{[230]}$ photopatterning, ${ }^{[231]}$ direct laser writing for scaffold fabrication, ${ }^{[134,232]}$ etc. In the years to come, we expect to see rapid and important advances arising from the merger of self-assembling technologies with precision processing techniques.

Note added in proof: While this review was under consideration, the first peptide bioinks for 3D bioprinting were reported. ${ }^{[233]}$ These consist of a subclass of lysine-containing hexapeptides that undergo instantaneous gelation within physiological conditions. The resulting biocompatible scaffolds support long term 3D cultures of encapsulated human stem cells, as well as the differentiation of primary cells into organotypic skin and gastrointestinal epithelial.

\section{Acknowledgements}

Y.L and M.G. contributed equally to this work. Y.L. and C.A.E.H. acknowledge support from the Institute of Bioengineering and Nanotechnology (Biomedical Research Council, Agency for Science, Technology and Research, Singapore). M.G., M.O.G. and A.B.T. acknowledge support from the Scientific and Technological Research Council of Turkey (TUBITAK) grant number 113T045. M.G. is supported by TUBITAK BIDEB fellowship. M.O.G and A.B.T. acknowledges support from the Turkish Academy of Sciences Distinguished Young Scientist Award (TUBA-GEBIP).A.M. acknowledges support from "AngioMatTrain" 
"Development of biomaterial-based delivery systems for ischemic conditions- An integrated Pan-European approach", Marie Curie Industry -Initial Training Network (ITN), call FP7-PEOPLE-2012-ITN and from "PHOTOPEPMAT" Design, production and Laser PHOTO structuring of self-assembling PEPtides and proteins destined for bioMATerials applications" Greek Secretariat for Research and Technology, ARISTEIA II Excellence Grant number 3941 which is part of the action "Education and Lifelong Learning" and co-financed by the European Social Fund and National Funds.

Received: May 28, 2015

Revised: July 24, 2015

Published online: October 13, 2015

[1] E. Ruoslahti, Ann. Rev. Cell DevBiol. 1996, 12, 697.

[2] K. Tashiro, G. C. Sephel, B. Weeks, M. Sasaki, G. R. Martin, H. K. Kleinman, Y. Yamada, J. Biol. Chem. 1989, 264, 16174.

[3] S. Y. Boateng, S. S. Lateef, W. Mosley, T. J. Hartman, L. Hanley, B. Russell, Am. J. Physiol.-Cell Ph 2005, 288, C30.

[4] J. E. Gagner, W. Kim, E. L. Chaikof, Acta Biomater. 2014, 10, 1542.

[5] L. Cai, S. C. Heilshorn, Acta Biomater. 2014, 10, 1751.

[6] a) S. Gomes, I. B. Leonor, J. F. Mano, R. L. Reis, D. L. Kaplan, Prog. Polym. Sci. 2012, 37, 1-17; b) A. Heidebrecht, T. Scheibel, in Advances in Applied Microbiology, Vol. 82 (Eds: S. Sariaslani, G. M. Gadd), Elsevier Academic Press Inc, San Diego, 2013, pp. 115-153; c) A. Rising, M. Widhe, J. Johansson, M. Hedhammar, Cell. Mol. Life Sci. 2011, 68, 169; d) J. A. Werkmeister, J. A. M. Ramshaw, Biomed. Mater. 2012, 7, 29.

[7] J. C. Rodriguez-Cabello, J. Reguera, A. Girotti, F. J. Arias, M. Alonso, in Ordered Polymeric Nanostructures at Surfaces, Vol. 200 (Eds: G. J. Vancso, G. Reiter), Springer-Verlag Berlin, Berlin 2006, pp. 119-167.

[8] T. D. Sutherland, J. H. Young, S. Weisman, C. Y. Hayashi, D. J. Merritt, in Annual Review of Entomology, (Ed: Gene E. Robinson), Vol. 55, Annual Reviews, Palo Alto 2010, pp. 171-188.

[9] C. L. Craig, C. Riekel, Comp. Biochem. Physiol. B-Biochem. Mol. Biol. 2002, 133, 493.

[10] D. Kaplan, W. W. Adams, B. Farmer, C. Viney, in Silk Polymers: Materials Science and Biotechnology, Vol. 544 (Eds: D. Kaplan, W. W. Adams, B. Farmer, C. Viney), American Chemical Society, Washington, 1994, pp. 2-16.

[11] F. Vollrath, Int. J. Biol. Macromol. 1999, 24, 81.

[12] J. M. Gosline, M. E. Demont, M. W. Denny, Endeavour 1986, 10, 37.

[13] F. Vollrath, Sci. Am. 1992, 266, 70.

[14] A. Rising, H. Nimmervoll, S. Grip, A. Fernandez-Arias, E. Storckenfeldt, D. P. Knight, F. Vollrath, W. Engstrom, Zool. Sci. 2005, 22, 273.

[15] N. A. Ayoub, J. E. Garb, R. M. Tinghitella, M. A. Collin, C. Y. Hayashi, PLoS One 2007, 2, 13.

[16] C. Y. Hayashi, R. V. Lewis, Bioessays 2001, 23, 750.

[17] A. H. Simmons, C. A. Michal, L. W. Jelinski, Science 1996, $271,84$.

[18] O. Liivak, A. Flores, R. Lewis, L. W. Jelinski, Macromolecules 1997, 30, 7127.

[19] J. D. van Beek, S. Hess, F. Vollrath, B. H. Meier, Proc. Natl. Acad. Sci. USA 2002, 99, 10266.

[20] C. Riekel, C. Branden, C. Craig, C. Ferrero, F. Heidelbach, M. Muller, Int. J. Biol. Macromol. 1999, 24, 179.

[21] J. Kummerlen, J. D. van Beek, F. Vollrath, B. H. Meier, Macromolecules 1996, 29, 2920.

[22] R. V. Lewis, Chem. Rev. 2006, 106, 3762.
[23] C. Y. Hayashi, N. H. Shipley, R. V. Lewis, Int. J. Biol. Macromol. 1999, 24, 271

[24] S. L. Adrianos, F. Teule, M. B. Hinman, J. A. Jones, W. S. Weber, J. L. Yarger, R. V. Lewis, Biomacromolecules 2013, 14, 1751.

[25] J. M. Gosline, P. A. Guerette, C. S. Ortlepp, K. N. Savage, J. Exp. Biol. 1999, 202, 3295

[26] L. W. Jelinski, Curr. Opin. Solid State Mater. Sci. 1998, 3, 237.

[27] F. Vollrath, D. Porter, Soft Matter 2006, 2, 377.

[28] A. Rising, G. Hjalm, W. Engstrom, J. Johansson, Biomacromolecules 2006, 7, 3120.

[29] J. E. Garb, N. A. Ayoub, C. Y. Hayashi, BMC Evol. Biol. 2010, 10, 16.

[30] R. J. Challis, S. L. Goodacre, G. M. Hewitt, Insect Mol. Biol. 2006, $15,45$.

[31] D. Motriuk-Smith, A. Smith, C. Y. Hayashi, R. V. Lewis, Biomacromolecules 2005, 6, 3152 .

[32] M. Hedhammar, A. Rising, S. Grip, A. S. Martinez, K. Nordling, C. Casals, M. Stark, J. Johansson, Biochemistry 2008, 47, 3407.

[33] D. Huemmerich, C. W. Helsen, S. Quedzuweit, J. Oschmann, R. Rudolph, T. Scheibel, Biochemistry 2004, 43, 13604.

[34] F. Hagn, C. Thamm, T. Scheibel, H. Kessler, Angew. Chem. Int. Ed. 2011, 50, 310.

[35] F. Hagn, L. Eisoldt, J. G. Hardy, C. Vendrely, M. Coles, T. Scheibel, H. Kessler, Nature 2010, 465, 239.

[36] G. Askarieh, M. Hedhammar, K. Nordling, A. Saenz, C. Casals, A. Rising, J. Johansson, S. D. Knight, Nature 2010, 465, 236.

[37] N. Kronqvist, M. Otikovs, V. Chmyrov, G. Chen, M. Andersson, K. Nordling, M. Landreh, M. Sarr, H. Jornvall, S. Wennmalm, J. Widengren, Q. Meng, A. Rising, D. Otzen, S. D. Knight, K. Jaudzems, J. Johansson, Nat. Commun. 2014, 5, 11.

[38] F. Hagn, J. Pept. Sci. 2012, 18, 357.

[39] J. Newman, C. Newman, Int. J. Dermatol. 1995, 34, 290.

[40] R. G. Harrison, J. Expt. Zool. 1914, 17, 24.

[41] X.-X. Xia, Z.-G. Qian, C. S. Ki, Y. H. Park, D. L. Kaplan, S. Y. Lee, Proc. Natl. Acad. Sci. USA 2010, 107, 14059.

[42] T. Scheibel, Microb. Cell. Fact. 2004, 3, 10.

[43] M. Humenik, M. Magdeburg, T. Scheibel, J. Struct. Biol. 2014, 186, 431.

[44] U. Slotta, S. Hess, K. Spiess, T. Stromer, L. Serpell, T. Scheibel, Macromol. Biosci. 2007, 7, 183.

[45] A. J. Geddes, K. D. Parker, E. D. Atkins, E. Beighton, J. Mol. Biol. $1968,32,343$

[46] S. Rammensee, U. Slotta, T. Scheibel, A. R. Bausch, Proc. Natl. Acad. Sci. USA 2008, 105, 6590.

[47] K. D. Hermanson, D. Huemmerich, T. Scheibel, A. R. Bausch, Adv. Mater. 2007, 19, 1810.

[48] U. K. Slotta, S. Rammensee, S. Gorb, T. Scheibel, Angew. Chem. Int. Ed. 2008, 47, 4592.

[49] D. Huemmerich, U. Slotta, T. Scheibel, Appl. Phys. A 2006, 82, 219.

[50] U. Slotta, M. Tammer, F. Kremer, P. Koelsch, T. Scheibel, Supramol. Chem. 2006, 18, 465.

[51] S. Rammensee, D. Huemmerich, K. D. Hermanson, T. Scheibel, A. R. Bausch, Appl. Phys. A 2006, 82, 261.

[52] J. G. Hardy, T. R. Scheibel, J. Polym. Sci. Polym. Chem. 2009, 47, 3957.

[53] C. Vendrely, T. Scheibel, Macromol. Biosci. 2007, 7, 401.

[54] K. Spiess, A. Lammel, T. Scheibel, Macromol. Biosci. 2010, 10, 998.

[55] K. Spiess, S. Wohlrab, T. Scheibel, Soft Matter 2010, 6, 4168.

[56] S. Wohlrab, S. Muller, A. Schmidt, S. Neubauer, H. Kessler, A. Leal-Egana, T. Scheibel, Biomaterials 2012, 33, 6650.

[57] P. H. Zeplin, N. C. Maksimovikj, M. C. Jordan, J. Nickel, G. Lang, A. H. Leimer, L. Roemer, T. Scheibel, Adv. Funct. Mater. 2014, 24, 2658.

[58] M. Stark, S. Grip, A. Rising, M. Hedhammar, W. Engstrom, G. Hjalm, J. Johansson, Biomacromolecules 2007, 8, 1695. 
[59] M. Widhe, H. Bysell, S. Nystedt, I. Schenning, M. Malmsten, J. Johansson, A. Rising, M. Hedhammar, Biomaterials 2010, 31, 9575.

[60] M. Widhe, U. Johansson, C. O. Hillerdahl, M. Hedhammar, Biomaterials 2013, 34, 8223.

[61] O. S. Rabotyagova, P. Cebe, D. L. Kaplan, Biomacromolecules 2009, 10, 229.

[62] C. W. P. Foo, S. V. Patwardhan, D. J. Belton, B. Kitchel, D. Anastasiades, J. Huang, R. R. Naik, C. C. Perry, D. L. Kaplan, Proc. Natl. Acad. Sci. USA 2006, 103, 9428.

[63] L. L. S. Canabady-Rochelle, D. J. Belton, O. Deschaume, H. A. Currie, D. L. Kaplan, C. C. Perry, Biomacromolecules 2012, 13, 683.

[64] S. Gomes, I. B. Leonor, J. F. Mano, R. L. Reis, D. L. Kaplan, Soft Matter 2011, 7, 4964.

[65] S. C. Gomes, I. B. Leonor, J. F. Mano, R. L. Reis, D. L. Kaplan, Biomaterials 2011, 32, 4255

[66] F. W. Keeley, C. M. Bellingham, K. A. Woodhouse, Philos. Trans. R. Soc. Lond. Ser. B-Biol. Sci. 2002, 357, 185.

[67] W. J. Cook, H. Einspahr, T. L. Trapane, D. W. Urry, C. E. Bugg, J. Am. Chem. Soc. 1980, 102, 5502.

[68] D. W. Urry, T. Hugel, M. Seitz, H. E. Gaub, L. Sheiba, J. Dea, J. Xu, T. Parker, Philos. Trans. R. Soc. Lond. Ser. B-Biol. Sci. 2002, 357, 169.

[69] J. C. Rodriguez-Cabello, L. Martin, M. Alonso, F. J. Arias, A. M. Testera, Polymer 2009, 50, 5159.

[70] D. E. Meyer, A. Chilkoti, Biomacromolecules 2002, 3, 357.

[71] J. C. Rodriguez-Cabello, J. Reguera, A. Girotti, M. Alonso, A. M. Testera, Prog. Polym. Sci. 2005, 30, 1119.

[72] A. J. Simnick, D. W. Lim, D. Chow, A. Chilkoti, Polym. Rev. 2007, 47, 121.

[73] D. L. Nettles, A. Chilkoti, L. A. Setton, Adv. Drug Delivery Rev. 2010, 62, 1479.

[74] J. Reguera, A. Fahmi, P. Moriarty, A. Girotti, J. C. Rodriguez-Cabello, J. Am. Chem. Soc. 2004, 126, 13212.

[75] A. Girotti, J. Reguera, J. C. Rodriguez-Cabello, F. J. Arias, M. Alonso, A. M. Testera, J. Mater. Sci-Mater. Med. 2004, 15, 479.

[76] X. Punet, R. Mauchauffe, M. I. Giannotti, J. C. Rodriguez-Cabello, F. Sanz, E. Engel, M. A. Mateos-Timoneda, J. A. Planell, Biomacromolecules 2013, 14, 2690.

[77] E. Salvagni, G. Berguig, E. Engel, J. Carlos Rodriguez-Cabello, G. Coullerez, M. Textor, J. A. Planell, F. Javier Gil, C. Aparicio, Colloids Surf. B 2014, 114, 225.

[78] Y. Li, X. Chen, A. J. Ribeiro, E. D. Jensen, K. V. Holmberg, J. Carlos Rodriguez-Cabello, C. Aparicio, Adv. Healthcare Mater. 2014, 3, 1638.

[79] E. Tejeda-Montes, K. H. Smith, E. Rebollo, R. Gomez, M. Alonso, J. Carlos Rodriguez-Cabello, E. Engel, A. Mata, Acta Biomater. 2014, 10, 134.

[80] E. Tejeda-Montes, A. Klymov, M. R. Nejadnik, M. Alonso, J. C. Rodriguez-Cabello, X. F. Walboomers, A. Mata, Biomaterials 2014, 35, 8339.

[81] K. S. Straley, S. C. Heilshorn, Soft Matter 2009, 5, 114.

[82] K. J. Lampe, A. L. Antaris, S. C. Heilshorn, Acta Biomater. 2013, 9, 5590.

[83] R. R. Costa, C. A. Custodio, A. M. Testero, F. J. Arias, J. C. Rodriguez-Cabello, N. M. Alves, J. F. Mano, Adv. Funct. Mater. 2009, 19, 3210.

[84] R. R. Costa, C. A. Custodio, F. J. Arias, J. C. Rodriguez-Cabello, J. F. Mano, Small 2011, 7, 2640.

[85] R. R. Costa, C. A. Custodio, F. J. Arias, J. C. Rodriguez-Cabello, J. F. Mano, Nanomed. Nanotechnol. Biol. Med. 2013, 9, 895.

[86] R. R. Costa, A. Girotti, M. Santos, F. J. Arias, J. F. Mano, J. C. Rodriguez-Cabello, Acta Biomater. 2014, 10, 2653.
[87] A. Fernandez-Colino, F. Javier Arias, M. Alonso, J. Carlos Rodriguez-Cabello, Biomacromolecules 2014, 15, 3781.

[88] R. Machado, A. da Costa, V. Sencadas, C. Garcia-Arevalo, C. M. Costa, J. Padrao, A. Gomes, S. Lanceros-Mendez, J. Carlos Rodriguez-Cabello, M. Casal, Biomed. Mater. 2013, 8, 065009.

[89] a) G. A. Bowden, A. M. Paredes, G. Georgiou, Bio-Technology 1991 9, 725; b) G. Taylor, M. Hoare, D. R. Gray, F. A. O. Marston, BioTechnology 1986, 4, 553.

[90] a) L. Wang, Prion 2009, 3, 139; b) L. Wang, S. K. Maji, M. R. Sawaya, D. Eisenberg, R. Riek, PLoS Biol. 2008, 6, 1791.

[91] a) E. Garcia-Fruitos, A. Aris, A. Villaverde, Appl. Environ. Microbiol. 2008, 74, 1960; b) E. Garcia-Fruitos, N. Gonzalez-Montalban, M. Morell, A. Vera, R. M. Ferraz, A. Aris, S. Ventura, A. Villaverde, Microb. Cell. Fact. 2005, 4, 27.

[92] J. Seras-Franzoso, C. Diez-Gil, E. Vazquez, E. Garcia-Fruitos, R. Cubarsi, I. Ratera, J. Veciana, A. Villaverde, Nanomedicine 2012, 7, 79.

[93] E. Garcia-Fruitos, E. Rodriguez-Carmona, C. Diez-Gil, R. M. Ferraz, E. Vazquez, J. L. Corchero, M. Cano-Sarabia, I. Ratera, N. Ventosa, J. Veciana, A. Villaverde, Adv. Mater. 2009, 21, 4249.

[94] E. Garcia-Fruitos, J. Seras-Franzoso, E. Vazquez, A. Villaverde, Nanotechnology 2010, 21, 205101.

[95] E. Vazquez, J. L. Corchero, J. F. Burgueno, J. Seras-Franzoso, A. Kosoy, R. Bosser, R. Mendoza, J. M. Martinez-Lainez, U. Rinas, E. Fernandez, L. Ruiz-Avila, E. Garcia-Fruitos, A. Villaverde, Adv. Mater. 2012, 24, 1742 .

[96] A. Villaverde, Nanomedicine 2012, 7, 1277.

[97] a) Y. Loo, S. Zhang, C. A. Hauser, Biotechnology Advances 2012, 30, 593; b) E. C. Wu, S. G. Zhang, C. A. E. Hauser, Adv. Funct. Mater. 2012, 22, 456.

[98] C. A. E. Hauser, S. G. Zhang, Chem Soc Rev 2010, 39, 2780

[99] S. Zhang, T. Holmes, C. Lockshin, A. Rich, Proc. Natl. Acad. Sci. USA 1993, 90, 3334.

[100] H. Yokoi, T. Kinoshita, S. Zhang, Proc. Natl. Acad. Sci. USA 2005 $102,8414$.

[101] a) Z. Luo, S. Wang, S. Zhang, Biomaterials 2010, 32, 2013-2020; b) Z. Luo, X. Zhao, S. Zhang, Macromol. Biosci. 2008, 8, 785.

[102] C. E. Semino, J. Dent. Res. 2008, 87, 606.

[103] R. G. Ellis-Behnke, Y. X. Liang, D. K. Tay, P. W. Kau, G. E. Schneider, S. Zhang, W. Wu, K. F. So, Nanomed. Nanotechnol. Biol. Med. 2006, 2, 207.

[104] a) J. Kisiday, M. Jin, B. Kurz, H. Hung, C. Semino, S. Zhang, A. J. Grodzinsky, Proc. Natl. Acad. Sci. USA 2002, 99, 9996; b) S. A. Maher, R. L. Mauck, L. Rackwitz, R. S. Tuan, J. Tissue Eng. Regen. Med. 2010, 4, 25

[105] H. Misawa, N. Kobayashi, A. Soto-Gutierrez, Y. Chen, A. Yoshida, J. D. Rivas-Carrillo, N. Navarro-Alvarez, K. Tanaka, A. Miki, J. Takei, T. Ueda, M. Tanaka, H. Endo, N. Tanaka, T. Ozaki, Cell Transplant 2006, 15, 903.

[106] H. Henriksson, M. Hagman, M. Horn, A. Lindahl, H. Brisby, J. Tissue Eng. Regen. Med.Regen. Med. 2011, 6, 738.

[107] C. E. Semino, J. R. Merok, G. G. Crane, G. Panagiotakos, S. Zhang, Differentiation 2003, 71, 262.

[108] a) R. G. Ellis-Behnke, Y. X. Liang, S. W. You, D. K. Tay, S. Zhang, K. F. So, G. E. Schneider, Proc. Natl. Acad. Sci. USA 2006, 103, 5054; b) L. Yla-Outinen, T. Joki, M. Varjola, H. Skottman, S. Narkilahti, J. Tissue Eng. Regen. Med.Regen. Med. 2014, 8, 186.

[109] M. E. Davis, J. P. Motion, D. A. Narmoneva, T. Takahashi, D. Hakuno, R. D. Kamm, S. Zhang, R. T. Lee, Circulation 2005, 111 , 442.

[110] Y. Kumada, S. Zhang, PLoS One 2010, 5, e10305.

[111] a) F. Gelain, A. Horii, S. Zhang, Macromol. Biosci. 2007, 7, 544; b) A. Horii, X. Wang, F. Gelain, S. Zhang, PLoS One 2007, 2, e190. 
[112] a) Y. Nagai, L. D. Unsworth, S. Koutsopoulos, S. Zhang, J. Controlled Release 2006, 115, 18; b) F. Gelain, L. D. Unsworth, S. Zhang, J. Controlled Release 2010, 145, 231; c) E. L. Bakota, Y. Wang, F. R. Danesh, J. D. Hartgerink, Biomacromolecules 2011, 12, 1651.

[113] M. E. Davis, P. C. Hsieh, T. Takahashi, Q. Song, S. Zhang, R. D. Kamm, A. J. Grodzinsky, P. Anversa, R. T. Lee, Proc. Natl. Acad. Sci. USA 2006, 103, 8155.

[114] J. P. Jung, J. L. Jones, S. A. Cronier, J. H. Collier, Biomaterials 2008, 29, 2143.

[115] a) J. P. Jung, J. V. Moyano, J. H. Collier, Integr. Biol. (Camb) 2011 , 3, 185; b) J. P. Jung, A. K. Nagaraj, E. K. Fox, J. S. Rudra, J. M. Devgun, J. H. Collier, Biomaterials 2009, 30, 2400.

[116] Y. F. Tian, G. A. Hudalla, H. Han, J. H. Collier, Biomater. Sci. 2013, 1, 1037.

[117] S. Ramachandran, Y. Tseng, Y. B. Yu, Biomacromolecules 2005, 6 1316.

[118] L. Aulisa, H. Dong, J. D. Hartgerink, Biomacromolecules 2009, 10, 2694.

[119] E. L. Bakota, O. Sensoy, B. Ozgur, M. Sayar, J. D. Hartgerink, Biomacromolecules 2013, 14, 1370.

[120] E. L. Bakota, L. Aulisa, K. M. Galler, J. D. Hartgerink, Biomacromolecules 2011, 12, 82.

[121] K. M. Galler, L. Aulisa, K. R. Regan, R. N. D’Souza, J. D. Hartgerink, J. Am. Chem. Soc. 2010, 132, 3217.

[122] K. M. Galler, J. D. Hartgerink, A. C. Cavender, G. Schmalz, R. N. D'Souza, Tissue Eng. Part A 2012, 18, 176.

[123] N. C. Wickremasinghe, V. A. Kumar, J. D. Hartgerink, Biomacromolecules 2014, 15, 3587.

[124] A. Aggeli, M. Bell, N. Boden, J. N. Keen, P. F. Knowles, T. C. B. McLeish, M. Pitkeathly, S. E. Radford, Nature 1997, 386, 259.

[125] A. Aggeli, M. Bell, L. M. Carrick, C. W. Fishwick, R. Harding, P. J. Mawer, S. E. Radford, A. E. Strong, N. Boden, J. Am. Chem. Soc. 2003, 125, 9619.

[126] S. Kyle, S. H. Felton, M. J. McPherson, A. Aggeli, E. Ingham, Adv. Healthcare Mater. 2012, 1, 640.

[127] A. Firth, A. Aggeli, J. L. Burke, X. Yang, J. Kirkham, Nanomedicine 2006, 1, 189.

[128] J. Kirkham, A. Firth, D. Vernals, N. Boden, C. Robinson, R. C. Shore, S. J. Brookes, A. Aggeli, J. Dent. Res. 2007, 86, 426.

[129] P. A. Brunton, R. P. Davies, J. L. Burke, A. Smith, A. Aggeli, S. J. Brookes, J. Kirkham, Br. Dent. J. 2013, 215, E6.

[130] K. Papanikolopoulou, G. Schoehn, V. Forge, V. T. Forsyth, C. Riekel, J. F. Hernandez, R. W. H. Ruigrok, A. Mitraki, J. Biol. Chem. 2005, $280,2481$.

[131] P. Tamamis, E. Kasotakis, A. Mitraki, G. Archontis, J. Phys. Chem. B 2009, 113, 15639.

[132] E. Kasotakis, E. Mossou, L. Adler-Abramovich, E. P. Mitchell, V. T. Forsyth, E. Gazit, A. Mitraki, Biopolymers 2009, 92, 164

[133] E. Kasotakis, A. Mitraki, Biopolymers 2012, 98, 501

[134] K. Terzaki, E. Kalloudi, E. Mossou, E. P. Mitchell, V. T. Forsyth, E. Rosseeva, P. Simon, M. Vamvakaki, M. Chatzinikolaidou, A. Mitraki, M. Farsari, Biofabrication 2013, 5, 45002

[135] a) J. P. Schneider, D. J. Pochan, B. Ozbas, K. Rajagopal, L. Pakstis, J. Kretsinger, J. Am. Chem. Soc. 2002, 124, 15030; b) D. J. Pochan, J. P. Schneider, J. Kretsinger, B. Ozbas, K. Rajagopal, L. Haines, J. Am. Chem. Soc. 2003, 125, 11802

[136] L. A. Haines, K. Rajagopal, B. Ozbas, D. A. Salick, D. J. Pochan, J. P. Schneider, J. Am. Chem. Soc. 2005, 127, 17025

[137] K. Rajagopal, M. S. Lamm, L. A. Haines-Butterick, D. J. Pochan, J. P. Schneider, Biomacromolecules 2009, 10, 2619.

[138] a) B. Ozbas, K. Rajagopal, L. Haines-Butterick, J. P. Schneider, D. J. Pochan, J. Phys. Chem. B 2007, 111, 13901; b) C. M. Micklitsch,
P. J. Knerr, M. C. Branco, R. Nagarkar, D. J. Pochan, J. P. Schneider, Angew. Chem. 2011, 50, 1577.

[139] S. Sathaye, H. Zhang, C. Sonmez, J. P. Schneider, C. M. MacDermaid, C. D. Von Bargen, J. G. Saven, D. J. Pochan, Biomacromolecules 2014, 15, 3891.

[140] L. Haines-Butterick, K. Rajagopal, M. Branco, D. Salick, R. Rughani, M. Pilarz, M. S. Lamm, D. J. Pochan, J. P. Schneider, Proc. Natl. Acad. Sci. 2007, 104, 7791.

[141] R. V. Rughani, D. A. Salick, M. S. Lamm, T. Yucel, D. J. Pochan, J. P. Schneider, Biomacromolecules 2009, 10, 1295.

[142] a) R. P. Nagarkar, R. A. Hule, D. J. Pochan, J. P. Schneider, J. Am. Chem. Soc. 2008, 130, 4466-4474; b) R. P. Nagarkar, R. A. Hule, D. J. Pochan, J. P. Schneider, Biopolymers 2010, 94, 141.

[143] a) M. C. Branco, D. J. Pochan, N. J. Wagner, J. P. Schneider, Biomaterials 2009, 30, 1339; b) M. C. Branco, D. J. Pochan, N. J. Wagner, J. P. Schneider, Biomaterials 2010, 31, 9527.

[144] M. Gungormus, M. Branco, H. Fong, J. P. Schneider, C. Tamerler, M. Sarikaya, Biomaterials 2010, 31, 7266.

[145] D. A. Salick, J. K. Kretsinger, D. J. Pochan, J. P. Schneider, J. Am. Chem. Soc. 2007, 129, 14793.

[146] A. S. Veiga, C. Sinthuvanich, D. Gaspar, H. G. Franquelim, M. A. Castanho, J. P. Schneider, Biomaterials 2012, 33, 8907.

[147] a) E. F. Banwell, E. S. Abelardo, D. J. Adams, M. A. Birchall, A. Corrigan, A. M. Donald, M. Kirkland, L. C. Serpell, M. F. Butler, D. N. Woolfson, Nat. Mater. 2009, 8, 596; b) E. H. Bromley, K. J. Channon, P. J. King, Z. N. Mahmoud, E. F. Banwell, M. F. Butler, M. P. Crump, T. R. Dafforn, M. R. Hicks, J. D. Hirst, A. Rodger, D. N. Woolfson, Biophys. J. 2009, 98, 1668.

[148] a) M. G. Ryadnov, D. N. Woolfson, Angew. Chem. Int. Ed. 2003, 42, 3021; b) M. G. Ryadnov, D. N. Woolfson, Nat Mater 2003, 2, 329.

[149] M. G. Ryadnov, D. N. Woolfson, J. Am. Chem. Soc. 2004, 126, 7454.

[150] Z. N. Mahmoud, D. J. Grundy, K. J. Channon, D. N. Woolfson, Biomaterials 2010, 31, 7468 .

[151] Z. N. Mahmoud, S. B. Gunnoo, A. R. Thomson, J. M. Fletcher, D. N. Woolfson, Biomaterials 2011, 32, 3712.

[152] N. Mehrban, E. Abelardo, A. Wasmuth, K. L. Hudson, L. M. Mullen, A. R. Thomson, M. A. Birchall, D. N. Woolfson, Adv. Healthcare Mater. 2014, 3, 1387.

[153] K. Inouye, Y. Kobayashi, Y. Kyogoku, Y. Kishida, S. Sakakibara, D. J. Prockop, Arch. Biochem. Biophys. 1982, 219, 198.

[154] a) J. A. Fallas, V. Gauba, J. D. Hartgerink, J Biol Chem 2009, 284 26851; b) V. Gauba, J. D. Hartgerink, J. Am. Chem. Soc. 2007, 129, 15034; c) V. Gauba, J. D. Hartgerink, J. Am. Chem. Soc. 2007, 129, 2683; d) L. E. O'Leary, J. A. Fallas, J. D. Hartgerink, J. Am. Chem. Soc. 2011, 133, 5432; e) L. E. Russell, J. A. Fallas, J. D. Hartgerink, J. Am. Chem. Soc. 2010, 132, 3242.

[155] a) S. Rele, Y. Song, R. P. Apkarian, Z. Qu, V. P. Conticello, E. L. Chaikof, J. Am. Chem. Soc. 2007, 129, 14780; b) B. Sarkar, L. E. O'Leary, J. D. Hartgerink, J. Am. Chem. Soc. 2014, 136, 14417; c) A. A. Jalan, K. A. Jochim, J. D. Hartgerink, J. Am. Chem. Soc. 2014, 136, 7535.

[156] a) M. A. Cejas, W. A. Kinney, C. Chen, J. G. Vinter, H. R. Almond Jr., K. M. Balss, C. A. Maryanoff, U. Schmidt, M. Breslav, A. Mahan, E. Lacy, B. E. Maryanoff, Proc. Natl. Acad. Sci. USA 2008, 105, 8513; b) K. Kar, S. Ibrar, V. Nanda, T. M. Getz, S. P. Kunapuli, B. Brodsky, Biochemistry 2009, 48, 7959.

[157] C. M. Yamazaki, S. Asada, K. Kitagawa, T. Koide, Biopolymers 2008, $90,816$.

[158] a) D. E. Przybyla, J. Chmielewski, J. Am. Chem. Soc. 2008, 130, 12610; b) M. M. Pires, D. E. Przybyla, J. Chmielewski, Angew. Chem. 2009, 48, 7813.

[159] V. Hernandez-Gordillo, J. Chmielewski, Biomaterials 2014, 35, 7363.

[160] V. A. Kumar, N. L. Taylor, A. A. Jalan, L. K. Hwang, B. K. Wang, J. D. Hartgerink, Biomacromolecules 2014, 15, 1484. 
[161] a) P. J. Stahl, S. M. Yu, Soft Matter 2012, 8, 10409; b) J. E. Kim, S. H. Kim, Y. Jung, J. Biosci. Bioeng. 2014, 120, 91.

[162] Y. Li, B. H. San, J. L. Kessler, J. H. Kim, Q. Xu, J. Hanes, S. M. Yu, Macromol. Biosci. 2015, 15, 52.

[163] C. A. Hauser, R. Deng, A. Mishra, Y. Loo, U. Khoe, F. Zhuang, D. W. Cheong, A. Accardo, M. B. Sullivan, C. Riekel, J. Y. Ying, U. A. Hauser, Proc. Natl. Acad. Sci. USA 2011, 108, 1361.

[164] A. Mishra, Y. H. Loo, R. H. Deng, Y. J. Chuah, H. T. Hee, J. Y. Ying, C. A. E. Hauser, Nano Today 2011, 6, 232.

[165] Y. Loo, Y. C. Wong, E. Z. Cai, C. H. Ang, A. Raju, A. Lakshmanan, A. G. Koh, H. J. Zhou, T. C. Lim, S. M. Moochhala, C. A. Hauser, Biomaterials 2014, 35, 4805.

[166] W. Y. Seow, C. A. Hauser, Adv. Healthcare Mater. 2013, 2, 1219.

[167] M. R. Reithofer, K.-H. Chan, A. Lakshmanan, D. H. Lam, A. Mishra, B. Gopalan, M. Joshi, S. Wang, C. A. E. Hauser, Chem. Sci. 2014, 5, 625.

[168] N. S. de Groot, T. Parella, F. X. Aviles, J. Vendrell, S. Ventura, Biophys. J. 2007, 92, 1732.

[169] J. J. Panda, A. Mishra, A. Basu, V. S. Chauhan, Biomacromolecules 2008, 9, 2244

[170] J. J. Panda, R. Dua, A. Mishra, B. Mittra, V. S. Chauhan, ACS applied materials Q interfaces 2010, 2, 2839.

[171] A. Mahler, M. Reches, M. Rechter, S. Cohen, E. Gazit, Adv. Mater. 2006, 18, 1365.

[172] G. Fichman, E. Gazit, Acta Biomater. 2014, 10, 1671.

[173] R. Roytman, L. Adler-Abramovich, K. S. Kumar, T. C. Kuan, C. C. Lin, E. Gazit, A. Brik, Org. Biomol. Chem. 2011, 9, 5755.

[174] R. Orbach, L. Adler-Abramovich, S. Zigerson, I. Mironi-Harpaz, D. Seliktar, E. Gazit, Biomacromolecules 2009, 10, 2646.

[175] a) R. Jayakumar, M. Murugesan, C. Asokan, M. Aulice Scibioh, Langmuir 2000, 16, 1489; b) V. Jayawarna, S. M. Richardson, A. R. Hirst, N. W. Hodson, A. Saiani, J. E. Gough, R. V. Ulijn, Acta Biomater. 2009, 5, 934.

[176] M. Zhou, R. V. Ulijn, J. E. Gough, J. Tissue Eng. 2014, 5, 2041731414531593

[177] M. Zhou, A. M. Smith, A. K. Das, N. W. Hodson, R. F. Collins, R. V. Ulijn, J. E. Gough, Biomaterials 2009, 30, 2523.

[178] S. E. Paramonov, H. W. Jun, J. D. Hartgerink, J. Am. Chem. Soc. 2006, 128, 7291.

[179] J. D. Hartgerink, E. Beniash, S. I. Stupp, Proc. Natl. Acad. Sci. USA 2002, 99, 5133.

[180] G. A. Silva, C. Czeisler, K. L. Niece, E. Beniash, D. A. Harrington, J. A. Kessler, S. I. Stupp, Science 2004, 303, 1352.

[181] J. D. Hartgerink, E. Beniash, S. I. Stupp, Science 2001, 294, 1684.

[182] S. Ganesh, S. Prakash, R. Jayakumar, Biopolymers 2003, 70, 346.

[183] H. Cui, M. J. Webber, S. I. Stupp, Biopolymers 2010, 94, 1.

[184] M. J. Webber, E. J. Berns, S. I. Stupp, Isr. J. Chem. 2013, 53, 530.

[185] B. W. Ninham, P. Lo Nostro, Molecular Forces and Self Assembly in Colloid, Nanosciences and Biology, Cambridge University Press, Cambridge, UK 2010.

[186] K. L. Niece, J. D. Hartgerink, J. J. Donners, S. I. Stupp, J. Am. Chem. Soc. 2003, 125, 7146.

[187] M. O. Guler, R. C. Claussen, S. I. Stupp, J. Mater. Chem. 2005, 15, 4507.

[188] M. O. Guler, L. Hsu, S. Soukasene, D. A. Harrington, J. F. Hulvat, S. I. Stupp, Biomacromolecules 2006, 7, 1855.

[189] S. Sur, J. B. Matson, M. J. Webber, C. J. Newcomb, S. I. Stupp, ACS Nano 2012, 6, 10776.

[190] M. J. Webber, J. Tongers, M. A. Renault, J. G. Roncalli, D. W. Losordo, S. I. Stupp, Acta Biomater. 2010, 6, 3.

[191] H. Storrie, M. O. Guler, S. N. Abu-Amara, T. Volberg, M. Rao, B. Geiger, S. I. Stupp, Biomaterials 2007, 28, 4608.

[192] R. Pytela, M. D. Pierschbacher, S. Argraves, S. Suzuki, E. Ruoslahti, MethEnzymol. 1987, 144, 475.
[193] T. D. Sargeant, C. Aparicio, J. E. Goldberger, H. Cui, S. I. Stupp, Acta Biomater. 2012, 8, 2456.

[194] H. Hosseinkhani, M. Hosseinkhani, F. Tian, H. Kobayashi, Y. Tabata, Biomaterials 2006, 27, 4079.

[195] T. D. Sargeant, M. S. Rao, C. Y. Koh, S. I. Stupp, Biomaterials 2008, 29, 1085.

[196] Z. Huang, T. D. Sargeant, J. F. Hulvat, A. Mata, P. Bringas Jr., C. Y. Koh, S. I. Stupp, M. L. Snead, J. Bone Mineral Res. 2008, 23, 1995.

[197] G. Uzunalli, Z. Soran, T. S. Erkal, Y. S. Dagdas, E. Dinc, A. M. Hondur, K. Bilgihan, B. Aydin, M. O. Guler, A. B. Tekinay, Acta Biomater. 2014, 10, 1156.

[198] M. Mizuno, R. Fujisawa, Y. Kuboki, J. Cellular Pathol. 2000, 184, 207.

[199] J. Luo, Y. W. Tong, ACS Nano 2011, 5, 7739.

[200] H. Ceylan, S. Kocabey, H. Unal Gulsuner, O. S. Balcik, M. O. Guler, A. B. Tekinay, Biomacromolecules 2014, 15, 2407.

[201] J. M. Anderson, J. B. Vines, J. L. Patterson, H. Chen, A. Javed, H. W. Jun, Acta Biomater. 2011, 7, 675.

[202] K. C. Dee, T. T. Andersen, R. Bizios, J. Biomed. Mater. Res. 1998, 40, 371.

[203] H. Ceylan, S. Kocabey, A. B. Tekinay, M. O. Guler, Soft Matter 2012 8, 3929.

[204] H. Ceylan, A. B. Tekinay, M. O. Guler, Biomaterials 2011, 32, 8797.

[205] J. Silver, J. H. Miller, Nat. Rev. Neurosci. 2004, 5, 146.

[206] V. M. Tysseling-Mattiace, V. Sahni, K. L. Niece, D. Birch, C. Czeisler, M. G. Fehlings, S. I. Stupp, J. A. Kessler, J. Neurosci. 2008, 28, 3814.

[207] B. Mammadov, R. Mammadov, M. O. Guler, A. B. Tekinay, Acto Biomater. 2012, 8, 2077.

[208] S. Sakashita, E. Engvall, E. Ruoslahti, FEBS Lett. 1980, 116, 243.

[209] N. Wang, J. P. Butler, D. E. Ingber, Science 1993, 260, 1124.

[210] C. M. Lo, H. B. Wang, M. Dembo, Y. L. Wang, Biophys. J. 2000, 79, 144.

[211] E. Hadjipanayi, V. Mudera, R. A. Brown, J. Tissue Eng. Regen. Med. 2009, 3, 77 .

[212] A. J. Engler, S. Sen, H. L. Sweeney, D. E. Discher, Cell 2006, 126, 677.

[213] E. T. Pashuck, H. G. Cui, S. I. Stupp, J. Am. Chem. Soc. 2010, 132, 6041.

[214] J. C. Stendahl, M. S. Rao, M. O. Guler, S. I. Stupp, Adv. Funct. Mater. 2006, 16, 499.

[215] M. A. Greenfield, J. R. Hoffman, M. O. de la Cruz, S. I. Stupp, Langmuir 2010, 26, 3641.

[216] H. Ceylan, M. Urel, T. S. Erkal, A. B. Tekinay, A. Dana, M. O. Guler, Adv. Funct. Mater. 2013, 23, 2081

[217] R. M. Capito, H. S. Azevedo, Y. S. Velichko, A. Mata, S. I. Stupp, Science 2008, 319, 1812.

[218] S. Zhang, M. A. Greenfield, A. Mata, L. C. Palmer, R. Bitton, J. R. Mantei, C. Aparicio, M. O. de la Cruz, S. I. Stupp, Nat. Mater. 2010, 9, 594 .

[219] M. T. McClendon, S. I. Stupp, Biomaterials 2012, 33, 5713.

[220] H. W. Jun, V. Yuwono, S. E. Paramonov, J. D. Hartgerink, Adv. Mater. 2005, 17, 2612

[221] T. Muraoka, H. Cui, S. I. Stupp, J. Am. Chem. Soc. 2008, 130, 2946.

[222] M. J. Webber, C. J. Newcomb, R. Bitton, S. I. Stupp, Soft Matter 2011, 7, 9665.

[223] Y. Qu, S. C. Payne, R. P. Apkarian, V. P. Conticello, J. Am. Chem. Soc. 2000, 122, 5014.

[224] S. G. Zhang, T. Holmes, C. Lockshin, A. Rich, Proc. Natl. Acad. Sci. USA 1993, 90, 3334

[225] P. Tamamis, K. Terzaki, M. Kassinopoulos, L. Mastrogiannis, E. Mossou, V. T. Forsyth, E. P. Mitchell, A. Mitraki, G. Archontis, J. Phys. Chem. B 2014, 118, 1765. 
[226] C. A. E. Hauser, R. S. Deng, A. Mishra, Y. H. Loo, U. Khoe, F. R. Zhuang, D. W. Cheong, A. Accardo, M. B. Sullivan, C. Riekel, J. Y. Ying, U. A. Hauser, Proc. Natl. Acad. Sci. USA 2011, 108, 1361.

[227] J. Smadbeck, K. H. Chan, G. A. Khoury, B. Xue, R. C. Robinson, C. A. E. Hauser, C. A. Floudas, PLoS Comput. Biol. 2014, 10, 17.

[228] N. P. King, W. Sheffler, M. R. Sawaya, B. S. Vollmar, J. P. Sumida, I. Andre, T. Gonen, T. O. Yeates, D. Baker, Science 2012, 336, 1171.

[229] A. Prakash, S. J. Parsons, S. Kyle, M. J. McPherson, Microb. Cell. Fact. 2012, 11, 10.
[230] W. Nuansing, D. Frauchiger, F. Huth, A. Rebollo, R. Hillenbrand, A. M. Bittner, Faraday Discuss. 2013, 166, 209.

[231] I. S. Carrico, S. A. Maskarinec, S. C. Heilshorn, M. L. Mock, J. C. Liu, P. J. Nowatzki, C. Franck, G. Ravichandran, D. A. Tirrell, J. Am. Chem. Soc. 2007, 129, 4874.

[232] A. Selimis, V. Mironov, M. Farsari, Microelectron. Eng. 2015 , 132, 83.

[233] Y. Loo, A. Lakshmanan, M. Ni, L. L. Toh, S. Wang, C. A. E. Hauser, Nanoletters 2015, DOI: 10.1021/acs.nanolett.5b02859, in press. 